\title{
The effect of leaded gasoline on elderly mortality: Evidence from regulatory exemptions
}

\author{
Alex Hollingsworth and Ivan Rudik*
}

June 8, 2020

\begin{abstract}
Leaded gasoline is still used globally for aviation and automotive racing. Exploiting regulatory exemptions and a novel quasi-experiment, we find that leaded gasoline use in racing increases ambient lead, elevated blood lead rates, and elderly mortality. The mortality estimates indicate that each gram of lead added to gasoline exceeds $\$ 1,100$ in damages. Our setting allows us to rule out potential confounders, such as correlated pollutants or socioeconomic status. We provide the first causal estimates linking adult mortality to leaded gasoline, highlight the value of banning on-road leaded gasoline, and present policy-relevant cost estimates at the lowest ambient levels to date.
\end{abstract}

JEL: I00, I18, Q53

Keywords: lead, air pollution, mortality, childhood health, gasoline

*Hollingsworth: hollinal@indiana.edu. O'Neill School of Public and Environmental Affairs. Indiana University, 1315 E. Tenth Street, Bloomington, IN, 47405. Rudik: irudik@cornell.edu. Charles H. Dyson School of Applied Economics and Management. Cornell University, Warren Hall, Ithaca, NY, 14853. We thank Patrick Carlin, Livy Crim, Sam Kuster, and Shyam Raman for research assistance. We thank Lindsay Allen, Judd Boomhower, Karen Clay, Brian Dillon, Maoyong Fan, Teevrat Garg, Scott Grosse, Dave Keiser, Jonathan Ketcham, Cathy Kling, David Konisky, Gabe Lade, David Molitor, Julian Reif, Jessica Reyes, Nick Sanders, Edson Severnini, Kosali Simon, Gregory Steele, Coady Wing, Nikos Zirogiannis, Eric Zou, and seminar participants at the AERE Summer Conference, the Annual Health Economics Conference, the ASHEcon Annual Conference, Carnegie Mellon University, Cornell University, EPA NCEE, the Heartland Workshop, Indiana University, the Inter-American Development Bank, Miami University, the NBER EEE Spring Meetings, UC Davis, UC San Diego, the University of Connecticut, and the University of Louisville for valuable comments. 


\section{Introduction}

Lead $(\mathrm{Pb})$ is a toxic heavy metal associated with numerous adverse outcomes ranging from increased aggressive behavior to premature mortality. In response to mounting health concerns, countries around the world began taking action in the 1970s to reduce lead exposure. In 1975, Japan phased lead out of regular gasoline and the United States mandated all new model-year cars to have emission control devices that required unleaded instead of leaded gasoline (Newell and Rogers, 2003; Yoshinaga, 2012). Many European and Asian countries began lead phasedowns in the 1980s (Nriagu, 1990), while African and Middle Eastern countries generally began the process in the 1990s or 2000s (Thomas, 1995; Lovei, 1998). As of 2020, leaded gasoline has been phased out of regular on-road use in all but one country (UN Environment Programme, 2020). The reduction of lead in gasoline produced steep declines in ambient lead concentrations, representing one of the greatest public health achievements in recent history. ${ }^{1}$

Despite these advances, the phaseout of lead from gasoline remains incomplete. While virtually every country has banned the sale of leaded gasoline for on-road use, it is still widely allowed for off-road uses such as aviation and automotive racing. ${ }^{2}$ The continued use of lead remains a major public health concern as thousands of communities still grapple with lead contamination from legacy sources (Pell and Schneyer, 2016), and research increasingly suggests there is no safe level of exposure (Centers for Disease Control and Prevention, 2012; Lanphear, 2017).

In this paper we use the automotive racing exemption from the United States Clean Air Act to causally identify the external effects of leaded gasoline. We take advantage of a novel quasi-experiment where two major racing organizations, the National Association for Stock Car Auto Racing (NASCAR) and the Automobile Racing Club of America (ARCA), switched from leaded to unleaded gasoline in $2007 .{ }^{3}$ Using difference-in-differences and event study designs, we estimate the relationship between leaded gasoline use and each link in the causal chain from release of lead in the air, to accumulation of lead in blood, and finally to

\footnotetext{
${ }^{1}$ Lead was used in a variety of products because of its efficacy and versatility. It was added to gasoline for its lubrication properties and to boost octane, reducing the likelihood of pre-ignition; it was added to paint to increase moisture resistance, brightness, and durability, as well as to accelerate drying; and it has been used in pipes and pipe solder because of its malleability.

${ }^{2}$ In the United States, federal regulations allow unleaded gasoline to contain up to 0.05 grams of lead per gallon. This is about $2 \%$ of the lead content added to gasoline in the 1970 s. See 40 CFR $\S 80.140$ and 40 CFR $\S 80.173($ b).

${ }^{3}$ The EPA had been concerned about racing lead emissions leading up to 2007. A 2006 report on lead writes, "As was the case with on-road emissions during the time of universal leaded gasoline use, the combustion of racing fuel likely elevates ambient $\mathrm{Pb}$ concentrations in the nearby area. This may pose some health risk for some subpopulations, such as residents living in the vicinity of racetracks, fuel attendants, racing crew and staff, and spectators." (U.S. Environmental Protection Agency, 2006).
} 
impacts on human mortality. We find that each leaded race significantly increases nearby ambient lead concentrations in the weeks following the race. We further find that leaded races increase the prevalence of elevated blood lead levels (EBLLs) in children and increase elderly mortality. This provides the first causal evidence that leaded gasoline exposure increases adult mortality.

We estimate that the reduction in annual lead emissions from deleading NASCAR and ARCA races yielded social benefits of $\$ 1,800$ per child in counties with racetracks, and $\$ 600$ per child in bordering counties through avoided IQ reductions. The benefits from avoided premature elderly mortality in racetrack and bordering counties are over $\$ 15$ million per race, totaling $\$ 2.2$ billion per year. These annual benefits are more than the estimated value of all NASCAR teams combined (Forbes, 2020).

The mortality effects alone put a lower bound on the social cost of a gram of lead in gasoline at $\$ 1,100$. These magnitudes, while large, are consistent with prior observational findings on the relationship between adult mortality and lead exposure (Pirkle et al., 1985; Lustberg and Silbergeld, 2002; Menke et al., 2006; Lanphear et al., 2018). For comparison, the equivalent mortality reduction from deleading NASCAR and ARCA races could be generated by reducing $\mathrm{PM}_{2.5}$ concentrations in the areas surrounding racetracks by $11 \mu \mathrm{g} / \mathrm{m}^{3}$, 90\% of 2006 levels (Deryugina et al., 2019).

The deleading of automotive races is an ideal setting to identify the effects of lead since it overcomes identification challenges such as residential sorting and correlated declines in emission of lead and other pollutants at the tailpipe. The switch to unleaded fuel was the only fuel-relevant change made by NASCAR or ARCA in 2007, and races continued in the same places and at roughly the same times of year. In our empirical approach, we compare changes in population outcomes, before and after deleading, between those who live near racetracks and those who live further away. This enables within-population comparisons that alleviate problems with persistent confounders such as socioeconomic status, the stock of soil lead, the presence of leaded household paint, and lead emissions from nearby municipal airports.

Races emit large quantities of lead that significantly increase ambient concentrations, providing sufficient statistical power for our analysis. Figure 1 compares the magnitude of lead emissions from races to the distribution of annual airborne lead emissions at Toxic Release Inventory (TRI) facilities, and to annual lead emissions at airports. A single threehour race emits more lead than the annual total of $70 \%$ of all lead-emitting facilities in the TRI, and as much lead as the average airport in an entire year. If all races were aggregated into a single TRI entity they would emit an estimated 2 million grams of lead per year, collectively ranking as the $30^{\text {th }}$ largest emitter out of over 5,000 facilities and accounting for 
Figure 1: Automotive racing and aviation lead emissions compared to distribution of all lead-emitting facilities in the 2005 TRI.

\section{5 distribution of annual airborne lead emissions for lead-emitting TRI facilities}

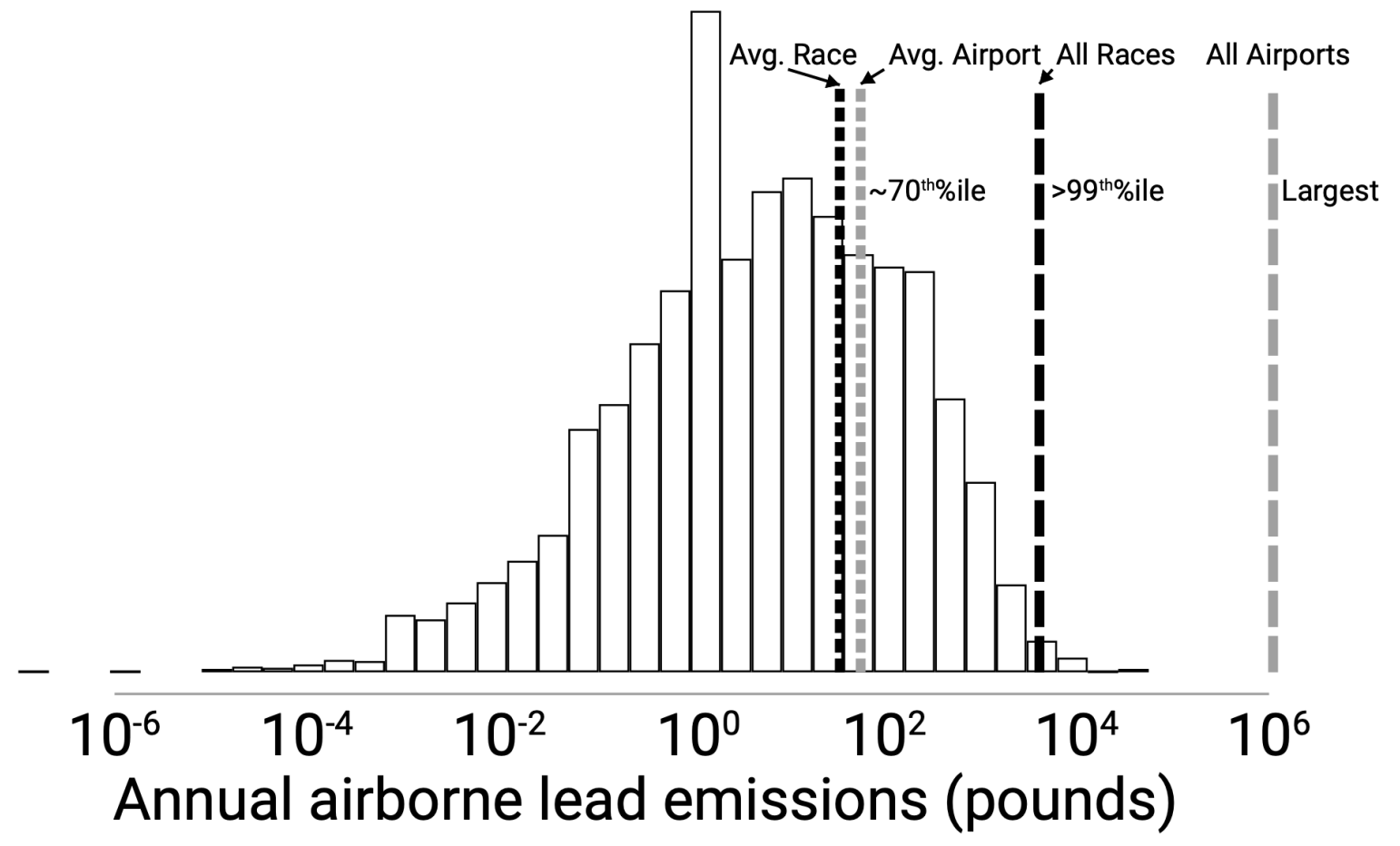

Note: Toxic Release Inventory (TRI) facility emissions are the sum of fugitive and stack emissions in 2005, the year prior to unleaded race tests. The distribution is similar for 2006. We only include TRI facilities with positive quantities of airborne lead emissions. TRI and airport emissions are annual totals while average race emissions are about a three hour total. Airborne lead emissions from both automotive races and aircraft are not reported in the TRI. We obtain the amount of lead emitted from NASCAR and ARCA races using an estimate of 3.2 race miles per gallon as the average fuel economy. The methodology behind the fuel economy estimate can be found in Section A.10, and total emissions are calculated in Section A.11.

roughly half a percent of all annual U.S. lead emissions. ${ }^{4,5}$

This work makes several contributions to the literature. The main contribution is that we use a quasi-experiment to causally link three economically relevant outcomes to well-defined sources and quantities of leaded gasoline. In turn, we provide the first causal evidence of the effects of leaded gasoline exposure on adult mortality, and construct a credible lower bound on

\footnotetext{
${ }^{4}$ This is 800 times the median annual TRI facility emissions and 25 times the average.

${ }^{5}$ Prior research has demonstrated that employees on race teams (e.g. pit crews, mechanics) had high blood lead levels prior to the 2007 deleading. Blood lead levels for employees on NASCAR race teams in 1968 and 2006 were over $7 \mu \mathrm{g} / \mathrm{dl}$ higher than the population averages in those same years. Testing in 2006 showed that $40 \%$ of NASCAR team members had blood lead levels above $10 \mu \mathrm{g} / \mathrm{dl}$, the threshold at the time for elevated blood lead (Polacek and Collins, 1968; O'Neil et al., 2006).
} 
the social cost of lead in gasoline. Second, the deleading of racing fuel allows us to separately identify the effect of lead emissions from other correlated pollutants, socioeconomic factors, and legacy lead in the soil and on the road. This is a critical distinction between prior research designs and our approach. Third, we show that the effects of deleading are readily apparent in the raw data, and we use the same study design to estimate the effects on each link in the emission-outcome chain, assuring internal validity. Fourth, our work sheds light on the adverse effects of lead at some of the lowest levels of ambient lead exposure studied in the literature. ${ }^{6}$ This allows us to provide policy-relevant estimates that are pertinent to modern exposure levels. A nascent literature, to which this paper contributes, increasingly demonstrates that there is no safe level of lead exposure (Aizer et al., 2018; Grönqvist et al., 2018; Lanphear et al., 2018).

This paper also helps to quantify both the value of the global deleading of on-road gasoline and the large social costs of continued usage of leaded gasoline for racing and aviation. While NASCAR and ARCA now use unleaded fuel, leaded racing fuel can still be legally purchased at hundreds of locations across the U.S. and remains widely used in both professional and amateur races. Our mortality cost estimate indicates that the efficient price for leaded racing fuel is orders of magnitude higher than current prices, which range from $\$ 10-\$ 20$ per gallon. The continued use of leaded racing fuel puts participants, attendees, and those who live nearby at risk of bearing undue external costs. Although we do not directly study aviation gasoline, our results are suggestive that the use of leaded fuel by piston-engine aircraft remains a major threat to public health worldwide. Over a quarter of a million aircraft across the world still use leaded avgas (Federal Aviation Administration, 2020), and over 500,000 gallons are used each day in the United States alone (Kessler, 2013).

The paper proceeds as follows. Section 2 describes the physiology of lead and relevant prior research. Section 3 reports data sources. Section 4 contains methods and results. Section 5 computes the value of external effects of leaded gasoline on blood lead levels, and premature mortality. Section 6 concludes. The appendix contains the history of NASCAR and ARCA's switch to unleaded fuel, information on the ambient lead sample, information on other events at tracks, an additional cross-sectional soil analysis, information on collinearity issues, summary statistics, robustness checks and an alternative split-sample instrumental variables approach, associations related to environmental justice, a balance table, results from a survey testing knowledge about NASCAR fuel use, an out-of-sample validation of our ambient air estimates, a counterfactual prediction of ambient lead levels if leaded gas

\footnotetext{
${ }^{6}$ One caveat to our findings is that the same quantity of emissions may differentially affect health if released over a longer time period. Short-lived, but high-rate exposure (e.g., an automotive race) may affect health differently than constant but low-rate exposure (e.g. industrial facility).
} 
was still used for on-road driving, and additional calculations used to put our effects into context.

\section{The Physiology of Lead and Prior Work}

Lead can enter the body through the skin, digestive tract, or by inhalation. ${ }^{7}$ Once in the blood stream, lead can be deposited in both soft (e.g., liver and brain) and hard (e.g. teeth and bone) tissues. Lead has a half life of approximately 30 days in the blood, up to a few years in soft tissues, and several decades in hard tissues. It serves no purpose in the human body, however it competes with and displaces necessary metals such as calcium, zinc, and magnesium. This displacement has a number of negative physiological consequences ranging from impaired cellular signaling to cellular death.

Tetraethyl lead (TEL) is the primary lead compound added to gasoline. TEL boosts octane, reducing the likelihood of pre-ignition of the gasoline. TEL is particularly toxic, even when compared to forms of lead historically found in household paint (Agency for Toxic Substances and Disease Registry, 2018). TEL is easily absorbed through the skin and other major routes of entry, and it can also cross the blood-brain barrier (Abadin and Pohl, 2010). These properties make it extremely harmful at low levels of exposure. ${ }^{8}$

A large body of prior work has studied the correlation between lead exposure and adverse health outcomes. While lead affects nearly every organ in the body, the most well-known impacts are on the nervous system. This is particularly salient for young children, where long run IQ declines are associated with early life exposure (Baghurst et al., 1992; Lanphear et al., 2005). Children are more sensitive to lead because, conditional on exposure, they absorb more lead than adults and because their nervous systems are still developing (Lidsky and Schneider, 2003).

Lead is also associated with increased cardiovascular ailments including hypertension, and higher rates of plaque build up and clotting in blood vessels. Jointly these cardiovascular issues serve to increase the risk of ischemic heart disease and death (Lanphear et al., 2018). Previous research has found strikingly large estimates of the association between lead exposure and adult mortality. Lanphear et al. (2018) estimate that over 400,000 (18\%) deaths per year in the U.S. are associated with lead exposure; Pirkle et al. (1985) find that

\footnotetext{
${ }^{7}$ See Papanikolaou et al. (2005), Garza et al. (2006), and U.S. Environmental Protection Agency (2006) for more details on how it enters and affects the body; Ranft et al. (2008) for a review of how ambient lead concentrations correlate more strongly with blood lead levels than soil lead concentrations; and He et al. (2009) and Oh et al. (2017) for more on how mean blood lead and ambient lead levels rapidly decreased following the enactment of leaded gasoline regulations in Korea and China.

${ }^{8}$ Workers at Du Pont's first TEL plant began dying from lead poisoning within a month of operation, and over $80 \%$ of workers at General Motors and Standard Oil's first TEL plant died or had severe lead poisoning (Kitman, 2000).
} 
the decrease in blood lead levels (BLLs) in the late 1970s was associated with a $6 \%$ decrease in all-cause mortality; Lustberg and Silbergeld (2002) find that having BLLs in the range of $10-19 \mu \mathrm{g} / \mathrm{dl}$ is associated with a $17 \%$ increase in the risk of all-cause mortality; and Menke et al. (2006) find that having BLLs above $3 \mu \mathrm{g} / \mathrm{dl}$ is associated with a $30 \%$ increase in allcause mortality. These correlational studies have generally found the strongest mortality associations with cardiovascular-related causes of death.

Despite lead's clear physiological effects, it is difficult to recover causal estimates using observational data because exposure is not randomly assigned. In addition to gasoline and paint, lead exposure is a byproduct of a host of processes including refining, manufacturing, power generation, smelting, mining, and even drinking water transportation. Many of these processes generate substantial disamenities for nearby residents, including increased exposure to lead and other pollutants (e.g. Currie et al., 2015a; Klemick et al., 2019).

Lead exposure is also correlated with a number of potentially confounding factors like year of birth, place of residence, and socioeconomic status. The types of places that have leaded pipes, high soil lead content, or are near polluting facilities, are also different from locations with lower lead exposure in other ways. Leaded pipes and pipes that contain leaded solder are more likely to be found in older homes (Levin et al., 2008), and industrial facilities are more likely to locate in disadvantaged communities (Ash and Boyce, 2018; Christensen et al., 2019b). All else equal, low-income and minority communities face higher ambient pollution levels and greater exposure to lead (Levin et al., 2008; Miranda et al., 2011), and even within a given community, low-income residents may face greater lead exposure due to an increased prevalence of leaded paint (Jacobs et al., 2002). In general, socioeconomic status is tightly linked to both health and lead exposure (Meara, 2001; Currie and Stabile, 2003; Adams et al., 2004; Currie, 2009; Cutler et al., 2012).

Recent work has taken significant care to address many of the potential confounders associated with non-random lead exposure. A common strategy is to use fixed effects estimators that exploit cohort or group level differences in exposure to lead. Previous work has used this strategy to show that lead exposure through drinking water has negative effects on cognition, fertility, and infant mortality (Ferrie et al., 2012; Clay et al., 2014; Grossman and Slusky, 2019), that the Flint lead crisis was capitalized into housing values (Christensen et al., 2019a), that early life interventions may offset some of the negative effects of lead exposure (Billings and Schnepel, 2018; Sorensen et al., 2019), and that leaded aviation gasoline increases the blood lead levels of those who live near airports (Zahran et al., 2017). ${ }^{9}$

\footnotetext{
${ }^{9}$ In addition to the lead literature, this paper also complements the broader pollution literature on the impacts of vehicle emissions (Auffhammer and Kellogg, 2011; Currie and Walker, 2011; Knittel et al., 2016), the impacts of toxics (Currie et al., 2015b; Persico and Venator, 2018), and the effects of lead remediation (Billings and Schnepel, 2017; Gazze, 2018; Sorensen et al., 2019).
} 
Another common approach is to use a variable correlated with exposure to lead as an instrument, such as distance from a major road or state average gasoline lead content, in order to address issues with non-random lead exposure, avoidance behavior, or measurement error. This strand of literature has shown that lead can increase rates of crime, delinquent behavior, and enrollment in special education; as well as decrease fertility and test scores (Reyes, 2007, 2011, 2015; Feigenbaum and Muller, 2016; Gazze, 2016; Aizer et al., 2018; Clay et al., 2018; Aizer and Currie, 2019; Clay et al., 2019). These empirical approaches often exploit leaded gasoline phasedowns to generate variation in lead exposure that is plausibly exogenous to socioeconomic confounders (Reyes, 2007, 2011, 2015; Grönqvist et al., 2018; Clay et al., 2018).

One challenge with using historic leaded gasoline reductions to generate variation in lead exposure is that these reductions did not occur in isolation. Legislation intended to reduce ambient concentrations of lead and other pollutants was often introduced at similar times. As an example, consider the case of the U.S. lead phasedown that began in the 1970s following the passage of the Clean Air Act. The Clean Air Act established National Ambient Air Quality Standards (NAAQS) for six criteria pollutants, and a number of programs and regulations were implemented to maintain compliance with these standards. Aggregate emissions of both directly and indirectly targeted pollutants gradually declined by $73 \%$ from 1970 to 2016 as a result of this portfolio of programs (U.S. Environmental Protection Agency, 1989, 1990; Lee, 1991; Greenstone, 2002; Schmalensee and Stavins, 2018). ${ }^{10}$

Some of these regulations, such as catalytic converter mandates, simultaneously targeted both lead and other pollutants. In the U.S., the key driver of the leaded fuel emissions reductions was the mandated adoption of catalytic converters in new model-year cars beginning in 1975 (Newell and Rogers, 2003). Catalytic converters are emission control devices that convert $\mathrm{CO}$, nitrogen oxides $\left(\mathrm{NO}_{x}\right)$, and VOCs into benign compounds like water and nitrogen (Newell and Rogers, 2003; Ravindra et al., 2004). The pollutants controlled by catalytic converters have been linked to adverse health outcomes by a large body of prior work, and catalytic converter usage has been linked to large improvements in health in the U.S. and other countries (Mott, 2002; Currie and Neidell, 2005; Greenstone and Hanna, 2014;

\footnotetext{
${ }^{10}$ Figure A1 shows the consistent declines in mean ambient concentrations of all pollutants except for ozone. This general pattern of correlated, overlapping pollution regulations exists in countries other than the U.S. For example, Swedish air pollution regulations began in 1969 with the passage of the Swedish Environmental Protection Act. Following their EPA formation, many new laws were implemented to address various sources of emissions such as high-sulfur fuel oil, mercury, pesticides, and lead in gasoline. This generated simultaneous decreases in ambient concentrations of a wide range of pollutants (Naturvårdsverket, 2010). Sweden also began targeting reductions in motor vehicle emissions in 1969 and tightened emissions restrictions several times thereafter. This occurred simultaneously with leaded gasoline phasedowns in 1972 and mandated adoptions of catalytic converters in 1988 (Lovei, 1998). See Lundqvist (1979) for a brief policy overview and comparison to the U.S.
} 
Alexander and Schwandt, 2019). Although catalytic converters do not directly reduce lead emissions, lead damages the devices, effectively prohibiting leaded fuel use. As new cars with catalytic converters replaced older cars, emissions of lead, $\mathrm{CO}, \mathrm{NO}_{x}$, and VOCs all declined simultaneously at the point source.

Jointly, the portfolio of pollution policies deployed in the U.S. and other countries led to a gradual and correlated decline in the ambient concentrations of many pollutants. This presents problems for separately identifying the effects of lead from the effects of other pollutants. Our research setting overcomes the challenges in separately identify the effect of lead since race cars do not use catalytic converters or other emission control devices, and the removal of lead was the only relevant change made to the fuel between 2006 and 2007.

\section{Data}

Here we describe our data. Summary statistics can be found in Section A.4 of the appendix.

Racing data: Race data were obtained from Racing Reference, a site that catalogs historical races for NASCAR, ARCA, and a number of other racing series. We collected data on the universe of races for the four racing series that were required to switch to unleaded fuel in 2007, NASCAR's three national series and the ARCA Menards Series. For robustness checks, we also collected race data for all regional NASCAR K\&N Pro Series, which are the main series for which we cannot determine the leaded fuel status at any point in time in our sample. For each race we record the number of drivers, the number of laps needed for race completion, the length of each lap, the actual number of miles driven in the race by each driver, the racetrack location, and the date of the race. Race miles are observed and not estimated from lap length. We have information on every race in each of the national series since their inception: 1949 for the Monster Energy Cup, 1982 for the Xfinity Series, and 1995 for the Gander Outdoors Truck Series. ${ }^{11}$ Track location was ascertained through Google Maps and manually confirmed. Figure A3 shows the geographic distribution of counties that have a racetrack or border a county with a racetrack.

For a placebo test, we also collected data on the NTT IndyCar Series races from ChampCarStats. IndyCar races are an ideal comparison group since they do not use leaded fuel, and because they use many of the same tracks as NASCAR and ARCA, but take place at different times of the year. ${ }^{12}$ IndyCar allows us to test whether or not our ambient lead

\footnotetext{
${ }^{11}$ These series have gone by several different names since their inception. We use their 2019 names when discussing them in this paper.

${ }^{12}$ IndyCar has not used lead additives since 1964 when it began using pure methanol, an alcohol-based fuel. In 2006, it switched to a 90/10 ethanol/methanol blend, and in 2007 it switched to a 98/2 ethanol/gasoline blend.
} 
estimates are simply picking up on lead emissions from spectators' vehicles and generators, or resuspension of legacy lead. ${ }^{13}$

Pollution data: Daily pollution data were obtained from the EPA's AirData datasets, which report pre-generated daily summaries by pollutant at each air enforcement monitor. For every recorded monitor day from 1980 to 2018, data were collected for CO, $\mathrm{NO}_{2}, \mathrm{PM}_{10}$, $\mathrm{PM}_{2.5}, \mathrm{~Pb}, \mathrm{VOCs}$, and $\mathrm{O}_{3}$. Daily data on lead levels prior to 1980 were provided by the EPA by request. All events were included in the calculation of a daily mean.

Weather data: Weather data come from the National Oceanic and Atmospheric Administration's (NOAA) NCEP-NCAR Reanalysis 1 model, which provides daily weather data in a $2.5^{\circ}$ latitude by $2.5^{\circ}$ longitude global grid (Kalnay et al., 1996). We extracted data from 1948-2018 on surface level (i.e. 0.995 sigma level) average air temperature $\left(\mathrm{C}^{\circ}\right)$, pressure (kPA), relative humidity (\%), and wind. Wind data are reported within each cell by two vectors: a $\mathrm{u}$-wind vector that measures east to west wind in meters per second and a $\mathrm{v}$-wind vector that reports north to south wind in meters per second. Using these two vectors, we calculate wind-speed $(\mathrm{m} / \mathrm{s})$ and wind direction. ${ }^{14}$ To proxy for precipitation, we extracted data on daily precipitable water $\left(\frac{\mathrm{kg}}{\mathrm{m}^{2}}\right)$ in each $2.5^{\circ}$ by $2.5^{\circ}$ atmospheric column; these data are not reported at the surface level. To estimate the daily weather conditions at each pollution monitor, we first determine the $2.5^{\circ}$ latitude by $2.5^{\circ}$ longitude grid cell in which each pollution monitor is located. We then assign the daily weather data for each cell to all pollution monitors within it.

Blood lead data: Blood lead data were obtained from the Centers for Disease Control and Prevention (CDC) State Surveillance Data. Data are reported at the county-year level from 2005-2015. The blood lead data report the percentage of children tested in a given county-year that had elevated blood lead levels, which would be a BLL above $10 \mu \mathrm{g} / \mathrm{dl}$. The CDC funded 29 states, Washington D.C., and 5 cities to sample blood lead in children under 72 months old. 5 additional states also voluntarily submitted data. Blood lead sampling was targeted at high-risk areas. Section A.7 describes two tests of whether targeting is a concern

\footnotetext{
${ }^{13}$ In addition to NASCAR, ARCA, and IndyCar, there are other racing series in the U.S. such as Formula 1, National Hot Rod Association (NHRA) drag racing, and a large number of regional and local series. Like NASCAR, Formula 1 historically allowed leaded fuel but switched to unleaded gasoline in 1996 (Collins, 2012). We omit Formula 1 races from our analysis because there is at most one Formula 1 race per year in the U.S., and the fuel switch occurred prior to the earliest years used in our results. We do not include data on NHRA series since racers have the option to use a wide range of fuels including gasoline, diesel, propane, or nitromethane. In the series that require a specific fuel (e.g. the Mello Yello Drag Racing Series, which requires either nitromethane or methanol) we are unaware of any changes to fuel rules that coincide with NASCAR and ARCA deleading. In Section A.5 of the appendix, we discuss changes in car performance across time, where racetracks are located, where lead monitors are located relative to racetracks, and other events that occur at the racetracks in more detail.

${ }^{14}$ Wind speed $=\sqrt{u^{2}+v^{2}}$. Wind direction $=\bmod \left(\operatorname{atan} 2(-u,-v) \cdot \frac{180}{\pi}-180,360\right)$.
} 
for identification. We do not find evidence that this is the case.

Here we focus on confirmed cases of elevated blood lead. Confirmed cases of elevated blood lead in children require a venous blood draw registering a BLL above $10 \mu \mathrm{g} / \mathrm{dl}$, or two separate capillary draws within two weeks registering BLLs above $10 \mu \mathrm{g} / \mathrm{dl}$. This helps avoid measurement error in readings from a single capillary draw, which can be easily contaminated.

Mortality data: Mortality data come from the restricted CDC National Vital Statistics System, and population data come from the National Cancer Institute's Surveillance, Epidemiology, and End Result (SEER) program. Mortality data report information at the individual level of death. We observe cause of death; age at death; county, month, and year of death; and county of residence. The SEER data are reported from 1999-2016. We report the age-standardized death rate per 100,000 population of each cohort. The reference population we use to standardize is the U.S. population for each cohort in 2000. For our analysis we focus on the elderly population $(65+)$, but we also report results for infants (under 1 year old) in Section A.8 of the appendix.

Covariate data: In some specifications we control for socioeconomic variables. ${ }^{15}$ We collect county level data on median income from the U.S. Census, unemployment rates from the Bureau of Labor Statistics, and percent non-white from the SEER program. We obtain data from the Toxic Release Inventory on lead emissions from industrial facilities. Facilities included in the TRI emissions data must have at least 10 employees and manufacture, process, or use above 100 pounds of general lead compounds. The threshold is 25,000 pounds if the facility is using lead in brass, stainless steel, or bronze alloys. We augment the lead emissions data with county level payroll data for the manufacturing sector from the County Business Patterns dataset as a way to proxy for other emissions, address the censoring of smaller facilities, and address the known measurement error issues in the TRI database (De Marchi and Hamilton, 2006).

\section{Methods and results}

Here we describe our empirical methods and present our results for each outcome of interest. All of our results exploit the deleading of NASCAR and ARCA fuel in 2007. Due to differences in the granularity of our outcomes data across both time and space, we use a slightly different specification for ambient lead outcomes versus the blood lead and mortality

\footnotetext{
${ }^{15}$ In Section A.9.2 of the appendix, we report how counties with racetracks differ from other counties along socioeconomic indicators that were omitted from our set of covariates such as percent in poverty. We find that conditional on covariates and fixed effects, race counties, border counties, and control counties are similar on these margins.
} 
outcomes. In addition, we choose geographic units of comparable size across each analysis, further ensuring that results are commensurable. Sections A.6-A.9 contain alternative specifications, robustness checks, and additional analyses for all outcomes.

\subsection{Ambient lead concentrations}

\subsubsection{Ambient lead concentrations methods}

To estimate the effect of leaded races on ambient lead concentrations we estimate an event study and a spatial lag model. The following equation is our simplest specification, a monitorday design that underlies results displayed in the tables:

$$
\begin{aligned}
& \operatorname{asinh}(\mathrm{Pb})_{m d w y}= \beta_{l} \text { leaded race miles } m d w y \\
&+\gamma \mathbf{X}_{m d w y}+\beta_{u} \text { unleaded race miles } \\
& m d w y \\
&+\Omega_{w y}+\varepsilon_{m d w y}
\end{aligned}
$$

$\operatorname{asinh}(\mathrm{Pb})_{m d w y}$ is the inverse hyperbolic sine of the measured lead concentration at monitor $m$ on day $d$ in week-of-year $w$ and year $y$. We use the asinh transform because the empirical lead concentration distribution is right-skewed and has a large number of zero-valued observations. The asinh transform is similar to the natural log transform insofar as it is monotonic and compresses the influence of large outliers. It does this with the additional advantage of preserving zero valued inputs without needing additional manipulation.

$\mathbf{X}_{m d w y}$ is a vector of covariates containing the average temperature, precipitable water, relative humidity, surface pressure, and wind speed on the day of the reading. $\Theta_{m y}$ is a set of monitor-by-year fixed effects that flexibly control for monitor-specific annual trends in lead concentrations, and $\Omega_{w y}$ is a set of week-by-year fixed effects that control for within-week shocks that are common across monitors. $\varepsilon_{m d w y}$ is the error term. Standard errors are robust to heteroskedasticity and clustered at the county level since the errors of nearby monitors are likely to be correlated. In our main results we restrict our sample to begin in 1996, when on-road leaded fuel was banned. This avoids potential confounding from spectator travel to the racetrack.

leaded race miles $_{m d w y}$ is the number of leaded race miles that occurred within 50 miles of monitor $m$, in the week prior to monitor $m$ 's lead reading on day $d .{ }^{16}$ unleaded race miles $s_{\text {mdwy }}$ is the same but for unleaded race miles. Our coefficients of interest are $\beta_{l}$ and $\beta_{u}$. $\beta_{l}$ is the effect of the leaded race miles driven in the past week on ambient lead readings within 50 miles, and $\beta_{u}$ is the same but for unleaded miles. Identification of $\beta_{l}$ comes from variation

\footnotetext{
${ }^{16}$ Section A.6 of the appendix shows our results are robust to using alternative cutoffs to 50 miles.
} 
Figure 2: Ambient lead concentrations in the four weeks before and after the last leaded race (left) or unleaded race (right).

A.

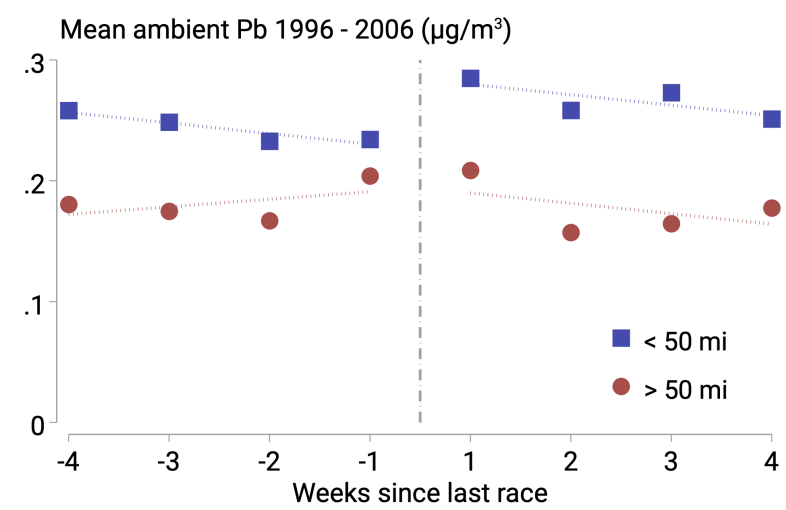

B.

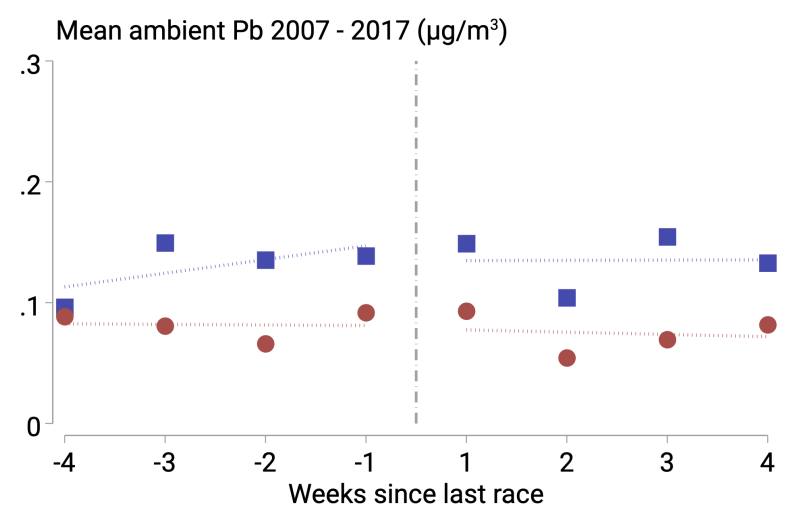

Note: This figure plots ambient lead concentrations across time and space. The left panel (A) plots average ambient lead concentrations 4 weeks before and after a race from 1996-2006, years when races were leaded. The right panel (B) is the same, but for 2007-2017, years when races were unleaded. Negative values on the $\mathrm{x}$-axis indicate monitor readings that occurred in the weeks prior to a race, and positive values on the $\mathrm{x}$-axis indicate monitor readings that occurred in the weeks after a race.

in leaded miles at a monitor, within a year, off of week-of-year averages across monitors. ${ }^{17}$ Identification of $\beta_{u}$ comes from the same variation but in unleaded race miles.

To estimate a distance gradient we use a spatial lag model. This specification also includes four variables in addition to those in equation (1). The four variables are the number of leaded and unleaded miles that occurred within the last week between 50-75 miles and 75-100 miles away from the monitor. To estimate a time gradient and test for any pre-trends in lead concentrations prior to a race, we use an event study specification. This specification includes 14 additional variables: the number of leaded and unleaded race miles that occurred within 50 miles, but 8-14 days, 15-21 days, and 22-28 days in the past; and the number of leaded and unleaded race miles that occurred within 50 miles, but 0-7 days, 8-14 days, 15-21 days, and 22-28 days in the future.

\subsubsection{Ambient lead concentrations results}

First we plot the raw data. Figure 2 plots the average ambient concentration of lead by weeks since the most recent race in the 11 years prior to deleading (left panel) and the 11 years after

\footnotetext{
${ }^{17}$ Note that identification of $\beta_{l}$ does not rely upon unleaded race miles being driven. We are comparing monitor readings on days with positive leaded race miles in the past week to monitor readings on days without. These are primarily days without any kind of race in the past week. The same is true for identification of $\beta_{u}$ and leaded miles.
} 
deleading (right panel). Negative values on the x-axis indicate monitor readings that occurred in the weeks prior to a race, and positive values on the $\mathrm{x}$-axis indicate monitor readings that occurred in the weeks after a race. During leaded race years, lead concentrations prior to a race show a slight downward trend within 50 miles of a racetrack, and are flat or slightly increasing further away. In the week after a race, concentrations jump by over $20 \%$ compared to concentrations the week prior at monitors within 50 miles. The jump slowly attenuates until it reaches pre-race levels after 4 weeks. There is essentially no change in concentrations outside 50 miles. The right panel shows that once NASCAR and ARCA deleaded, the post-race jump in ambient lead concentrations vanishes.

Table 1: The effect of race miles on ambient lead concentrations at monitors within 50 miles of a racetrack.

\begin{tabular}{lccccccc}
\hline & $(1)$ & $(2)$ & $(3)$ & $(4)$ & $(5)$ & $(6)$ & $(7)$ \\
\hline Leaded race miles in past week (100k) & $0.16^{* *}$ & $0.14^{*}$ & $0.14^{* *}$ & $0.13^{* *}$ & $0.13^{* *}$ & $0.13^{* *}$ & $0.13^{* * *}$ \\
& $(0.08)$ & $(0.08)$ & $(0.07)$ & $(0.06)$ & $(0.05)$ & $(0.05)$ & $(0.05)$ \\
Unleaded race miles in past week (100k) & $0.07^{* * *}$ & $0.06^{* *}$ & $0.06^{* *}$ & $0.02^{*}$ & 0.01 & 0.01 & -0.00 \\
& $(0.03)$ & $(0.02)$ & $(0.02)$ & $(0.01)$ & $(0.01)$ & $(0.01)$ & $(0.01)$ \\
\hline Monitor FE & Yes & Yes & Yes & Yes & Yes & No & No \\
Year FE & Yes & Yes & Yes & No & No & No & No \\
Daily Weather Controls & No & Yes & Yes & Yes & Yes & Yes & Yes \\
Week FE & No & No & Yes & Yes & Yes & Yes & No \\
State-by-Year FE & No & No & No & Yes & No & No & No \\
County-by-Year FE & No & No & No & No & Yes & No & No \\
Monitor-by-Year FE & No & No & No & No & No & Yes & Yes \\
Week-by-Year FE & No & No & No & No & No & No \\
Clustered Standard Errors & County & County & County & County & County & County & County \\
\hline Adjusted $R^{2}$ & 0.35 & 0.35 & 0.35 & 0.39 & 0.41 & 0.44 & 0.45 \\
Observations & 312296 & 312296 & 312296 & 312291 & 312285 & 312277 & 312277 \\
\hline
\end{tabular}

Note: $* \mathrm{p}<0.1, * * \mathrm{p}<0.05, * * * \mathrm{p}<0.01$. Robust standard errors clustered at the county level in parentheses. The dependent variable is $\operatorname{asinh}(\mathrm{Pb})$. Monitor-specific daily weather variables include air temperature, pressure, relative humidity, wind speed, and daily precipitable water. Column 7 shows estimates from equation (1).

Table 1 displays estimates that gradually build up to our preferred set of fixed effects and controls in column 7 , which corresponds to equation (1). ${ }^{18}$ The top row shows estimates of the effect of 100,000 leaded miles in the past week, and the second row shows estimates of the effect of 100,000 unleaded miles in the past week. Column 1 controls for only monitor fixed effects and year fixed effects. In this simple comparison, the estimated effect of 100,000 leaded miles on $\operatorname{asinh}(\mathrm{Pb})$ is 0.16 , and the effect of 100,000 unleaded miles is 0.07. As we add monitor-specific daily weather controls (column 2) and week-of-year fixed effects (column 3), neither coefficient meaningfully changes. Including state-by-year fixed effects (column 4) reduces the impact of leaded miles to 0.13 and the impact of unleaded miles to 0.02 . Further

\footnotetext{
${ }^{18}$ In the sample there are 205 lead monitors that were treated at least once by a leaded race within 50 miles, and 635 lead monitors that had never been treated.
} 
refining the spatial fixed effects to county-by-year (column 5) or monitor-by-year (column 6) and adding week-by-year fixed effects (column 7) continues to attenuate the estimated relationship between unleaded race miles and ambient lead levels, while leaving the estimated effect of leaded race miles on ambient lead concentrations relatively unchanged.

The inclusion of flexible time-trends (at the state, county, or monitor level) are important for our identification since they help guard against the possibilities that our estimates only reflect spurious differential trends (e.g. declining ambient lead levels in areas far from racetracks) or that our findings are caused by local changes in pollution, policy, or other unobservables (e.g. the closing of a manufacturing plant). Incorporating monitor-by-year and week-by-year fixed effects, as we do in our preferred specification in column 7 , ensures that our treatment effect estimates are derived from within monitor-year variation in the quantities of leaded and unleaded miles, and address common seasonal patterns in ambient concentrations. Using this specification, we estimate that every 100,000 leaded miles driven in the past week increases ambient $\operatorname{asinh}(\mathrm{Pb})$ levels by 0.13 , which is equivalent to a $14 \%$ increase in mean concentrations. ${ }^{19}$ We further estimate a precise zero effect of unleaded miles on ambient lead concentrations; we can statistically distinguish the leaded and unleaded miles estimates from each other.

Figure 3 plots the estimated time and distance gradients. The left panel plots our event study estimates of the effect of 100,000 race miles by weeks since the last race within 50 miles. In the weeks prior to exposure to either type of race miles, we do not detect any change in ambient lead concentrations. In the first week after exposure to 100,000 leaded miles we estimate that $\operatorname{asinh}(\mathrm{Pb})$ increases by 0.15 , a $16 \%$ increase in mean concentrations. The effect then tapers off toward zero in the weeks after. All estimates for unleaded miles are centered around zero with no clear trend over time, suggesting that unleaded races do not resuspend legacy lead or have other attributes that increase ambient lead levels.

The right panel of Figure 3 plots spatial lag estimates of the effect of 100,000 race miles in the past week on $\operatorname{asinh}(\mathrm{Pb})$ by distance bands. We find an intuitive decreasing gradient in distance for leaded miles. We estimate an effect of $14 \%$ in the 0-50 mile distance band, which declines to $3 \%$ in the 50-75 mile band, and to approximately zero in the 75-100 mile band. In contrast, we do not find any discernible relationship between unleaded miles and distance from racetrack to monitor.

Robustness checks, and alternative specifications: Section A.6 of the appendix further demonstrates the robustness of our estimates to a variety of specifications and sample definitions. It also contains event study estimates including baseball and IndyCar as

\footnotetext{
${ }^{19}$ See Bellemare and Wichman (2019) for how to compute asinh elasticities. They are slightly different than log elasticities, so the percentage changes we report will not always match the coefficient estimate.
} 
Figure 3: The effect of race miles on ambient lead by weeks since most recent race (left) and by distance from track (right).

A.

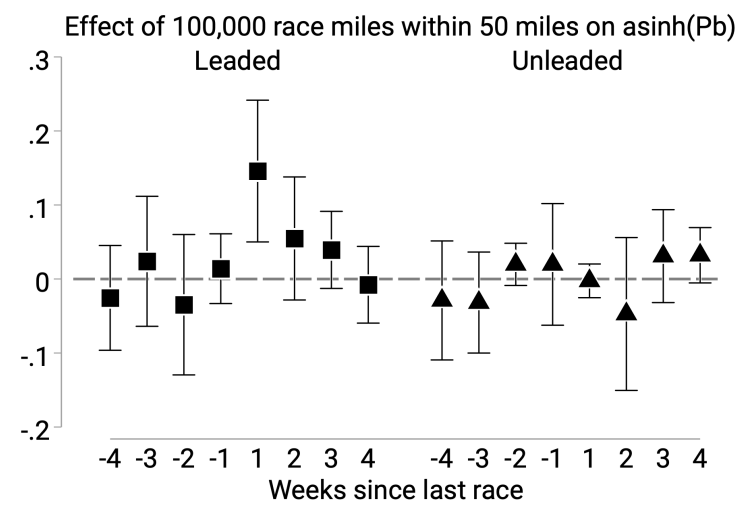

B.

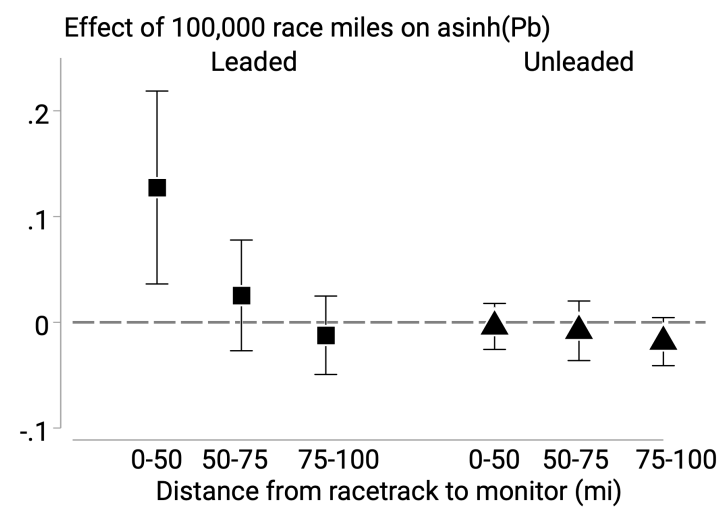

Note: This figure shows the effect of 100,000 leaded and unleaded race miles on ambient lead concentrations across both time and space. The left panel (A) plots the estimated time gradient, while the right panel (B) plots the estimated distance gradient. For each panel, all coefficients come from one regression. Each regression controls for week-by-year fixed effects, monitor-by-year fixed effects, and daily monitor-specific weather controls. The dependent variable is $\operatorname{asinh}(\mathrm{Pb})$. Brackets denote $95 \%$ confidence intervals, calculated from robust standard errors clustered at the county level. For the time panel (A), negative values on the $\mathrm{x}$-axis indicate monitor readings that occurred in the weeks prior to a race, and positive values on the $\mathrm{x}$-axis indicate monitor readings that occurred in the weeks after a race. For the time panel, only race miles within 50 miles are included. For the distance panel (B), only race miles within the past seven days are considered.

additional comparison groups showing they have no effect on ambient lead concentrations, and that there is no differential effect of leaded versus unleaded races on concentrations of other potentially confounding pollutants. Section A.9.1 contains a cross-sectional analysis of soil lead, showing higher concentrations near racetracks. In Section A.10, we use our estimates to predict how daily historic vehicle traffic affects mean air quality in major cities. Over the range of common support, our estimates predict historic mean lead levels quite well, lending further credibility to our in-sample estimates. This section also reports results from a counterfactual prediction of ambient lead concentrations as if lead were still added to gasoline at 1970 levels. 


\subsection{Blood lead}

\subsubsection{Blood lead methods}

Our elevated blood lead level outcomes are at the county-year level, so we use the following event study specification:

$$
\begin{aligned}
\operatorname{asinh}(\mathrm{EBLL})_{s c y}= & \sum_{t \in \mathcal{Y}} \beta_{t}^{r} 1(\text { race in county })_{s c t}+\sum_{t \in \mathcal{Y}} \beta_{t}^{b} 1(\text { race in border county })_{s c t} \\
& +\gamma \mathbf{X}_{s c y}+\Theta_{c}+\Omega_{s y}+\varepsilon_{s c y} .
\end{aligned}
$$

$\operatorname{asinh}(E B L L)_{s c y}$ is the inverse hyperbolic sine of the elevated blood level prevalence in state $s$, county $c$, and year $y$. We again use the inverse hyperbolic sine transform because of the distribution of elevated blood lead rates is right-skewed and contains a large number of zero-valued observations. $\sum_{t \in \mathcal{Y}} 1$ (race in county $)_{s c t}$ is our main set of treatment variables. They are indicator variables that are equal to 1 if there was a race in county $c$ in year $t .{ }^{20} \mathcal{Y}$ is the set of years from 2005 to 2015 with 2007 omitted. The $\beta_{t}^{r}$ s capture the effect of having a race in a year $t$ on $\operatorname{asinh}(E B L L)_{s c y}$ in year $y$, relative to the difference in $\operatorname{asinh}(E B L L)_{s c y}$ between race counties and control counties in 2007. Control counties in year $t$ are those that did not have a race and did not border a county with a race in year $t$. This does allow for some counties to be in the control group in one year and in one of the treatment groups in another. However, since the half-life of blood lead is short, and there are generally not NASCAR or ARCA races in the first or last 40 days of the year, effects of leaded races on the prevalence of elevated blood lead in the next year would be small.

$\sum_{t \in \mathcal{Y}} 1$ (race in border county $)_{s c t}$ is a set of indicator variables equal to 1 if there was a race in a county that borders county $c$ in year $t$, but there was no race in county $c$ itself. The $\beta_{t}^{b}$ s capture the effect of not having a race, but bordering a county with a race in a particular year on $\operatorname{asinh}(E B L L)_{s c y}$, relative to the difference in $\operatorname{asinh}(E B L L)_{s c y}$ between border counties and control counties in 2007. This second set of variables is to determine if there is a distance gradient for EBLL rates like we found for ambient lead.

\footnotetext{
${ }^{20}$ The sum of leaded and unleaded race miles in a county does not change much from year to year since the race schedule is usually the same on an annual basis, and races typically maintain the same length over time. The only variation in the sum of the two types of miles generally comes from weather-related issues, or crashes or retirements during a race. Since total race miles is approximately fixed and total race miles $=$ leaded miles + unleaded miles, using total miles in a given county-year as treatment variables will be effectively the same as using dummy variables after conditioning on county fixed effects, and trying to separately estimate the effect of leaded and unleaded miles will have the usual multicollinearity issues. Figure A20 of the appendix shows the high degree of collinearity between leaded and unleaded miles. We explore outcomes in a difference-in-differences framework with varying treatment intensity using just leaded miles in Section A.7 of the appendix.
} 
$\mathbf{X}_{s c y}$ is a set of controls that includes the unemployment rate, median income, percent non-white, payroll in the manufacturing sector, and quantity of TRI lead emissions. The first three are to control for socioeconomic status and potential sorting across locations, while the latter two are to control for alternative sources of lead emissions. ${ }^{21} \Theta_{c}$ is a set of county fixed effects, and $\Omega_{s y}$ is a set of state-by-year fixed effects. $\varepsilon_{s c y}$ is the error term. Standard errors are robust to heteroskedasticity and are clustered at the county level. Identification of $\beta_{t}^{r}$ and $\beta_{t}^{b}$ comes from annual within-state variation in races, off of the county means. Since the sample of children tested is a non-random sample of those at risk for higher blood lead levels, an additional identification assumption is that this selection did not differentially change for race and border counties relative to control counties around the time of deleading. This is addressed further in Section A.7, where we show that the number of children tested in race counties did not change in race counties following deleading.

\subsubsection{Blood lead results}

We begin by plotting the raw data. Figure 4 plots average prevalence of elevated blood lead from 2005 to 2009 by county type, where the means are weighted by the square root of the number of children tested. ${ }^{22}$ Prior to the switch to unleaded fuel in 2007, all three types of counties exhibited slight downward trends in EBLL rates that are nearly parallel, although the rate of elevated blood lead in border counties and race counties were 1 and 2 percentage points higher than in control counties. In 2007, when NASCAR and ARCA permanently switched to unleaded gasoline, control county EBLL rates continued along the same trend, but race and border county EBLL rates dropped so that they were nearly identical to control counties. In subsequent years, EBLL rates across county types had similar levels and parallel trends.

Figure 5 plots estimates from our main regression. The top panel displays estimates for race counties. In 2005 and 2006 we estimate that race counties had EBLL rates that were $18 \%$ and $13 \%$ higher than in 2007 . The decrease from 2005 to 2006 is consistent with the fact that $14 \%$ of race miles driven in 2006 were unleaded race miles, thus decreasing exposure in race counties relative to 2005. For all years after 2007, the point estimates are all close to zero. The dashed line is the point estimate from our preferred difference-in-differences regression, where year-specific race county and border county indicator variables are replaced with two indicator variables: one for if there was a race in the county in 2005 or 2006, and

\footnotetext{
${ }^{21}$ Section A.9.5 of the appendix contains results from a Mechanical Turk survey indicating that the public may be generally unaware of the fuel used by NASCAR and when they have switched fuels. This alleviates concerns about sorting and other behavior that may bias our estimates.

${ }^{22}$ Leaving the data unweighted does not affect the results. We truncate the sample at 2009 for the plot since after 2009 some counties stop reporting and the composition of our sample changes.
} 
Figure 4: Mean percent of children with elevated blood lead levels by year and county type.

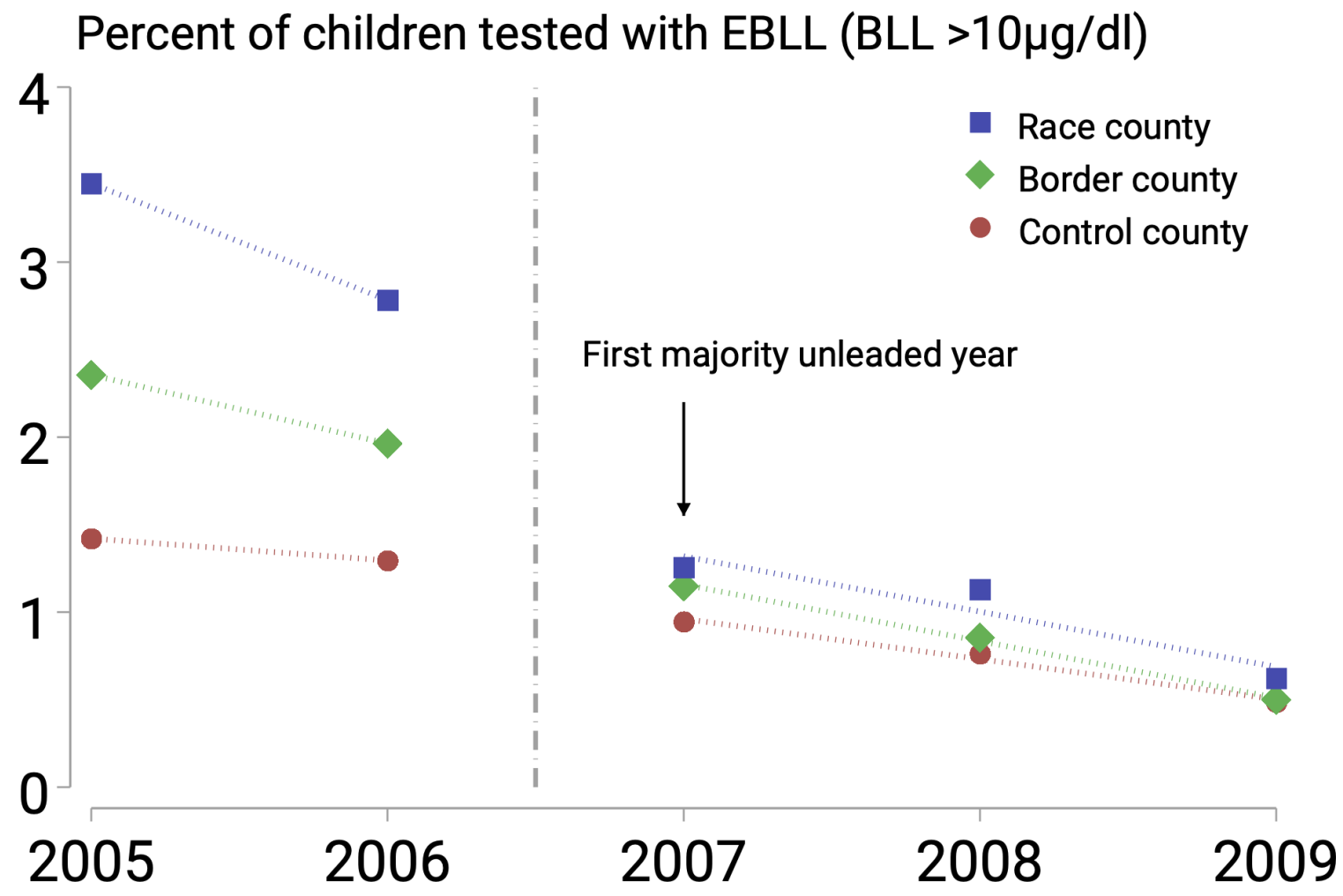

Note: Each point represents the mean percent of children tested with elevated blood lead levels by county type, weighted by the square root of the number of children tested. The results are similar when we do not weight the data. Elevated blood lead level means that the concentration of lead in the blood is at least 10 $\mu \mathrm{g} / \mathrm{dl}$. County type refers to if there was a NASCAR or ARCA race in that county (blue squares) or in a border county (green diamond) in that year. All other counties are considered control counties (red circle). For this figure we use a balanced panel of counties from 2005 to 2009. All data are included in our regression estimates.

one for if there was not a race in the county but there was one in a bordering county in 2005 or 2006. The estimates from this regression indicate that the prevalence of elevated blood lead was on average $17 \%$ higher in leaded race years versus unleaded race years.

The bottom panel shows estimates for border counties. Here we estimate an effect of $6 \%$ in 2005 and $5 \%$ in 2006 relative to 2007, and effects that are close to zero in the years after 2007. The difference-in-differences regression yields an estimate of $6 \%$ higher EBLL rates in leaded races years versus unleaded race years. The smaller estimated effect for border counties is consistent with a decreasing distance gradient. Section A.7 of the appendix includes estimates from the difference-in-differences regressions as we build up to our main specification, event study estimates when the outcome is the untransformed EBLL rate, and additional estimates using the quantity of leaded miles as treatment. 
Our event study results shed light on the mechanisms driving higher EBLL rates in race counties. EBLLs could be caused by exposure to newly emitted lead from races, exposure to legacy lead deposits, or some combination of the two. The switch to unleaded fuel affects the flow of new lead, which reduces airborne exposure and additional deposition to the existing stock of legacy lead. If the effects on EBLL rates were mainly a function of the stock of lead, we should expect the decrease in EBLL rates in race counties relative to control counties to occur more slowly over many years or perhaps to not find a decline at all. The observed, immediate decline in 2007 and subsequent plateau in both the regression estimates and raw data is consistent with higher EBLL rates being primarily a function of exposure to lead emissions from recent races.

Appendix Section A.9.2 reports results from a series of specifications that examine if omitted variables or differential trends could be driving the estimates between leaded races and the prevalence of elevated blood lead reported above. We follow Pei et al. (2019) and swap our dependent variable of interest with one of a number of socio-economic variables not included as control variables in our preferred specification. We find no clear, statistically significant or economically meaningful relationship between our independent variables of interest and these socio-economic variables, helping to alleviate concerns that our estimates are driven by omitted variables or differential trends.

\subsection{Elderly mortality}

\subsubsection{Elderly mortality methods}

Here we use the same empirical approach as the EBLL analysis since the data are at the same county-year level. The specification is:

$$
\begin{aligned}
\text { mortality rate }_{s c y}= & \sum_{t \in \mathcal{Y}} \beta_{t} 1(\text { race in county })_{s c t}+\sum_{t \in \mathcal{Y}} \beta_{t}^{b} 1(\text { race in border county })_{s c t} \\
& +\gamma \mathbf{X}_{s c y}+\Theta_{c}+\Omega_{s y}+\varepsilon_{s c y} .
\end{aligned}
$$

mortality rate $_{\text {scy }}$ is the cause-specific, age-standardized, elderly mortality rate in state $s$, county $c$, and year $y$. Since the mortality rate distributions are roughly normally distributed with very few zeros we do not use the inverse hyperbolic sine transformation. ${ }^{23}$ The mortality rate is in terms of deaths per 100,000 in the elderly cohort, which we define as those aged 65 and above. The rest of the specification is identical to equation (2). We study six causes of death. The first is all-cause mortality. This picks up an aggregate mortality impact

\footnotetext{
${ }^{23}$ Results are similar if we use an inverse hyperbolic sine transformation.
} 
and avoids potential misclassifications related to any particular cause of death. The next four causes of death are cardiovascular mortality, ischemic heart disease (IHD), respiratory mortality, and deaths of despair as defined by Case and Deaton (2015). We selected cardiovascular, IHD, and respiratory mortality because of the existing associational evidence that EBLLs are related to cardiovascular mortality and reduced respiratory function (Pirkle et al., 1985; Lustberg and Silbergeld, 2002; Jurdziak et al., 2015; Lanphear et al., 2018). We included deaths of despair because higher levels of blood or bone lead are associated with higher rates of drug addition, psychiatric symptoms such as depression and panic attacks, and suicide risk (Rhodes et al., 2003; Fishbein et al., 2008; Bouchard et al., 2009; Kim et al., 2015).

The last cause of death is a placebo: diabetes. Lead has a systemic effect on the human body making it difficult to come up with valid placebos a priori. However, since diabetes is a chronic disease, the sudden deleading of gasoline is unlikely to affect diabetes mortality rates. We find no effect of deleading on diabetes; the event study estimates can be found in Section A.8 of the appendix. Section A.8.1 of the appendix contains the specific CDC and International Classification of Diseases (ICD) codes used to define each of the six causes of death.

\subsubsection{Elderly mortality results}

We again begin with the raw data. Figure 6 plots the raw data for the age-standardized average all-cause mortality rate, where counties are weighted by the square root of the elderly population. All three types of counties exhibited steep downward trends over the sample period. All-cause mortality rates were nearly identical in race and control counties prior to the fuel switch, while border county rates were slightly lower but follow a parallel trend.

At the time of deleading in 2007, mortality rates of race counties dropped below those of control counties, and border county mortality rates also dropped relative to control counties. Trends in the post-period were also approximately parallel. Figure A14 in the appendix plots the data for cause-specific mortality and the figure shows similar patterns as for all-cause mortality.

The top left panel of Figure 7 plots our all-cause mortality estimates in event study form. There are no clear pre-trends in the estimated effect of being in a race or border county relative to a control county. All-cause mortality rates in race and border counties declined relative to control counties after deleading, and remained lower for the rest of the sample period. To get a better sense of the average size of the effect, the dashed line shows the estimated effect when we replace the event study with our preferred difference-in-differences specification with unleaded treatment beginning in 2007. We estimate a decline in elderly 
mortality rates of 91 deaths per 100,000 in race counties and 38 deaths per 100,000 in border counties.

Figure 7 also plots event study estimates for the other four mortality outcomes. Again, there are no clear pre-trends except for respiratory mortality. Mortality rates in race and border counties decrease relative to control counties at the time of deleading for all three causes of death, and then they remain lower. Here we find that cardiovascular mortality rates drop by 37 deaths per 100,000 in race counties after deleading, and drop by 12 deaths per 100,000 in border counties after deleading. IHD mortality rates drop by 53 deaths per 100,000 in race counties and 20 deaths per 100,000 in border counties, respiratory mortality rates drop by 20 deaths per 100,000 and 5 deaths per 100,000, and deaths of despair mortality rates drop by 4 deaths per 100,000 and 2 deaths per 100,000. In total, our results suggest that lead emissions have an immediate effect on elderly mortality. The smaller effects in border counties are consistent with the expected distance gradient. ${ }^{24}$

The appendix shows that we find weak evidence for effects on infant mortality, although an existing literature finds that lead exposure has negative effects on fertility, infant mortality, and infant health (Troesken, 2008; Clay et al., 2014; Grossman and Slusky, 2019). There are several possible reasons for this distinction. First, our findings indicate that leaded gasoline tends to increase elderly mortality through cardiovascular causes and deaths of despair. The former requires long term damage to the cardiovascular system while the latter is an adult cause of death. Second, our results are from a different medium of exposure. In our case, people are exposed to lead through the air while the previous literature has explored exposure through drinking water. Third, the level of exposure likely differs between our setting and others. We study a setting where ambient lead concentrations, as well as concentrations of other pollutants, are very low. If infant mortality increases only at higher levels of lead exposure then we will not estimate an economically significant effect.

\section{The social cost of leaded gasoline}

We value the external effects of leaded gasoline in two ways. First, we estimate the effect on future earnings from increases in blood lead concentrations and the associated decreases in IQ. Second, we value the effect of lead on premature all-cause elderly mortality and use this to provide a lower bound on the total social cost of leaded gasoline.

\footnotetext{
${ }^{24}$ One potential explanation for our findings is that they are actually caused by the great recession. We argue that this is unlikely. If improvements in mortality rates were driven by differential effects of worsening economic conditions, we would expect the differential decreases in mortality in race and border counties to vanish as the recession ended and the economy improved. We find little evidence that mortality rates rebounded along with economic conditions.
} 


\subsection{Blood lead, IQ, and future income}

To estimate the expected decreases in IQ from lead exposure, we combine estimates from our work with those from the prior literature. First, we translate our county level difference-indifferences estimates reported in Figure 5 into expected changes in individual BLLs. Recall that our county level estimates indicate that living in a race county increases the prevalence of those with EBLLs by $17 \%$ and that the threshold for EBLL is $10 \mu \mathrm{g} / \mathrm{dl}$. First, we assume the $17 \%$ estimate is the probability that living in a county with leaded races causes a child to have an elevated BLL value. Second, we conservatively assume that if a child does not test positively for EBLL, their baseline BLL level is just below the threshold at $9 \mu \mathrm{g} / \mathrm{dl}$, and if the child tests positively, their elevated BLL is right on the EBLL threshold at $10 \mu \mathrm{g} / \mathrm{dl}$. We make this last assumption because we are interested in the minimum individual changes that are consistent with our observed estimates. This helps to provide as conservative a valuation as possible because it is unlikely that all blood lead levels below the elevated threshold dropped to zero following deleading. This procedure suggests that the deleading of NASCAR and ARCA races resulted in a $0.17 \times(10 \mu \mathrm{g} / \mathrm{dl}-9 \mu \mathrm{g} / \mathrm{dl})=0.17 \mu \mathrm{g} / \mathrm{dl}$ expected decline in BLLs per child in race counties.

Next, we link changes in BLLs to changes in IQ. The average IQ point loss per $1 \mu \mathrm{g} / \mathrm{dl}$ for BLLs under $10 \mu \mathrm{g} / \mathrm{dl}$ is 0.513 (Lanphear et al., 2005; Gould, 2009).$^{25}$ In expectation, a child in a race county experienced a 0.087 IQ point decrease. Last, we link IQ to earnings following the procedure in Klemick et al. (2019), which estimates that a 1 IQ point decrease for a three year old is associated with a present value earnings loss of $\$ 20,568$ in 2019 dollars. ${ }^{26}$ Combining these estimates, the costs of reduced IQ are $\$ 1,789$ per child in race counties.

Because blood lead testing is targeted at high-risk areas, it is unclear whether we can map this number to an aggregate county-wide benefit from deleading. Instead, we consider the deleading benefits only obtained by the children in the EBLL dataset. The dataset reports that 75,725 children under 6 were tested in race counties in $2015 .{ }^{27}$ This gives us that the IQ-related social benefits for the cohort of children tested in 2015, who were never exposed to leaded NASCAR or ARCA races during their lifetime, is $\$ 135$ million. When we perform the same exercise for border counties we get that expected BLL declines are $0.06 \mu \mathrm{g} / \mathrm{dl}$, and expected IQ increases are 0.031 points. This gives a present value earnings gain per child of $\$ 638$ in 2019 dollars. In 2015, 242,385 children were tested in border counties for a total

\footnotetext{
${ }^{25}$ Previous estimates suggest that the relationship may be roughly half this size: between 0.185 and 0.323 IQ points per $1 \mu \mathrm{g} / \mathrm{dl}$ (Grosse et al., 2002).

${ }^{26}$ Recall that the children in the testing sample are 72 months and younger, so a three year old is near the middle of this age range.

${ }^{27}$ In 2015 approximately 1 million children 4 and younger lived in race counties, 3 million lived in border counties, and 15 million lived in control counties.
} 
earnings gain of $\$ 155$ million. In total, we estimate that the 2015 cohort of tested children in race and border counties obtained $\$ 290$ million in benefits from never being exposed to leaded races. ${ }^{28}$

This valuation has several limitations. First, we do not have data on actual blood lead levels so we do not directly observe how they change following deleading. Second, this valuation does not account for how long each child's blood lead was elevated and how this length may matter for IQ or future earnings. Finally, because lead is only detectable in the blood stream for a month following exposure, the procedure implicitly assumes that once blood lead returns to baseline levels, the IQ effects and associated future earnings losses also dissipate. This is in contrast to physiological evidence that lead exposure can permanently damage neurological pathways and development.

\section{$5.2 \quad$ Elderly mortality}

Since the effects of leaded races on elderly mortality are acute and permanent, the calculation of their dollar value is more straightforward and we use them to lower bound the social cost of leaded gasoline. We first use the difference-in-differences estimates shown in Figure 7, which indicate that race counties have higher all-cause elderly mortality rates by 91 deaths per 100,000 during leaded race years, and border counties have all-cause mortality rates higher by 38 deaths per 100,000. We then compute the number of premature deaths by combining the mortality estimates with data on the population over $65 .{ }^{29}$ In total, our estimates suggest that leaded races caused 32,000 premature elderly deaths between 19992006. Next, we translate the count of premature deaths into dollar terms. The average age of a person over 65 is 74, and the expected age of death is 87 conditional on reaching 74 (Centers for Disease Control and Prevention, 2017). Following Deryugina et al. (2019), we deflate the number of life-years lost by $31 \%$ to account for possible harvesting (i.e. that those who are likely to die prematurely from pollution are also more likely to die prematurely from other causes). We value each life year lost at approximately $\$ 140,000$ in 2019 dollars (Cutler, 2004). On average, each premature elderly death from lead exposure generates approximately $\$ 550,000$ in social costs, and total annual elderly mortality externalities are approximately $\$ 2.2$ billion per year.

To compute the social cost of lead in dollars per gram, we normalize the annual mortality cost by an estimate of the annual lead emissions. We estimate annual lead emissions to be

\footnotetext{
${ }^{28}$ If our estimates are mapped to the full population, the effect on elevated blood lead rates in race counties would result in approximately an extra 100 poisoned children in the average race county.

${ }^{29}$ In 2015 approximately 3 million elderly lived in race counties, 7 million lived in border counties, and 36 million lived in control counties.
} 
approximately 2 million grams in Section A.11. Combining these two estimates, the social cost of a gram of lead added to racing fuel is approximately $\$ 1,100$.

\section{Conclusion}

The main objective of this research is to causally estimate the effect of leaded gasoline on elderly mortality. We do so by exploiting both regulatory exemptions and a natural experiment that together serve to separately identify the effect of leaded gasoline from other potential confounders. The importance of our results extends beyond ascribing a value to au-

tomotive racing fuel decisions. Our findings indicate that even at present day levels of overall lead exposure, additional exposure can generate heightened mortality risk. The estimated relationship between lead exposure and these outcomes is both statistically significant and economically meaningful. Our estimates likely understate the true magnitude of the mortality effect of leaded gasoline. Due to the structure of the data and analysis, our mortality analysis is at the county-year level, which introduces measurement error that may attenuate our estimates.

The mortality estimates place a lower bound on the social cost of each gram of tetraethyl lead added to gasoline at roughly $\$ 1,100$. This estimate is conditional on several factors. First, since lead emissions from races affect outcomes through changes in ambient concentrations, the estimated social cost is conditional on the ambient levels of lead during the time-frame of our mortality analysis, 1999-2016. Ambient levels during this time were much lower than in earlier decades, and they continue to slowly decline. This matters for computing the social cost of lead if, as prior work suggests, the dose-response is non-linear with respect to ambient concentrations (e.g. Grönqvist et al., 2018). Second, the social cost estimate is the average marginal effect over the range of quantities of lead emitted across all races. The marginal effect of the first gram emitted by a race may be much different than the marginal effect of the $100,000^{\text {th }}$ gram emitted near the end of a multi-race weekend. If the lead dose-response function is nonlinear and ambient concentrations continue to decline, then understanding the marginal effect near the origin of the dose-response function is critical for future policy design.

An important issue not studied here is the lack of information about lead in gasoline. To the best of our knowledge, there is no public information on the quantity or location of leaded racing fuel sales. Depending on the location and timing of its use, the social cost of a particular gallon of leaded gasoline may vary dramatically. There is also little information available on the lead content of unleaded gasoline. Although its name implies the absence of lead, unleaded gasoline simply contains no added lead. Lead, in addition to other toxic heavy 
metals like cadmium, is naturally found in crude oil and may persist in trace amounts after the refining process. Lead can enter the unleaded fuel supply from storage tanks, pipes, solder, or through cross-contamination from use of the same pipelines for leaded aviation gasoline. More information on leaded gasoline sales and the lead content of unleaded fuel is critical for determining social costs and the appropriate amount of regulatory scrutiny.

Our findings shed light on the consequences of the continued use of leaded gasoline for racing and aviation. Our mortality cost estimate indicates that the the social cost of leaded racing fuel is substantially higher than the private costs reflected in current market prices. While we do not directly study leaded aviation fuel, our estimates are informative of the external costs associated with its use. Even if the external effects of aviation gasoline are only 1\% (\$10 per gram) of our racing fuel estimates, then the socially efficient price of leaded aviation fuel would be three times higher than current market prices. This suggests that there are significant global damages from leaded aviation gasoline.

Our findings also have implications for current lead poisoning policies. Much of the concern about lead is heavily focused on children as evidenced by the CDC's nationwide Childhood Lead Poisoning Prevention Program as well as numerous state and county level efforts. Our results demonstrate the large costs imposed on the elderly and that there are potential benefits from expanding lead exposure mitigation efforts to include this overlooked sensitive group.

\section{References}

Abadin, Henry G and Hana R Pohl (2010) "5: Alkyllead Compounds and Their Environmental Toxicology," in Organometallics in Environment and Toxicology, pp. 153-164.

Adams, Peter, Michael D. Hurd, Daniel L. McFadden, Angela Merrill, and Tiago Ribeiro (2004) "Healthy, Wealthy, and Wise? Tests for Direct Causal Paths between Health and Socioeconomic Status," Perspectives on the Economics of Aging.

Agency for Toxic Substances and Disease Registry (2018) "Case Studies in Environmental Medicine: Lead Toxicity,"Technical report.

Aizer, Anna and Janet Currie (2019) "Lead and juvenile delinquency: New evidence from linked birth, school and juvenile detention records," Review of Economics and Statistics, No. 0.

Aizer, Anna, Janet Currie, Peter Simon, and Patrick Vivier (2018) "Do low levels of blood lead reduce children's future test scores?" American Economic Journal: Applied Economics, Vol. 10, No. 1, pp. 307-41.

Alexander, Diane and Hannes Schwandt (2019) "The Impact of Car Pollution on Infant and Child Health: Evidence from Emissions Cheating."

ARCA Racing (2006) "Busy Day Ahead at Kansas; 2 Practice Sessions \& Qualifying."

Ash, Michael and James K. Boyce (2018) "Racial disparities in pollution exposure and employment at US industrial facilities," Proceedings of the National Academy of Sciences, Vol. 115, No. 42, pp. 10636-10641.

Associated Press (2006) "NASCAR officials pleased with first unleaded test."

Auffhammer, Maximilian and Ryan Kellogg (2011) "Clearing the air? The effects of gasoline 
content regulation on air quality," American Economic Review, Vol. 101, No. 6, pp. 26872722.

Baghurst, Peter, Anthony J McMichael, Neil R Wigg, Graham V Vimpani, Evelyn F Robertson, Russell J Roberts, and Shi-Lu Tong (1992) "Environmental Exposure to Lead and Children's Intelligence at the Age of Seven Years: The Port Pirie Cohort Study," New England Journal of Medicine, Vol. 327, No. 18, pp. 1279-1284.

Bay Area News Group (2006) "NASCAR to begin phasing in unleaded fuel," East Bay Times.

Bellemare, Marc F and Casey J Wichman (2019) "Elasticities and the inverse hyperbolic sine transformation," Oxford Bulletin of Economics and Statistics.

Belson, Ken (2011) "Gentlemen, Start Conserving."

Bernstein, Viv (2006) "NASCAR plans to switch to unleaded fuel in '08," New York Times. Billings, Stephen B and Kevin T Schnepel (2017) "The value of a healthy home: Lead paint remediation and housing values," Journal of Public Economics, Vol. 153, pp. 69-81.

(2018) "Life after lead: Effects of early interventions for children exposed to lead," American Economic Journal: Applied Economics, Vol. 10, No. 3, pp. 315-44.

Bouchard, Maryse F, David C Bellinger, Jennifer Weuve, Julia Matthews-Bellinger, Stephen E Gilman, Robert O Wright, Joel Schwartz, and Marc G Weisskopf (2009) "Blood lead levels and major depressive disorder, panic disorder, and generalized anxiety disorder in US young adults," Archives of general psychiatry, Vol. 66, No. 12, pp. 1313-1319.

Case, Anne and Angus Deaton (2015) "Rising morbidity and mortality in midlife among white non-Hispanic Americans in the 21st century," Proceedings of the National Academy of Sciences, Vol. 112, No. 49, pp. 15078-15083.

Centers for Disease Control and Prevention (2012) "CDC response to advisory committee on childhood lead poisoning prevention recommendations: low level lead exposure harms children: a renewed call of primary prevention," US Department of Health and Human Services, Atlanta, GA, USA. Available online: http://www. cdc. gov/nceh/lead/acclpp/cdc_response_lead_exposure_recs. pdf (accessed on 23 April 2014).

_ (2017) "National Vital Statistics Reports Deaths: Final Data for 2015," National vital statistics reports: from the Centers for Disease Control and Prevention, National Center for Health Statistics, National Vital Statistics System, Vol. 66, pp. 1-75.

Christensen, Peter, David A. Keiser, and Gabriel E. Lade (2019a) "Economic Effects of Environmental Crises: Evidence from Flint, Michigan."

Christensen, Peter, Ignacio Sarmiento-Barbieri, and Christopher Timmins (2019b) "Toxic Discrimination: Experimental Evidence of the Effect of Racial Discrimination on Toxics Exposures and their Damages.."

Clay, Karen, Margarita Portnykh, and Edson Severnini (2018) "Toxic Truth: Lead and Fertility,"Technical report, National Bureau of Economic Research.

- (2019) "The Legacy Lead Deposition in Soils and Its Impact on Cognitive Function in Preschool-Aged Children in the United States," Economics \& Human Biology.

Clay, Karen, Werner Troesken, and Michael Haines (2014) "Lead and mortality," Review of Economics and Statistics, Vol. 96, No. 3, pp. 458-470.

Collins, Sam (2012) "F1- Tech Explained: Formula 1 and the environment."

Currie, Janet (2009) "Healthy, Wealthy, and Wise: Socioeconomic Status, Poor Health in Childhood, and Human Capital Development," Journal of Economic Literature, Vol. 47, No. 1, pp. 87-122.

Currie, Janet, Lucas Davis, Michael Greenstone, and Reed Walker (2015a) "Environmental Health Risks and Housing Values: Evidence from 1,600 Toxic Plant Openings and Closings," The American Economic Review, Vol. 105, No. 2, pp. 678-709.

_ (2015b) "Environmental health risks and housing values: evidence from 1,600 toxic plant openings and closings," American Economic Review, Vol. 105, No. 2, pp. 678-709. 
Currie, Janet and Matthew Neidell (2005) "Air Pollution and Infant Health: What Can We Learn From California'S Recent Experience?," The Quarterly Journal of Economics, Vol. 120, No. 3, pp. 1003-1030.

Currie, Janet and Mark Stabile (2003) "Socioeconomic Status and Child Health: Why Is the Relationship Stronger for Older Children?," American Economic Review, Vol. 93, No. 5, pp. 1813-1823.

Currie, Janet and Reed Walker (2011) "Traffic congestion and infant health: Evidence from E-ZPass," American Economic Journal: Applied Economics, Vol. 3, No. 1, pp. 65-90.

Cutler, David M (2004) Your Money or Your Life: Strong Medicine for America's Health Care System, New York, New York: Oxford University Press.

Cutler, David M, Adriana Lleras-muney, and Tom Vogl (2012) "Socioeconomic status and health: Dimensions and Mechanisms," The Oxford Handbook of Health Economics.

De Marchi, Scott and James T Hamilton (2006) "Assessing the accuracy of self-reported data: an evaluation of the toxics release inventory," Journal of Risk and uncertainty, Vol. 32 , No. 1, pp. 57-76.

Deryugina, Tatyana, Garth Heutel, Nolan Miller, David Molitor, and Julian Reif (2019) "The Effect of Pollution on Health and Health Care Utilization: Evidence from Changes in Wind Direction."

Federal Aviation Administration (2020) "Fact Sheet - Leaded Aviation Fuel and the Environment," Technical report.

Feigenbaum, James J. and Christopher Muller (2016) "Lead exposure and violent crime in the early twentieth century," Explorations in Economic History, Vol. 62, pp. 51-86.

Ferrie, Joseph P, Karen Rolf, and Werner Troesken (2012) "Cognitive disparities, lead plumbing, and water chemistry: Prior exposure to water-borne lead and intelligence test scores among World War Two US Army enlistees," Economics \&6 Human Biology, Vol. 10, No. 1, pp. 98-111.

Fishbein, Diana H, Andrew C Todd, Erin P Ricketts, and Richard D Semba (2008) "Relationship between lead exposure, cognitive function, and drug addiction: Pilot study and research agenda," Environmental research, Vol. 108, No. 3, pp. 315-319.

Forbes (2020) "Nascar Team Values Flatline As Series Struggles, But Its Leaders Aim To Shift Into A Higher Gear."

Fryer, Jenna (2006) "NASCAR Pleased With Unleaded Fuel Test," Washington Post. - (2008) "Lower levels get hit a lot harder by skyrocketing fuel prices."

Garza, Anibal, Rosario Vega, and Enrique Soto (2006) "Cellular mechanisms of lead neurotoxicity. Med Sci Monit 12:RA57-RA65," Medical science monitor : international medical journal of experimental and clinical research, Vol. 12, pp. RA57-65.

Gazze, Ludovica (2016) "Lead policies, lead poisoning, and government spending," URL: http://home. uchicago. edu/lgazze/webfiles/LeadPolicies. pdf.

_ (2018) "The Price and Allocation Effects of Targeted Mandates: Evidence from Lead Hazards," Technical report.

Gould, Elise (2009) "Childhood lead poisoning: conservative estimates of the social and economic benefits of lead hazard control," Environmental health perspectives, Vol. 117, No. 7, pp. 1162-1167.

Greenstone, Michael (2002) "The impacts of environmental regulations on industrial activity: Evidence from the 1970 and 1977 clean air act amendments and the census of manufactures," Journal of political economy, Vol. 110, No. 6, pp. 1175-1219.

Greenstone, Michael and Rema Hanna (2014) "Environmental Regulations, Air and Water Pollution, and Infant Mortality in India," American Economic Review, Vol. 104, No. 10, pp. 3038-3072.

Grönqvist, Hans, J Peter Nilsson, and Per-Olof Robling (2018) "Early Lead Exposure and Outcomes in Adulthood." 
Grosse, Scott D., Thomas D. Matte, Joel Schwartz, and Richard J. Jackson (2002) "Economic gains resulting from the reduction in children's exposure to lead in the United States," Environmental Health Perspectives, Vol. 110, No. 6, pp. 563-569.

Grossman, Daniel S and David JG Slusky (2019) "The impact of the Flint water crisis on fertility," Demography, Vol. 56, No. 6, pp. 2005-2031.

He, Kangmin, Shunqin Wang, and Jinliang Zhang (2009) "Blood lead levels of children and its trend in China," Science of the Total Environment, Vol. 407, pp. 3986-3993.

Howard, Scripps (2005) "EPA asked NASCAR to switch six years ago," ESPN.

Jacobs, David E, Robert P Clickner, Joey Y Zhou, Susan M Viet, David A Marker, John W Rogers, Darryl C Zeldin, Pamela Broene, and Warren Friedman (2002) "The Prevalence of Lead-Based Paint Hazards in U.S. Housing," Environmental Health Perspectives, Vol. 110, No. 10, pp. 599-606.

Jurdziak, Marta, Pawel Gac, Helena Martynowicz, and Rafal Poreba (2015) "Function of respiratory system evaluated using selected spirometry parameters in persons occupationally exposed to lead without evident health problems," Environmental toxicology and pharmacology, Vol. 39, No. 3, pp. 1034-1040.

Kalnay, E, M Kanamitsu, R Kistler, W Collins, D Deaven, L Gandin, M. Iredell, S. Saha, G. White, J. Woollen, Y. Zhu, A. Leetmaa, R. Reynolds, M. Chelliah, W. Ebisuzaki, W. Higgins, J. Janowiak, K. C. Mo, C. Ropelewski, J. Wang, Roy Jenne, and Dennis Joseph (1996) "The NCEP/NCAR 40-Year Reanalysis Project," Bulletin of the American Meteorological Society, Vol. 77, No. 3, pp. 437-471.

Kessler, Rebecca (2013) "Sunset for leaded aviation gasoline?" Environmental health perspectives, Vol. 121, No. 2, p. a54.

Kim, Min-Gi, Jae-Hong Ryoo, Se-Jin Chang, Chun-Bae Kim, Jong-Ku Park, Sang-Baek Koh, and Yeon-Soon Ahn (2015) "Blood lead levels and cause-specific mortality of inorganic lead-exposed workers in South Korea," PloS one, Vol. 10, No. 10.

Kitman, Jamie Lincoln (2000) "The secret history of lead," NATION-NEW YORK-, Vol. 270, No. 11, pp. 11-11.

Klemick, Heather, Henry Mason, and Karen Sullivan (2019) "Superfund Cleanups and Children's Lead Exposure," EPA. National Center for Environmental Economics. Working Paper No. 19-01.

Knittel, Christopher R, Douglas L Miller, and Nicholas J Sanders (2016) "Caution, drivers! Children present: Traffic, pollution, and infant health," Review of Economics and Statistics, Vol. 98, No. 2, pp. 350-366.

Lanphear, Bruce P (2017) "Low-level toxicity of chemicals: No acceptable levels?" PLoS biology, Vol. 15, No. 12, p. e2003066.

Lanphear, Bruce P., Richard Hornung, Jane Khoury, Kimberly Yolton, Peter Baghurst, David C. Bellinger, Richard L. Canfield, Kim N. Dietrich, Robert Bornschein, Tom Greene, Stephen J. Rothenberg, Herbert L. Needleman, Lourdes Schnaas, Gail Wasserman, Joseph Graziano, and Russell Roberts (2005) "Low-level environmental lead exposure and children's intellectual function: An international pooled analysis," Environmental Health Perspectives, Vol. 113, No. 7, pp. 894-899.

Lanphear, Bruce P, Stephen Rauch, Peggy Auinger, Ryan W Allen, and Richard W Hornung (2018) "Low-level lead exposure and mortality in US adults: a population-based cohort study," The Lancet Public Health, Vol. 3, No. 4, pp. e177-e184.

Lee, Bryan (1991) "Highlights of the clean air act amendments off 1990," Journal of the Air \&6 Waste Management Association, Vol. 41, No. 1, pp. 16-19.

Levin, Ronnie, Mary Jean Brown, Michael E Kashtock, David E Jacobs, Elizabeth A Whelan, Joanne Rodman, Michael R Schock, Alma Padilla, and Thomas Sinks (2008) "Lead exposures in US children, 2008: implications for prevention," Environmental Health Perspectives, Vol. 116, No. 10, p. 1285. 
Lidsky, Theodore I and Jay S Schneider (2003) "Lead neurotoxicity in children: basic mechanisms and clinical correlates," Brain, Vol. 126, No. 1, pp. 5-19.

Lovei, Magda (1998) "Phasing Out Lead from Gasoline."

Lundqvist, Lennart J. (1979) "Who Is Winning the Race for Clean Air? An Evaluation of the Impacts of the US and Swedish Approaches to Air Pollution Control," Ambio, Vol. 8, No. 4, pp. 144-151.

Lustberg, Mark and Ellen Silbergeld (2002) "Blood lead levels and mortality," Archives of internal medicine, Vol. 162, No. 21, pp. 2443-2449.

Meara, Ellen (2001) "Why is health related to socioeconomic status? The case of pregnancy and low birth weight," Technical report.

Menke, Andy, Paul Muntner, Vecihi Batuman, Ellen K Silbergeld, and Eliseo Guallar (2006) "Blood lead below $0.48 \mathrm{mmol} / \mathrm{L}(10 \mathrm{mg} / \mathrm{dL})$ and mortality among US adults," Circulation, Vol. 114, No. 13, pp. 1388-1394.

Miranda, Marie Lynn, Sharon E Edwards, Martha H Keating, and Christopher J Paul (2011) "Making the Environmental Justice Grade: The Relative Burden of Air Pollution Exposure in the United States," International Journal of Environmental Research and Public Health, Vol. 8, No. 6, pp. 1755-1771.

Mott, Joshua A (2002) "National Vehicle Emissions Policies and Practices and Declining US Carbon Monoxide-Related Mortality," JAMA, Vol. 288, No. 8, p. 988.

Naturvårdsverket (2010) Sweden's Environment Problems and Protection: 1960-2010, Stockholm, 1st edition.

Newell, Richard G and Kristian Rogers (2003) "The US experience with the phasedown of lead in gasoline," Resources for the Future, Washington, DC, Vol. 2.

Nriagu, Jerome O (1990) "The rise and fall of leaded gasoline," Science of the total environment, Vol. 92, pp. 13-28.

Oh, Se-Eun, Gi Bog Kim, Sung Ho Hwang, Mina Ha, and Kyoung-Mu Lee (2017) "Longitudinal trends of blood lead levels before and after leaded gasoline regulation in Korea," Environmental Health and Toxicology, Vol. 32, p. e2017019.

O'Neil, Joseph, Gregory Steele, C Scott McNair, Matthew M Matusiak, and Jyl Madlem (2006) "Blood lead levels in NASCAR Nextel Cup teams," Journal of occupational and environmental hygiene, Vol. 3, No. 2, pp. 67-71.

Papanikolaou, Nikolas C, Eleftheria G Hatzidaki, Stamatis Belivanis, George N Tzanakakis, and Aristidis M Tsatsakis (2005) "Lead toxicity update. A brief review.," Medical science monitor, Vol. 11, No. 10, pp. RA329-RA336.

Pei, Zhuan, Jörn-Steffen Pischke, and Hannes Schwandt (2019) "Poorly Measured Confounders are More Useful on the Left than on the Right," Journal of Business E Economic Statistics, Vol. 37, No. 2, pp. 205-216.

Pell, M.B. and Joshua Schneyer (2016) "Special Report: Thousands of U.S. areas afflicted with lead poisoning beyond Flint's," Reuters.

Persico, Claudia and Joanna Venator (2018) "The Effects of Local Industrial Pollution on Students and Schools."

Pirkle, James L, Joel Schwartz, J Richard Landis, and William R Harlan (1985) "The relationship between blood lead levels and blood pressure and its cardiovascular risk implications," American journal of epidemiology, Vol. 121, No. 2, pp. 246-258.

Polacek, Micheal A. and Daniel P. Collins (1968) "Lead intoxication in automotive sports," Pre-Crash; Factors in Traffic Safety; 12th Annual Symposium; American Association; for Automotive Medicine, pp. 181-191.

Ranft, Ulrich, Thomas Delschen, Monika Machtolf, Dorothee Sugiri, and Michael Wilhelm (2008) "Lead concentration in the blood of children and its association with lead in soil and ambient air - Trends between 1983 and 2000 in Duisburg," Journal of Toxicology and Environmental Health - Part A: Current Issues, Vol. 71, No. 11-12, pp. 710-715. 
Ravindra, Khaiwal, László Bencs, and René Van Grieken (2004) "Platinum group elements in the environment and their health risk," Science of The Total Environment, Vol. 318, No. 1-3, pp. 1-43.

Reyes, Jessica Wolpaw (2007) "Environmental policy as social policy? The impact of childhood lead exposure on crime," The BE Journal of Economic Analysis 65 Policy, Vol. 7, No. 1.

(2011) "Childhood Lead and Academic Performance in Massachusetts."

(2015) "Lead exposure and behavior: effects on antisocial and risky behavior among children and adolescents," Economic Inquiry, Vol. 53, No. 3, pp. 1580-1605.

Rhodes, Daniel, Avron Spiro III, Antonio Aro, and Howard Hu (2003) "Relationship of bone and blood lead levels to psychiatric symptoms: the normative aging study," Journal of occupational and environmental medicine, Vol. 45, No. 11, pp. 1144-1151.

Schmalensee, Richard and Robert Stavins (2018) "Policy Evolution under the Clean Air Act,"Technical Report 11, National Bureau of Economic Research, Cambridge, MA.

Sorensen, Lucy C., Ashley M. Fox, Heyjie Jung, and Erika G. Martin (2019) "Lead exposure and academic achievement: evidence from childhood lead poisoning prevention efforts," Journal of Population Economics, Vol. 32, No. 1, pp. 179-218.

Stock Car Racing (2009) "ARCA at 50."

Sunoco (2018) "Sunoco Race Fuel 101: Lead and Leaded Racing Fuels."

Thomas, VM (1995) "The elimination of lead in gasoline," Annual Review of Energy and the Environment, Vol. 20, No. 1, pp. 301-324.

Troesken, Werner (2008) "Lead water pipes and infant mortality at the turn of the twentieth century," Journal of Human Resources, Vol. 43, No. 3, pp. 553-575.

UN Environment Programme (2020) "The Lead Campaign," Technical report.

U.S. Environmental Protection Agency (1989) "Final Rule: Volatility Regulations for Gasoline and Alcohol Blends Sold in Calendar Years 1989 and Beyond. 54 FR 11868,"Technical report.

_ (1990) "Final Rule: Volatility Regulations for Gasoline and Alcohol Blends Sold in Calendar Years 1992 and Beyond. 55 FR 23658,"Technical report.

- (1994) "Automobile emissions: An overview. Fact Sheet OMS-5."

(2006) "Air Quality Criteria for Lead."

Wusz, Tim (1994) "Gasoline for NASCAR Stock Car Racing: 1951-1994,"Technical report, SAE Technical Paper 942539.

Yoshinaga, Jun (2012) "Lead in the Japanese living environment," Environmental health and preventive medicine, Vol. 17, No. 6, pp. 433-443.

Zahran, Sammy, Terrence Iverson, Shawn P. McElmurry, and Stephan Weiler (2017) "The Effect of Leaded Aviation Gasoline on Blood Lead in Children," Journal of the Association of Environmental and Resource Economists, Vol. 4, No. 2, pp. 575-610. 
Figure 5: The effect of leaded races on the percent of children with elevated blood lead levels in race and border counties.

\section{Effect of a race on asinh(EBLL)}

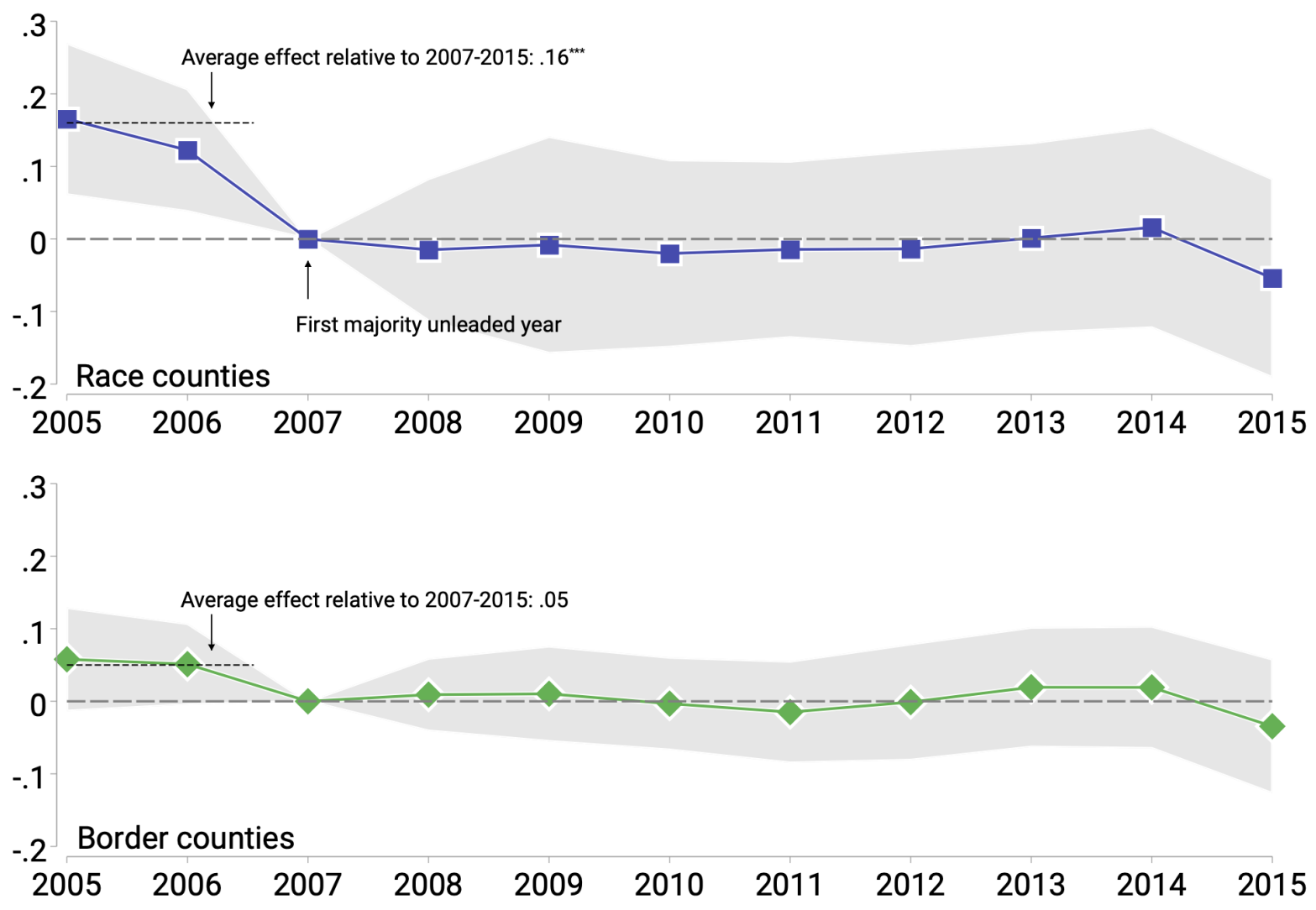

Note: The top panel reports coefficients (blue squares) for children living in race counties. The bottom panel reports coefficients (green diamonds) for children living in border counties. Each coefficient represents the effect of being in a particular county type relative to 2007, which is omitted. The regression includes state-by-year fixed effects, county fixed effects, and controls for the unemployment rate, median income, $\%$ non-white, tons of lead emitted from TRI facilities, and total manufacturing payroll. All coefficients come from the same regression. The regression is weighted by the square root of the number of children tested. The shaded gray areas denote the $95 \%$ confidence interval calculated from robust standard errors clustered at the county level. The dashed line is the average effect from our preferred difference-in-differences regression, where the race county treated group consists of those counties that had at least one leaded race prior to 2007, and the border county treated group consists of those counties that did not have a leaded race but bordered a county with a leaded race prior to 2007. This regression defines the post-period as 2007 and after. 
Figure 6: Mean all-cause elderly mortality rates by year and county type.

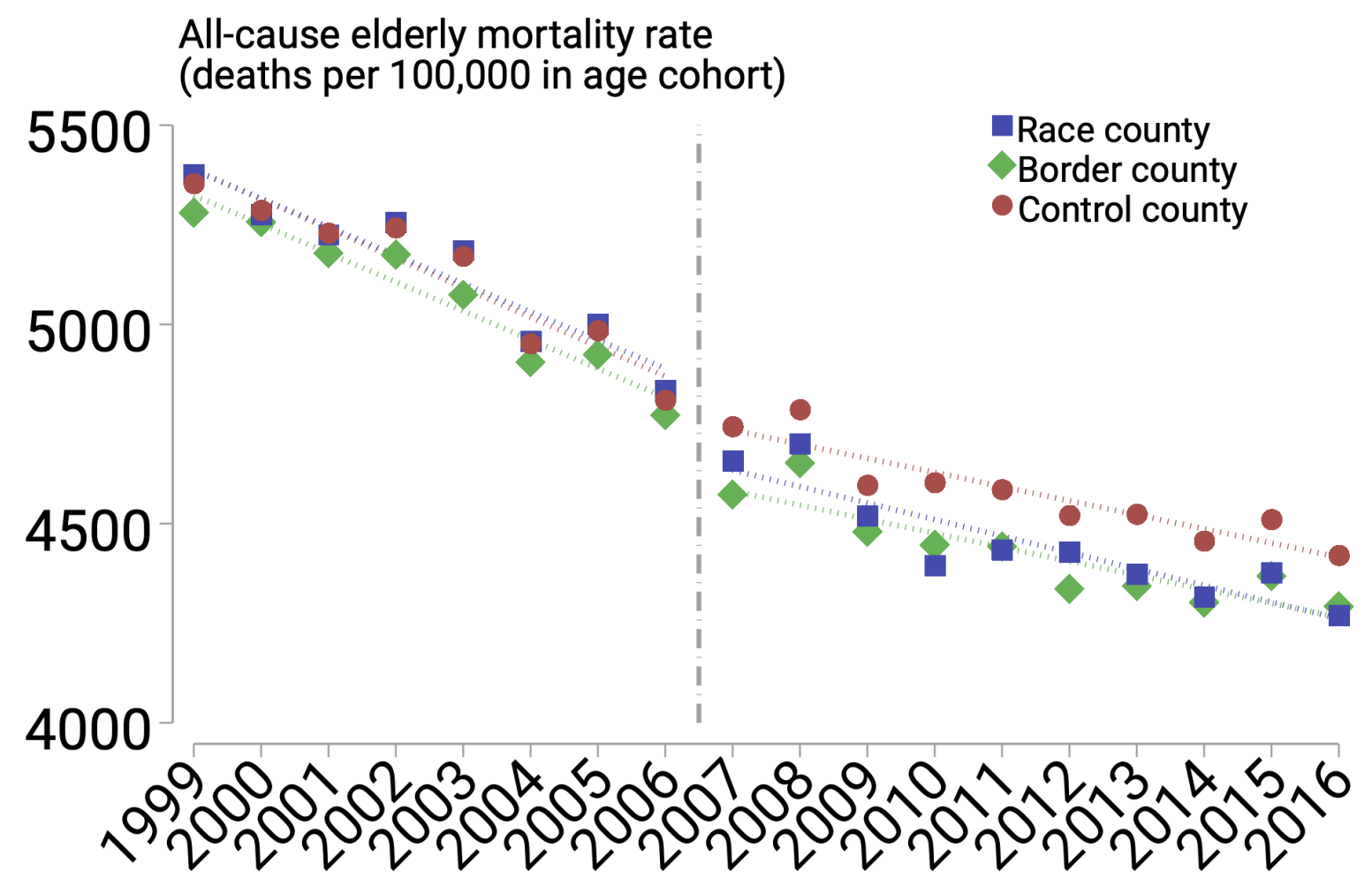

Note: Each point represents the mean age-standardized all-cause elderly mortality rate by county type weighted by the square root of elderly population. The elderly population of the entire U.S. in the year 2000 was used as the reference population for standardization. County type refers to if there was a NASCAR or ARCA race in that county (blue squares), or in a border county (green diamond) in that year. All other counties are considered control counties (red circle). For this figure and in our regression estimates we use a balanced panel of counties. 
Figure 7: The effect of leaded races on elderly mortality rates in race and border counties.

A.

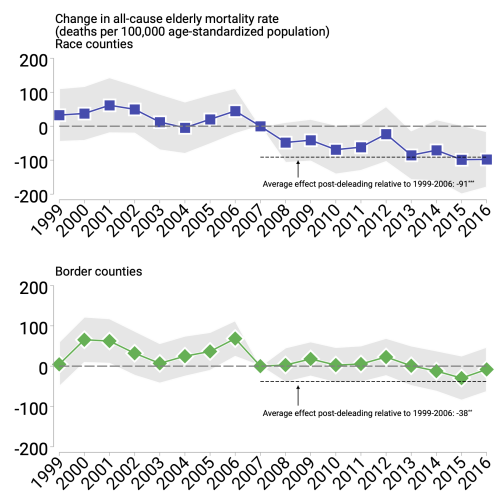

D.
B.

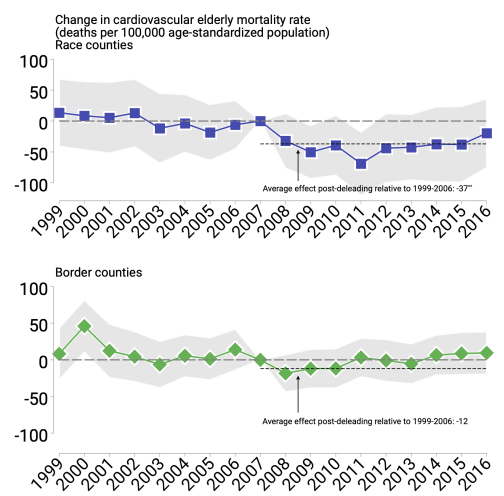

C.

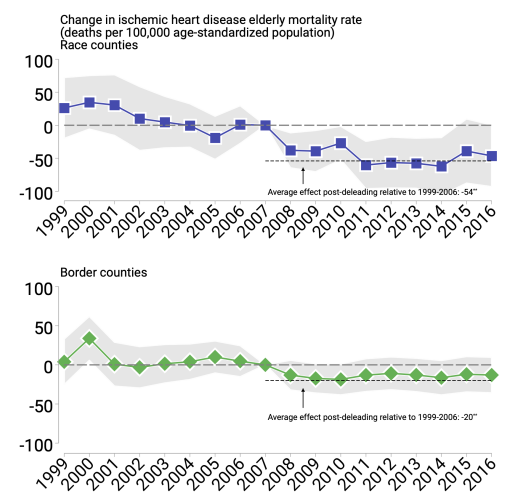

E.
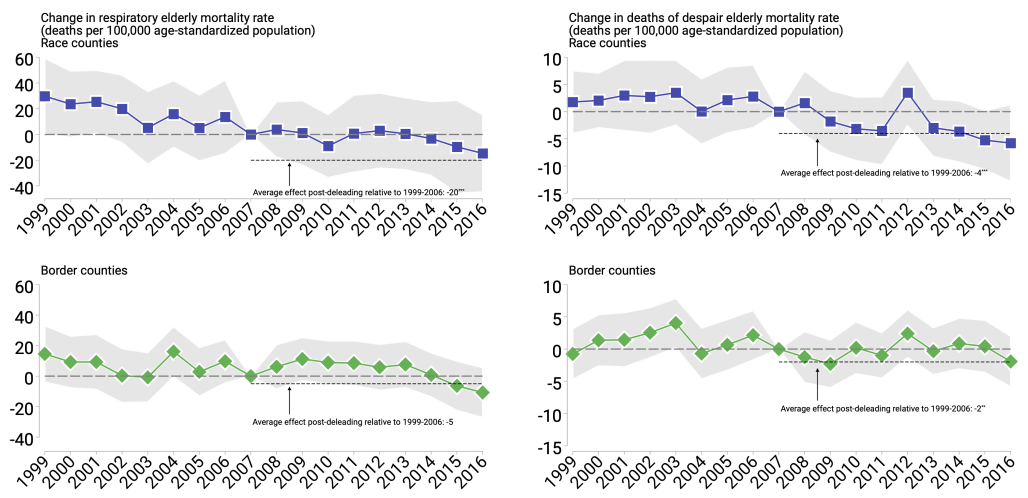

Note: Subfigure A shows estimates for all-cause mortality, Subfigure B shows estimates for cardiovascular mortality, Subfigure C shows estimates for ischemic heart disease (IHD) mortality, Subfigure D shows estimates for respiratory mortality, and Subfigure E shows estimates for deaths of despair (Case and Deaton, 2015). The top panel of each subfigure reports coefficients (blue squares) for race counties, and the bottom panel reports coefficients (green diamonds) for border counties. Each coefficient represents the effect on the age-standardized, elderly morality rate for that cause of death from being in a particular county type relative to 2007 , which is omitted. The regression includes state-by-year fixed effects, county fixed effects, and controls for the unemployment rate, median income, \% non-white, tons of lead emitted from TRI facilities, and total manufacturing payroll. All coefficients in each subfigure come from the same regression. The elderly population of the entire U.S. in the year 2000 was used as the reference population for age standardization. Each regression is weighted by the square root of the elderly population. The shaded gray areas denote the 95\% confidence interval calculated from robust standard errors clustered at the county level. The dashed line is the average effect of deleading from our preferred difference-in-differences regression, where the race county treated group consists of those counties that had at least one leaded race prior to 2007, and the border county treated group consists of those counties that did not have a leaded race but bordered a county with a leaded race prior to 2007. This regression defines the post-period as 2007 and after. 


\section{A Appendix: For Online Publication}

A.1 Automotive racing and the switch to unleaded fuel $\ldots \ldots \ldots \ldots \ldots$. . . . . . . A2

A.2 Correlated criteria pollutants since $1980 \ldots \ldots \ldots \ldots \ldots \ldots \ldots \ldots \ldots$

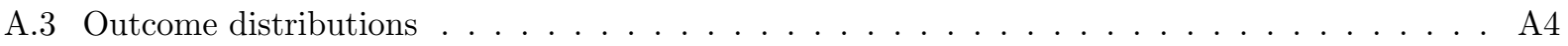

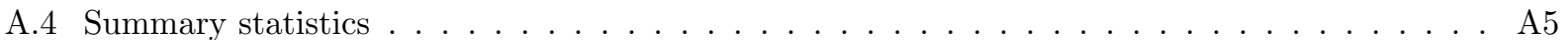

A.5 Racetracks: locations, other events, statistics, and distance to lead monitors . . . . . . . . A7

A.5.1 Racetrack counties and border counties . . . . . . . . . . . . . . . A7

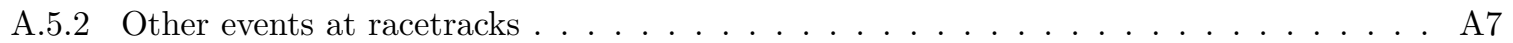

A.5.3 Distribution of monitor-racetrack distances $\ldots \ldots \ldots \ldots \ldots \ldots \ldots$

A.5.4 Racetrack statistics . . . . . . . . . . . . . . . . . . . . . . . A9

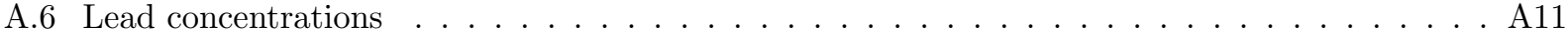

A.6.1 Specification and sample robustness $\ldots \ldots \ldots \ldots \ldots \ldots \ldots$ A11

A.6.2 Comparison tests and confounding pollutants . . . . . . . . . . . . . A15

A.6.3 Excluding observations by monitor-racetrack distance deciles . . . . . . . . . . . . . A19

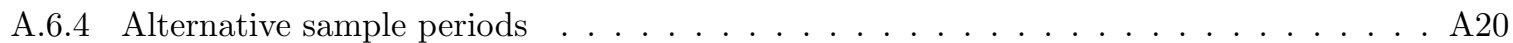

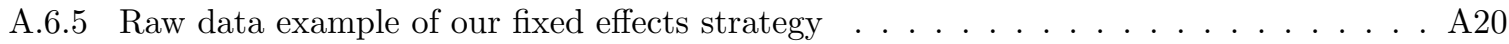

A.7 Blood lead . . . . . . . . . . . . . . . . . . . . . . . . . A25

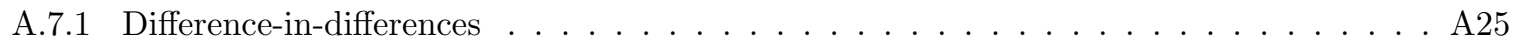

A.7.2 Untransformed outcome variable . . . . . . . . . . . . . . . A25

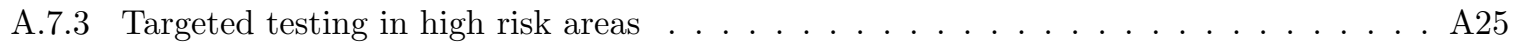

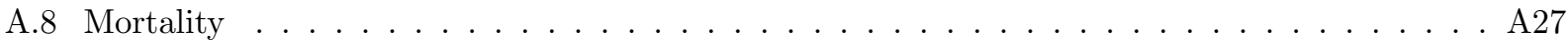

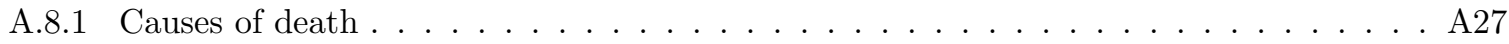

A.8.2 Raw data . . . . . . . . . . . . . . . . . . . . A27

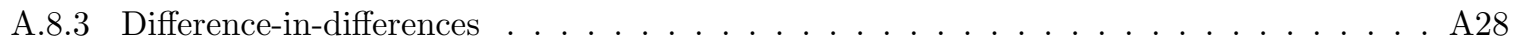

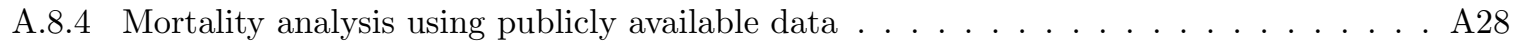

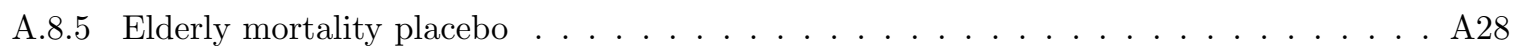

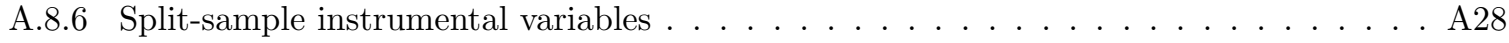

A.8.7 Infant mortality event studies . . . . . . . . . . . . . . . . . . A30

A.9 Other robustness checks, sensitivity checks, and analyses . . . . . . . . . . . . . A A42

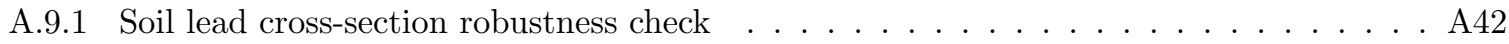

A.9.2 Balance table . . . . . . . . . . . . . . . . . . . . . . A43

A.9.3 Collinearity of leaded and unleaded miles in annual regressions . . . . . . . . . . A45

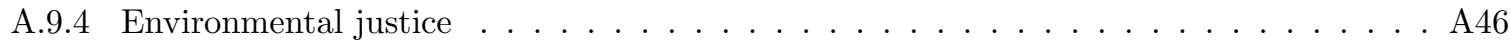

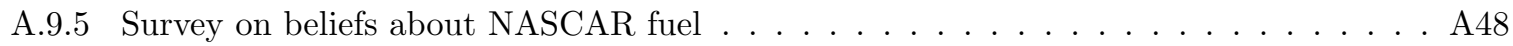

A.10 City lead emissions counterfactuals . . . . . . . . . . . . . . . . . . . A49

A.10.1 Estimating historical lead emissions from daily VMT . . . . . . . . . . . . . . A49

A.10.2 Converting race miles to grams of lead used per race . . . . . . . . . . . A50

A.10.3 Comparison of historic lead emitted from daily VMT to automotive racing sample . . A51

A.10.4 Out-of-sample historical prediction . . . . . . . . . . . . . . . . . A52

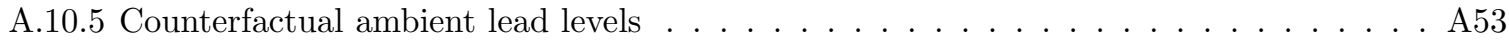

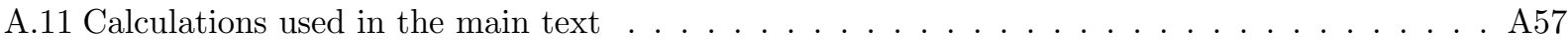

A.11.1 Deleading is equivalent to a $10 \mu \mathrm{g} / \mathrm{m}^{3}$ reduction in $\mathrm{PM}_{2.5}$ concentrations . . . . . . A57

A.11.2 NASCAR and ARCA used an estimated 2 million grams of TEL . . . . . . . . . A57 


\section{A.1 Automotive racing and the switch to unleaded fuel}

NASCAR is a racing organization that operates three national series with races across the U.S. Its most well-known national series is the Monster Energy Cup. The other two national series are a minor league series called the Xfinity Series and a modified pickup truck series called the Gander Outdoors Truck Series. NASCAR also runs several regional racing series that concentrate in particular areas of the U.S., such as the K\&N Pro Series East and West, and the Whelen Modified Tour. In total, NASCAR operates hundreds of races a year. In its national series, which are the races included in our main analysis, NASCAR enforces strict rules on vehicle dimensions and mandates that all vehicles use the exact same gasoline, which is provided by NASCAR and their fuel sponsor Sunoco.

In 2006, NASCAR announced that its three national racing series would switch to unleaded fuel. ${ }^{30}$ NASCAR set a tentative goal to switch at the beginning of 2008 , but also stated that their ultimate target was to make the switch in 2007 ahead of the Daytona 500 (Bernstein, 2006; Bay Area News Group, 2006). Prior to the official switch, NASCAR performed a four-week experiment with unleaded fuel: first in the Xfinity Series starting on July 29, 2006 at Gateway International Speedway, and then a two race test in the truck series in August 2006 at the O'Reilly Raceway Park in Indianapolis and at the Nashville Superspeedway. Both of these series then permanently switched to unleaded fuel on September 23, 2006 for the remainder of the 2006 season (Fryer, 2006). After the first tests at Gateway were successful, NASCAR announced a plan to switch in early 2007 (Fryer, 2006). NASCAR officially switched from leaded Sunoco Supreme to unleaded Sunoco 260 GTX across all three national series on the weekend of February 25, 2007, two weeks after the Daytona 500. ${ }^{31}$ Sunoco Supreme is a 112 octane fuel while Sunoco GTX is 98 octane; the difference between the two octane ratings can be fully explained by the removal of lead (Sunoco, 2018).

NASCAR operates several other regional racing series, such as the K\&N Pro Series. NASCAR still allows teams to use leaded fuel in these regional series. We do not include these regional series in our main analysis because it is unclear whether leaded, unleaded, or both types of fuel are used at individual races. For our main analysis we will focus on races

\footnotetext{
${ }^{30}$ The EPA had been pushing NASCAR to make the switch since at least 1998 (Howard, 2005). NASCAR originally partnered with Unocal to find a workable unleaded gasoline, however Unocal abandoned the partnership in 2003 (Associated Press, 2006).

${ }^{31}$ One other change that occurred during 2007 and 2008 was the adoption of the "Car of Tomorrow." The Car of Tomorrow was a new generation of cars aimed at improving safety in light of recent deaths during races. This model was used in some races during the 2007 Monster Energy Cup season before being fully phased in during the 2008 season. The Xfinity Series adopted the Car of Tomorrow for the 2011 season. Results - not shown due to space constraints, but available upon request-from an analysis of pole speeds (proxying for pure vehicle performance) and average race speeds and demonstrates that there have been only had minor fluctuations since 1999. This indicates that the new cars and deleading are unlikely to have affected vehicle performance in a way that confounds our results.
} 
from the national series, since we are certain about the leaded status of each race.

ARCA is a racing organization that was operated separately from NASCAR over our sample period. ARCA runs several different series and has a similar national/regional hierarchical structure to NASCAR. ARCA races are either run on the same racetrack as NASCAR races but several days earlier, or on smaller tracks not used by the national NASCAR series. ARCA racers have also historically used older model NASCAR vehicles (Stock Car Racing, 2009).

In 2006, ARCA announced plans for their top racing series, currently called the ARCA Menards Series, to switch to unleaded fuel the following year. Prior to the official switch, ARCA performed an unleaded fuel test during the Food World 250 at Talladega Superspeedway on October 6, 2006. Teams had the option of using leaded or unleaded fuel for the remainder of races in the 2006 season before permanently switching at beginning of the 2007 season (ARCA Racing, 2006).

In 2006, across the four national race series, leaded races accounted for $86 \%$ of all race miles, while unleaded races accounted for the remaining 14\%. For ease of exposition, throughout the paper we will refer to deleading as having occurred in 2007, since this is when the change was made permanent. When we report estimated effects in terms of leaded or unleaded miles driven, as in our ambient lead outcomes, we correctly account for the unleaded races in 2006. However, when we use an event study approach, as we do in our blood lead and mortality specifications, we report the average effect of all races in each county-year. Therefore the reported estimates from any event study estimate are slightly attenuated for 2006.

\section{A.2 Correlated criteria pollutants since 1980}

Figure A1 shows the trends in criteria pollutants and the Air Quality Index (AQI) in the United States since 1980. Average concentrations in the initial year of reporting for each pollutant are normalized to 1. AQI, and all criteria pollutants except for ozone, display correlated downward trends between 1980 and 2018. The correlation coefficients for each pair of non-ozone pollutants are all greater than 0.6. 
Figure A1: Criteria pollution concentrations and AQI since 1980.

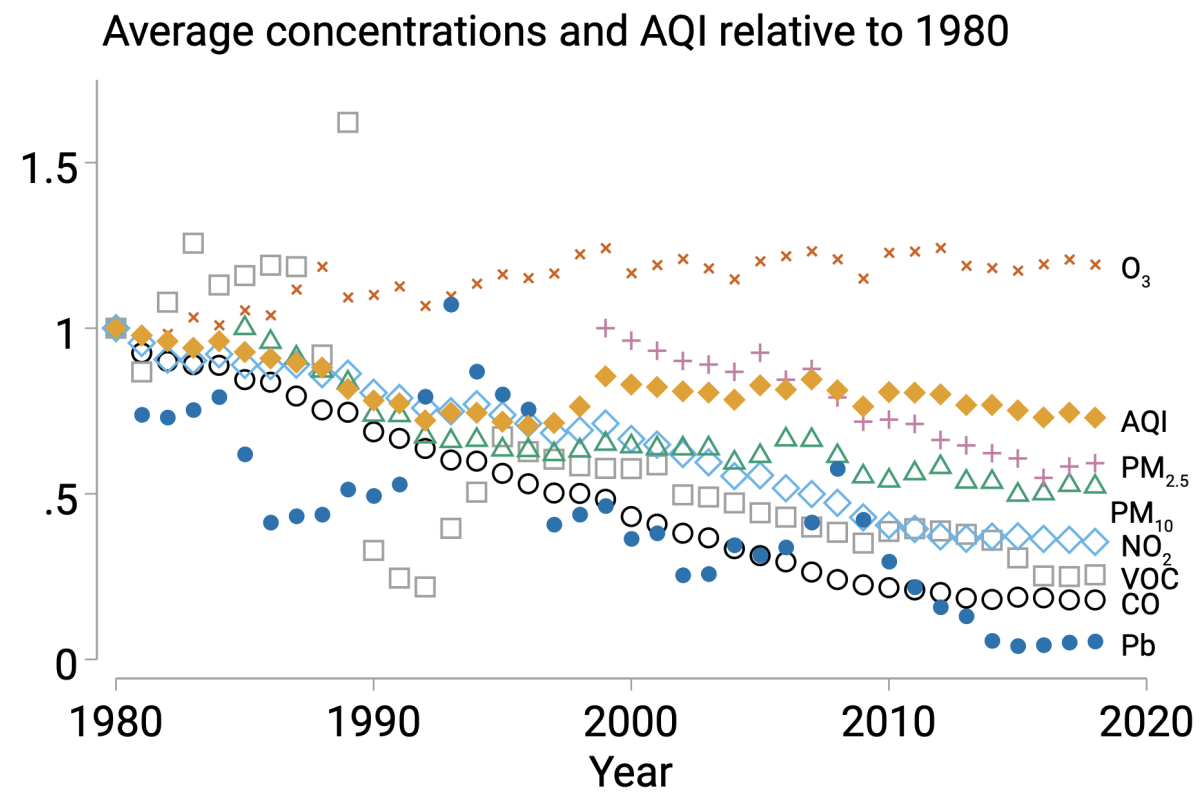

Note: AQI is the Air Quality Index, which is a function of all reported pollutant concentrations. Each point represents the annual mean relative to the mean from the first year reported for each pollutant/measure. Data come from the EPA AirData pre-generated daily datasets, which begin in 1980 for all pollutants/measures except for $\mathrm{PM}_{10}$ and $\mathrm{PM}_{2.5}$. All monitor-day readings are used to calculate the mean.

\section{A.3 Outcome distributions}

Figure A2 plots the distributions of our outcome variables. The left panel plots the ambient lead concentration distribution. It is highly right-skewed and approximately $10 \%$ of the sample consists of zeroes. The middle panel plots the distribution of the percent of children tested with elevated blood lead. Similar to the air data, the distribution is right-skewed and about a third of the data are zero-valued. The right panel plots the distribution of the all-cause elderly mortality rate. These data appear normally distributed although with a longer right tail as the distribution is bounded below by zero. 
Figure A2: Distributions of ambient lead concentrations (left), percent of children tested with elevated blood lead (middle), and the all-cause elderly mortality rate (right).
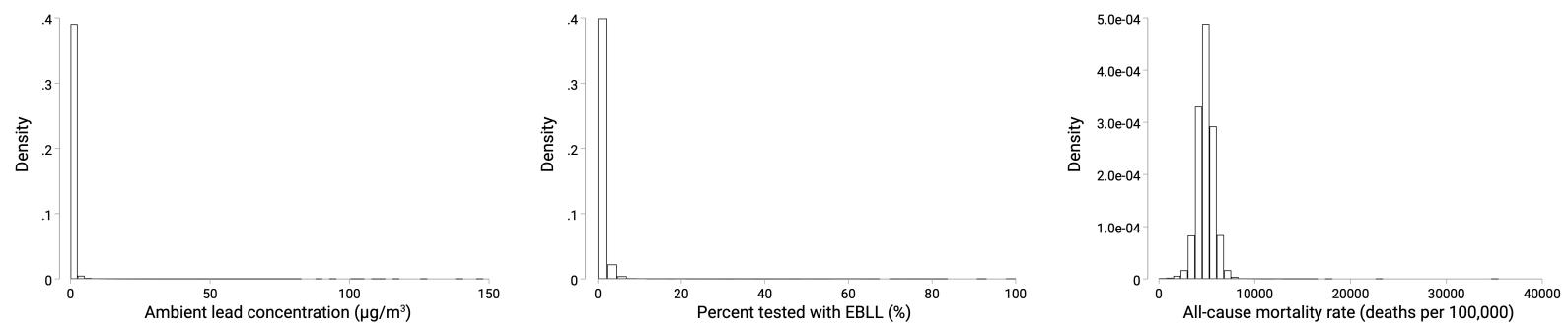

Note: Each subfigure plots the distributions of the untransformed outcome variables. The left panel plots the mean lead concentration readings $\left(\mu \mathrm{g} / \mathrm{m}^{3}\right)$, the middle panel plots the percent of children tested with elevated blood lead (\%), and the right panel plots the all-cause elderly mortality rate (deaths per 100,000 in the elderly population).

\section{A.4 Summary statistics}

Tables A1-A4 display the summary statistics for the variables used in each of our main regressions.

Table A1: Summary statistics for the ambient lead dataset.

\begin{tabular}{lrrrr}
\hline & Mean & S.D. & Min. & Max. \\
\hline Pb concentration $\left(\mu \mathrm{g} / \mathrm{m}^{3}\right)$ & 0.34 & 1.47 & 0.00 & 147.90 \\
Leaded miles past 7 days within 50 miles $(100,000 \mathrm{~s})$ & 0.00 & 0.01 & 0.00 & 0.41 \\
Unleaded miles past 7 days within 50 miles $(100,000 \mathrm{~s})$ & 0.00 & 0.01 & 0.00 & 0.37 \\
Air temperature $\left({ }^{\circ} \mathrm{C}\right)$ & 13.03 & 10.42 & -37.54 & 37.07 \\
Preciptable water $\left(\mathrm{kg} / \mathrm{m}^{2}\right)$ & 19.26 & 11.89 & -0.47 & 66.92 \\
Surface pressure $(\mathrm{kPa})$ & 97.10 & 5.31 & 74.22 & 104.48 \\
Relative humidity $(\%)$ & 74.38 & 18.73 & 0.00 & 100.01 \\
Wind speed $(\mathrm{m} / \mathrm{s})$ & 4.43 & 2.40 & 0.01 & 22.19 \\
\hline Observations & 875034 & & & \\
\hline
\end{tabular}

Note: These data range over our entire lead pollution dataset, 1957 to 2018. Relative humidity can be above $100 \%$ when the air is supersaturated. Ambient lead estimates are robust to forcing total precipitable water to be non-negative. 
Table A2: Summary statistics for the ambient lead data used in regressions from Table 1.

\begin{tabular}{lrrrr}
\hline & Mean & S.D. & Min. & Max. \\
\hline Pb concentration $\left(\mu \mathrm{g} / \mathrm{m}^{3}\right)$ & 0.14 & 0.76 & 0.00 & 57.47 \\
Leaded miles past 7 days within 50 miles $(100,000 \mathrm{~s})$ & 0.00 & 0.01 & 0.00 & 0.41 \\
Unleaded miles past 7 days within 50 miles $(100,000 \mathrm{~s})$ & 0.00 & 0.02 & 0.00 & 0.37 \\
Air temperature $\left({ }^{\circ} \mathrm{C}\right)$ & 13.24 & 10.24 & -36.38 & 37.07 \\
Preciptable water $\left(\mathrm{kg} / \mathrm{m}^{2}\right)$ & 19.73 & 12.07 & -0.25 & 66.92 \\
Surface pressure $(\mathrm{kPa})$ & 97.65 & 4.45 & 74.36 & 104.48 \\
Relative humidity $(\%)$ & 74.54 & 17.67 & 1.25 & 100.01 \\
Wind speed $(\mathrm{m} / \mathrm{s})$ & 4.27 & 2.33 & 0.03 & 19.79 \\
\hline Observations & 312277 & & & \\
\hline
\end{tabular}

Note: These data range from 1996 to 2018. Relative humidity can be above $100 \%$ when the air is supersaturated. Ambient lead estimates are robust to forcing total preciptable water to be non-negative.

Table A3: Summary statistics for the blood lead dataset.

\begin{tabular}{lrrrr}
\hline & Mean & S.D. & Min. & Max. \\
\hline EBLL rate (\%) & 0.92 & 3.92 & 0.00 & 100.00 \\
Race county & 0.01 & 0.12 & 0.00 & 1.00 \\
Border county & 0.08 & 0.27 & 0.00 & 1.00 \\
Unemployment rate (\%) & 0.07 & 0.03 & 0.02 & 0.29 \\
Median income (1,000 USD) & 43.48 & 11.45 & 17.84 & 119.53 \\
Percent non-white (\%) & 0.14 & 0.16 & 0.00 & 0.89 \\
TRI facility lead emissions (Metric tons) & 17.69 & 210.27 & 0.00 & 11275.01 \\
Manufacturing payroll (1,000 USD) & 208.51 & 591.96 & 0.00 & 12935.51 \\
\hline Observations & 22887 & & & \\
\hline
\end{tabular}


Table A4: Summary statistics for the mortality dataset.

\begin{tabular}{lrrrr}
\hline & Mean & S.D. & Min. & Max. \\
\hline General cardiovascular (deaths per 100,000) & 1845.19 & 586.15 & 0.00 & 35424.34 \\
Ischemic heart disease (deaths per 100,000) & 871.85 & 423.16 & 0.00 & 35424.34 \\
Respiratory (deaths per 100,000) & 588.21 & 235.42 & 0.00 & 8856.08 \\
All-cause (deaths per 100,000) & 4873.42 & 915.49 & 0.00 & 35424.34 \\
Diabetes (deaths per 100,000) & 149.75 & 119.03 & 0.00 & 8291.19 \\
Deaths of despair (deaths per 100,000) & 47.83 & 54.06 & 0.00 & 3248.70 \\
Race county & 0.01 & 0.11 & 0.00 & 1.00 \\
Border county & 0.07 & 0.25 & 0.00 & 1.00 \\
Unemployment rate (\%) & 0.06 & 0.03 & 0.01 & 0.30 \\
Median income (1,000 USD) & 41.65 & 11.62 & 0.00 & 134.61 \\
Percent non-white (\%) & 0.13 & 0.16 & 0.00 & 0.97 \\
TRI facility lead emissions (Metric tons) & 79.06 & 2516.61 & 0.00 & 275971.86 \\
Manufacturing payroll (1,000 USD) & 175.06 & 578.43 & 0.00 & 19471.85 \\
\hline Observations & 58063 & & & \\
\hline
\end{tabular}

Note: The maximum mortality rates for cardiovascular, IHD, and all-cause mortality are all the same because they are all from the same observation of a small county with a single IHD death. IHD is a subset of cardiovascular and all-cause mortality.

\section{A.5 Racetracks: locations, other events, statistics, and distance to lead monitors}

\section{A.5.1 Racetrack counties and border counties}

Figure A3 plots the county types for the EBLL and mortality analysis. The 75 counties in blue are those that had at least one NASCAR or ARCA race since 1995; the 365 counties in green are those that border race counties; the 2,700 counties in white are the control group. If a race county did not have a race in a particular year, it might be a control or border county for that year.

\section{A.5.2 Other events at racetracks}

Other events besides NASCAR and ARCA races occur at the racetracks in our sample. Here we document the set of events that occurred in 2017 at the tracks used for the national 
Figure A3: Map displaying counties with at least one race (blue) or that border a race county (green) since 1995.

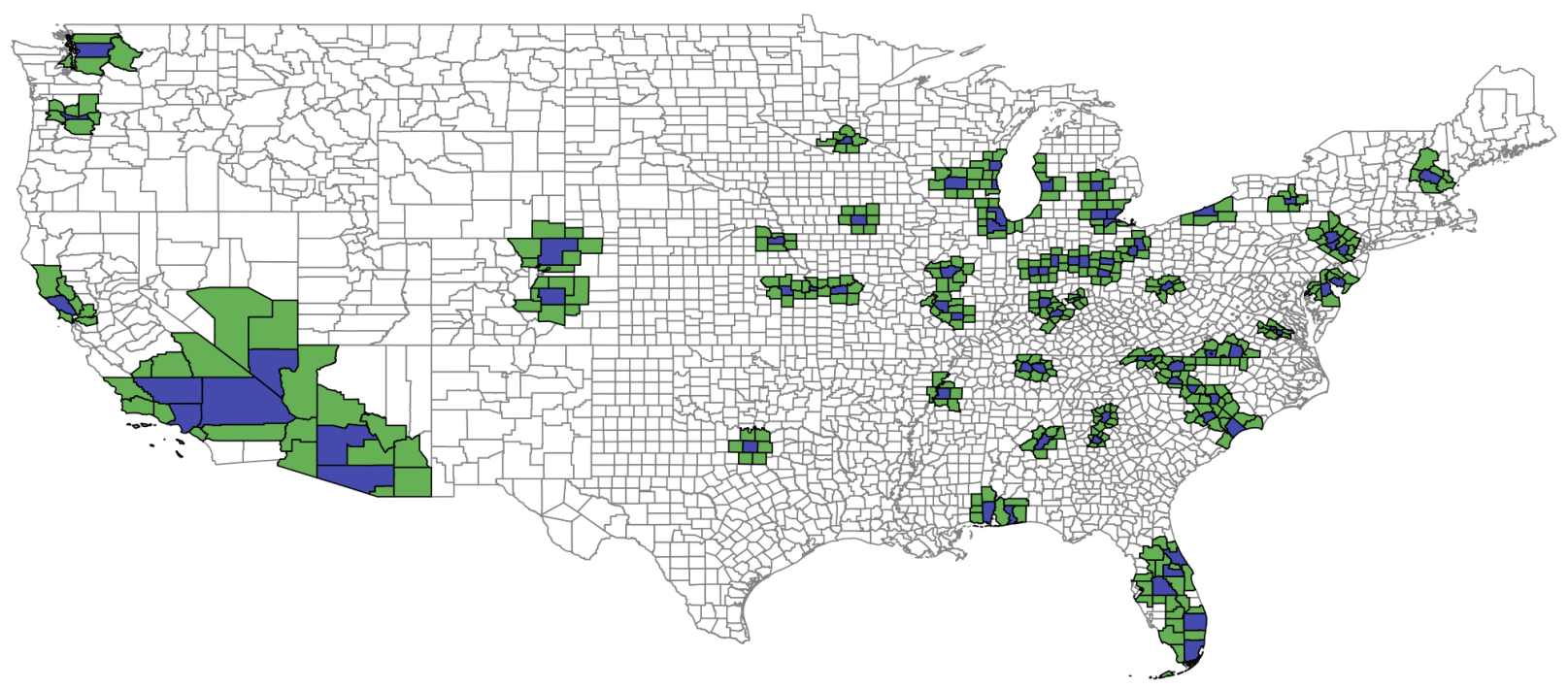

Note: White counties are control counties, blue counties are those that had at least one race since 1995, and green counties are those that have not had a race since 1995 but border a county that did.

NASCAR series. Data were obtained from cached versions of schedules on the racetrack websites. In total we were able to obtain information on 20 racetracks, including major ones like Auto Club Speedway, Daytona International Speedway, and Indianapolis Motor Speedway. We have documented that in 2017, these tracks had a total of 200 events. 84 of these events were individual NASCAR or ARCA races. 20 were non-automotive events like concerts, festivals, or marathons. The remaining 96 were automotive events. About a fifth of the 96 were days for a supercar (e.g. Ferrari, Lamborghini) driving school at Auto Club Speedway. Other common events at racetracks include drag racing, NHRA events, sprint car racing, IndyCar, and monster trucks.

\section{A.5.3 Distribution of monitor-racetrack distances}

Figure A4 displays the distributions of the distances of ambient lead monitor readings from the nearest racetrack by the status of the observation in our preferred specification. The first column shows the distributions for observations that had a leaded race in the last 7 days within 50 miles; the second column is for unleaded races in the last 7 days within 50 miles; and the third column is for observations at monitors that have never had a race within 50 miles. For each column, the top row shows a histogram of the data, the middle row shows the cumulative density function, and the bottom row scales the cumulative density function by the number of race miles per observation. 
The distributions across the first two columns show similar patterns. There are a moderate number of race miles driven within 3 miles of a monitor, however data in the 3-25 mile range is sparse. The modes of the distributions are at 30 miles and approximately $50 \%$ of observations occur 25-35 miles from a racetrack. The third column shows that the distribution of observations for monitors that never had a race within 50 miles is relatively smooth.

\section{A.5.4 Racetrack statistics}

Table A5 details statistics for each racetrack in our dataset for the ambient lead specifications, including the lap length, mean distance to the nearest monitor reading, and the fraction of treated observations accounted for by the racetrack. We limit the data to monitors within 50 miles for computing the statistics to preserve direct comparison with our preferred specification. Monitors tend to be located a substantial distance from racetracks. Averaging over the fourth column shows that the mean distance from a racetrack to a monitor is 25 miles. $40 \%$ of racetracks have a mean distance to a monitor of over 30 miles. The minimum distance column indicates that two thirds of racetracks do not have a monitor within 10 miles, and about $40 \%$ of racetracks do not have a monitor within 20 miles. The racetracks that account for larger fractions of our leaded miles in our sample also tend to be located further from racetracks as shown in the eighth and ninth columns. Only 1 of the 14 racetracks that contributes more than $1 \%$ of the leaded miles (column 9) in the sample has an average distance to a monitor of less than 20 miles. These 14 racetracks account for over $90 \%$ of our observations. The final two columns show that about a quarter of racetracks are, on average 25-35 miles from a monitor, and that 40\% of racetracks are on average 30-50 miles from a monitor. The 25-35 mile range accounts for over half of the race miles driven in our sample. These miles come from 13 distinct racetracks and 89 unique monitor-racetrack pairs out of a total of 47 racetracks and 216 monitor-stadium pairs. 
Figure A4: Distribution of distance from monitor to the nearest racetrack a with race in the past week by leaded and unleaded race status.

(a) leaded miles in the past week

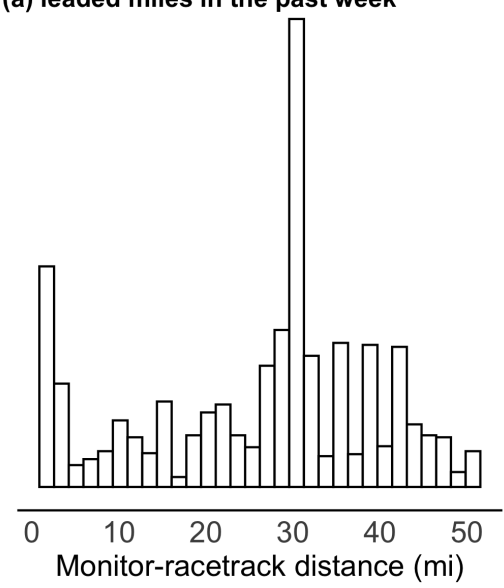

CDF of leaded race observations

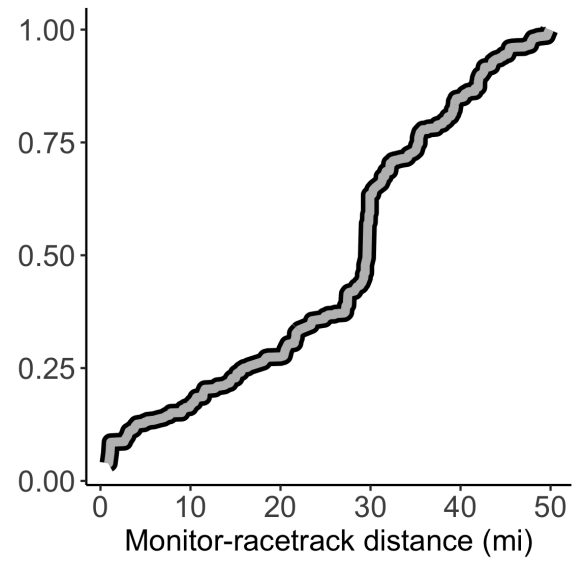

CDF of leaded race observations weighted by race miles

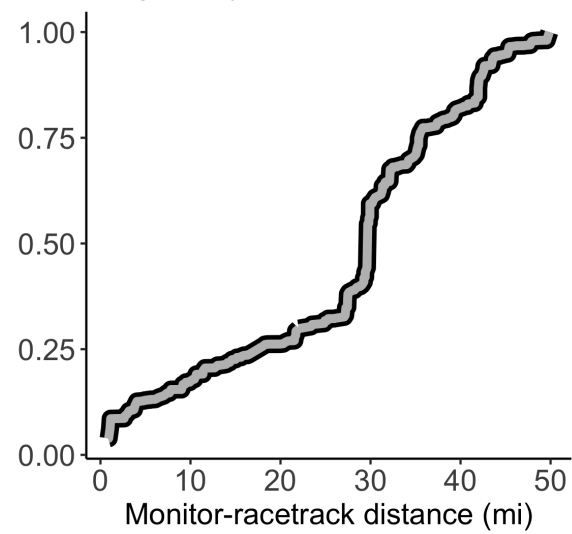

(b) unleaded miles in the past week

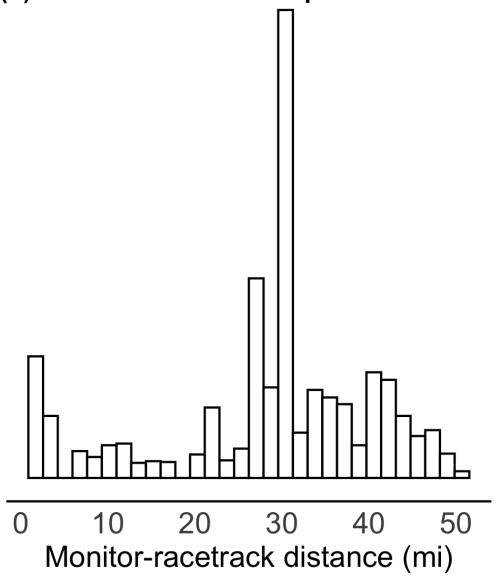

CDF of unleaded race observations

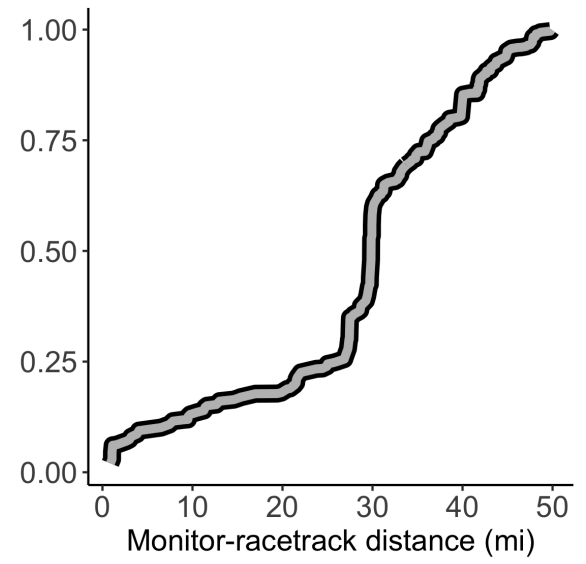

CDF of unleaded race observations weighted by race miles

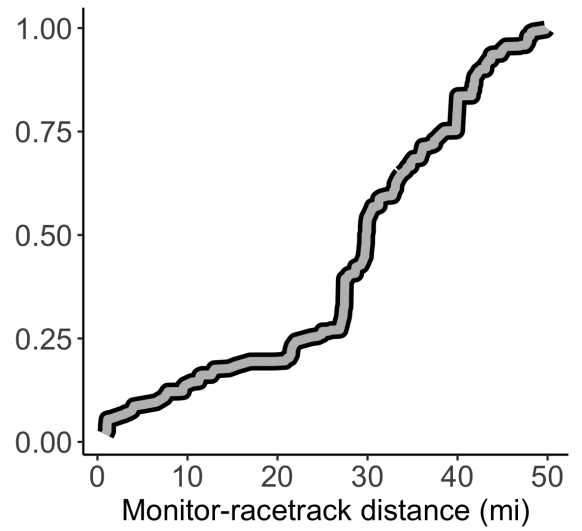

Note: Each column is differentiated by the status of the lead monitor reading in our preferred specification. The first column displays the distance distribution for daily lead monitor readings that occur within one week of a leaded race; the second column is the distribution of lead monitor readings that occur within one week of an unleaded race; and the third column displays the distribution of lead monitor readings whose monitors never had observations that occur within one week of a nearby race. The top row shows a series of histograms that display the distance between each daily lead monitor reading and the distance to the nearest race within the past week. The middle row shows the empirical cumulative density functions of the race observations, weighting each race equally. The bottom row displays the empirical cumulative density functions of the race data by distance, where we weigh each race by miles driven. $50 \%$ of our treated observations (column a) occur between 25 and 35 miles of a racetrack. 
Table A5: NASCAR/ARCA track locations, monitor distance, and \% of treatment contribution for ambient lead specifications.

\begin{tabular}{|c|c|c|c|c|c|c|c|c|c|c|}
\hline Track & Location & Lap Length (mi.) & $\begin{array}{l}\text { Mean Monitor } \\
\text { Dist. (mi) }\end{array}$ & S.D. & Min. & Max. & $\%$ of treated obs & $\begin{array}{l}\text { \% of treated obs } \\
\text { accounting for } \\
\text { miles driven } \\
\text { at track }\end{array}$ & $\begin{array}{c}\text { Mean dist } \\
\text { between } \\
25 \text { and } 35 \mathrm{mi}\end{array}$ & $\begin{array}{c}\text { Mean dist } \\
\text { between } \\
30 \text { and } 50 \mathrm{mi}\end{array}$ \\
\hline Alabama International Motor Speedway & Talladega, AL & 2.66 & 43.47 & 1.62 & 42.04 & 45.23 & 0.12 & 0.26 & 0 & 1 \\
\hline Phoenix International Raceway & Avondale, AZ & 1.00 & 14.86 & 1.38 & 13.75 & 16.33 & 0.27 & 0.25 & 0 & 0 \\
\hline Tucson Raceway Park & Tucson, AZ & 0.38 & 16.35 & 4.23 & 12.69 & 20.01 & 0.15 & 0.03 & 0 & 0 \\
\hline California Speedway & Fontana, CA & 2.00 & 26.74 & 15.96 & 0.91 & 47.09 & 4.66 & 6.23 & 1 & 0 \\
\hline Sonoma Raceway & Sonoma, CA & 2.52 & 25.06 & 6.10 & 15.00 & 31.90 & 0.46 & 0.35 & 1 & 0 \\
\hline Colorado National Speedway & Erie, $\mathrm{CO}$ & 0.38 & 20.08 & 3.29 & 16.33 & 25.19 & 0.54 & 0.13 & 0 & 0 \\
\hline Pikes Peak International Raceway & Fountain, $\mathrm{CO}$ & 1.00 & 21.29 & 3.34 & 18.28 & 24.85 & 0.93 & 0.63 & 0 & 0 \\
\hline Dover International Speedway & Dover, DE & 1.00 & 37.14 & 9.45 & 14.11 & 45.40 & 2.04 & 3.96 & 0 & 1 \\
\hline Daytona International Speedway & Daytona Beach, FL & 2.50 & 44.35 & 0.00 & 44.35 & 44.35 & 0.12 & 0.16 & 0 & 1 \\
\hline Miami-Dade Homestead Motorsports Complex & Homestead, FL & 1.50 & 21.78 & & 21.78 & 21.78 & 0.04 & 0.03 & 0 & 0 \\
\hline Lanier National Speedway & Braselton, GA & 0.40 & 15.48 & 7.64 & 10.09 & 20.88 & 0.08 & 0.02 & 0 & 0 \\
\hline Atlanta Motor Speedway & Hampton, GA & 1.54 & 31.60 & 6.64 & 28.01 & 42.36 & 0.31 & 0.64 & 1 & 1 \\
\hline Chicago Motor Speedway & Cicero, IL & 1.00 & 13.11 & 6.39 & 4.41 & 21.77 & 1.31 & 0.59 & 0 & 0 \\
\hline Gateway International Raceway & Madison, IL & 1.25 & 22.87 & 10.26 & 3.00 & 31.17 & 18.62 & 12.58 & 0 & 0 \\
\hline Illinois State Fairgrounds & Springfield, IL & 1.00 & 33.07 & 2.65 & 31.74 & 38.08 & 0.73 & 0.19 & 1 & 1 \\
\hline Anderson Speedway & Anderson, IN & 0.25 & 23.10 & 10.09 & 15.32 & 39.07 & 0.69 & 0.10 & 0 & 0 \\
\hline Indianapolis Raceway Park & Clermont, IN & 0.69 & 10.04 & 5.19 & 4.86 & 16.47 & 0.50 & 0.16 & 0 & 0 \\
\hline Indiana State Fairgrounds & Indianapolis, IN & 1.00 & 44.26 & 0.14 & 44.04 & 44.33 & 0.15 & 0.04 & 0 & 1 \\
\hline Salem Speedway & Salem, IN & 0.56 & 34.78 & 4.74 & 29.87 & 39.00 & 0.50 & 0.13 & 1 & 1 \\
\hline Indianapolis Motor Speedway & Speedway, IN & 2.50 & 25.47 & 22.05 & 3.83 & 49.87 & 3.12 & 5.17 & 1 & 0 \\
\hline Winchester Speedway & Winchester, IN & 0.50 & 20.70 & 0.16 & 20.52 & 20.84 & 2.27 & 0.50 & 0 & 0 \\
\hline Heartland Park Topeka & Topeka, KS & 1.80 & 12.35 & 4.77 & 8.39 & 20.28 & 0.19 & 0.07 & 0 & 0 \\
\hline Michigan Speedway & Brooklyn, MI & 2.00 & 35.04 & 0.00 & 35.04 & 35.04 & 0.08 & 0.04 & 0 & 1 \\
\hline Michigan International Speedway & Brooklyn, MI & 2.00 & 35.04 & 0.00 & 35.04 & 35.04 & 0.42 & 0.63 & 0 & 1 \\
\hline Flat Rock Speedway & Flat Rock, MI & 0.25 & 17.38 & 1.45 & 15.62 & 18.58 & 0.31 & 0.02 & 0 & 0 \\
\hline Berlin Raceway & Marne, MI & 0.44 & 15.50 & 6.16 & 9.01 & 22.10 & 0.35 & 0.06 & 0 & 0 \\
\hline I-70 Speedway & Odessa, MO & 0.54 & 39.90 & 1.93 & 38.12 & 43.67 & 0.35 & 0.09 & 0 & 1 \\
\hline Charlotte Motor Speedway & Concord, $\mathrm{NC}$ & 1.50 & 32.89 & 3.10 & 32.19 & 46.23 & 1.54 & 2.93 & 1 & 1 \\
\hline Hickory Speedway & Hickory, $\mathrm{NC}$ & 0.40 & 5.87 & & 5.87 & 5.87 & 0.04 & 0.01 & 0 & 0 \\
\hline North Carolina Motor Speedway & Rockingham, NC & 1.02 & 40.88 & 0.77 & 38.93 & 41.58 & 0.39 & 0.75 & 0 & 1 \\
\hline Flemington Speedway & Flemington, NJ & 0.62 & 41.59 & 6.72 & 20.40 & 49.58 & 4.74 & 1.33 & 0 & 1 \\
\hline Toledo Speedway & Toledo, $\mathrm{OH}$ & 0.50 & 42.51 & 3.19 & 36.42 & 45.46 & 2.20 & 0.52 & 0 & 1 \\
\hline Cloverleaf Speedway & Valley View, $\mathrm{OH}$ & 0.25 & 32.39 & 5.90 & 21.57 & 47.83 & 6.44 & 8.65 & 1 & 1 \\
\hline Pocono Raceway & Long Pond, PA & 2.50 & 36.40 & 9.61 & 18.09 & 43.56 & 5.63 & 11.17 & 0 & 1 \\
\hline Nazareth Speedway & Nazareth, PA & 1.00 & 34.99 & 8.85 & 7.66 & 47.91 & 5.51 & 3.24 & 1 & 1 \\
\hline Darlington Raceway & Darlington, SC & 1.37 & 25.44 & 13.40 & 9.17 & 40.32 & 2.35 & 3.95 & 1 & 0 \\
\hline Rambi Raceway & Myrtle Beach, SC & 0.50 & 27.08 & 11.61 & 5.23 & 33.99 & 0.73 & 0.29 & 1 & 0 \\
\hline Bristol Motor Speedway & Bristol, TN & 0.53 & 1.19 & 2.80 & 0.88 & 42.73 & 8.56 & 8.55 & 0 & 0 \\
\hline Memphis Motorsports Park & Memphis, TN & 0.75 & 14.88 & 0.48 & 13.99 & 15.15 & 1.23 & 0.56 & 0 & 0 \\
\hline Nashville Superspeedway & Nashville, TN & 1.33 & 21.72 & 0.35 & 20.37 & 22.04 & 2.20 & 2.15 & 0 & 0 \\
\hline Nashville Speedway & Nashville, TN & 0.50 & 20.92 & 7.07 & 2.63 & 32.92 & 2.35 & 1.08 & 0 & 0 \\
\hline Texas Motor Speedway & Fort Worth, TX & 1.50 & 30.21 & 2.89 & 27.27 & 42.19 & 15.73 & 20.55 & 1 & 1 \\
\hline Martinsville Speedway & Martinsville, VA & 0.53 & 38.71 & 0.00 & 38.71 & 38.71 & 0.08 & 0.07 & 0 & 1 \\
\hline Richmond Fairgrounds Raceway & Richmond, VA & 0.54 & 4.54 & 2.22 & 2.68 & 7.01 & 0.54 & 0.84 & 0 & 0 \\
\hline Evergreen Speedway & Monroe, WA & 0.65 & 26.08 & 0.00 & 26.08 & 26.08 & 0.19 & 0.06 & 1 & 0 \\
\hline Milwaukee Mile & West Allis, WI & 1.00 & 12.73 & 14.69 & 4.85 & 38.64 & 0.19 & 0.23 & 0 & 0 \\
\hline West Virginia Motor Speedway & Mineral Wells, WV & 0.62 & 5.51 & & 5.51 & 5.51 & 0.04 & 0.01 & 0 & 0 \\
\hline
\end{tabular}

\section{A.6 Lead concentrations}

\section{A.6.1 Specification and sample robustness}

Table A6 shows estimates from a set of alternative specifications for equation (1). Column 1 replaces asinh $(\mathrm{Pb})$ with just the untransformed mean reading; column 2 replaces asinh $(\mathrm{Pb})$ with $\ln (\mathrm{Pb}+1)$; column 3 clusters at the monitor level instead of county level; column 4 includes monitor-by-year-by-month fixed effects; column 5 controls for baseline ambient $\mathrm{Pb}$ levels prior to the race; column 6 includes data back to 1957; column 7 only uses miles from the national NASCAR series; column 8 includes regional NASCAR series; column 9 restricts the data to be within 50 days of a race; column 10 replaces the miles treatment variables with indicator variables for if there was a race in the past week to closer match the EBLL 
and mortality regressions; column 11 clusters at the state level; and column 12 uses Conley standard errors where the distance cutoff is 150 miles from the monitor and the time cutoff is 100 years. The estimates are robust across all specifications. 
Table A6: The effect of 100,000 race miles within 50 miles using alternative $\mathrm{Pb}$ functional forms, using race indicators instead of miles, alternative treatments of standard errors, controlling for baseline $\mathrm{Pb}$ levels, or using alternative samples.

\begin{tabular}{|c|c|c|c|c|c|c|c|c|c|c|c|c|}
\hline & $\begin{array}{c}(1) \\
\text { mean } \mathrm{Pb}\end{array}$ & $\begin{array}{c}(2) \\
\ln (\mathrm{Pb}+1)\end{array}$ & $\begin{array}{c}(3) \\
\operatorname{asinh}(\mathrm{Pb})\end{array}$ & $\begin{array}{c}(4) \\
\operatorname{asinh}(\mathrm{Pb})\end{array}$ & $\begin{array}{c}(5) \\
\operatorname{asinh}(\mathrm{Pb})\end{array}$ & $\begin{array}{c}(6) \\
\operatorname{asinh}(\mathrm{Pb})\end{array}$ & $\begin{array}{c}(7) \\
\operatorname{asinh}(\mathrm{Pb})\end{array}$ & $\begin{array}{c}(8) \\
\operatorname{asinh}(\mathrm{Pb})\end{array}$ & $\begin{array}{c}(9) \\
\operatorname{asinh}(\mathrm{Pb})\end{array}$ & $\begin{array}{c}(10) \\
\operatorname{asinh}(\mathrm{Pb})\end{array}$ & $\begin{array}{c}(11) \\
\operatorname{asinh}(\mathrm{Pb})\end{array}$ & $\begin{array}{c}(12) \\
\operatorname{asinh}(\mathrm{Pb})\end{array}$ \\
\hline Leaded race miles in past week (100k) & $\begin{array}{c}0.25^{*} \\
(0.13)\end{array}$ & $\begin{array}{c}0.10^{* * *} \\
(0.04)\end{array}$ & $\begin{array}{c}0.13^{* *} \\
(0.06)\end{array}$ & $\begin{array}{l}0.12^{* * * *} \\
(0.03)\end{array}$ & $\begin{array}{l}0.13^{* * *} \\
(0.05)\end{array}$ & $\begin{array}{l}0.10^{* *} \\
(0.04)\end{array}$ & $\begin{array}{c}0.13^{* *} \\
(0.06)\end{array}$ & $\begin{array}{c}0.08^{*} \\
(0.05)\end{array}$ & $\begin{array}{l}0.11^{* * *} \\
(0.03)\end{array}$ & & $\begin{array}{c}0.13^{*} \\
(0.06)\end{array}$ & $\begin{array}{l}0.13^{* *} \\
(0.06)\end{array}$ \\
\hline Unleaded race miles in past week (100k) & $\begin{array}{c}-0.02 \\
(0.02)\end{array}$ & $\begin{array}{c}-0.00 \\
(0.01)\end{array}$ & $\begin{array}{c}-0.00 \\
(0.01)\end{array}$ & $\begin{array}{c}0.02 \\
(0.02)\end{array}$ & $\begin{array}{c}-0.00 \\
(0.01)\end{array}$ & $\begin{array}{c}-0.00 \\
(0.01)\end{array}$ & $\begin{array}{c}-0.01 \\
(0.02)\end{array}$ & $\begin{array}{c}0.00 \\
(0.01)\end{array}$ & $\begin{array}{l}-0.02 \\
(0.02)\end{array}$ & & $\begin{array}{c}-0.00 \\
(0.01)\end{array}$ & $\begin{array}{l}-0.00 \\
(0.02)\end{array}$ \\
\hline Mean lead two weeks before race & & & & & $\begin{array}{l}0.02 * * * \\
(0.01)\end{array}$ & & & & & & & \\
\hline
\end{tabular}

1(Leaded race in past week) $(0.01)$

1 (Unleaded race in past week)

\begin{tabular}{|c|c|c|c|c|c|c|c|c|c|c|c|c|}
\hline & & & & & & & & & & & & \\
\hline Daily Weather Controls & Yes & Yes & Yes & Yes & Yes & Yes & Yes & Yes & Yes & Yes & Yes & Yes \\
\hline Monitor-by-Year FE & Yes & Yes & Yes & Yes & Yes & Yes & Yes & Yes & Yes & Yes & Yes & Yes \\
\hline Mon-by-Year-by-Month FE & No & No & No & Yes & No & No & No & No & No & No & No & No \\
\hline Week-by-Year FE & Yes & Yes & Yes & Yes & Yes & Yes & Yes & Yes & Yes & Yes & Yes & Yes \\
\hline Clustered Standard Errors & County & County & Monitor & County & County & County & County & County & County & County & State & Conley (150 miles) \\
\hline Years Included & 1996-2018 & 1996-2018 & 1996-2018 & 1996-2018 & 1996-2018 & 1957-2018 & $1996-2018$ & $1996-2018$ & 1996-2018 & $1996-2018$ & 1996-2018 & $1996-2018$ \\
\hline Races Included & Main Sample & Main Sample & Main Sample & Main Sample & Main Sample & Main Sample & NASCAR Only & Main Sample + Regional & Main Sample & Main Sample & Main Sample & Main Sample \\
\hline Restriction Around Race & None & None & None & None & None & None & None & None & \pm 50 days & None & None & None \\
\hline Adjusted $R^{2}$ & 0.29 & 0.47 & 0.45 & 0.44 & 0.45 & $\begin{array}{c}0.64 \\
0.694\end{array}$ & 0.45 & 0.45 & 0.45 & 0.45 & 0.45 & .45 \\
\hline Observations & 312277 & 312277 & 312277 & 311301 & 311207 & 872880 & 311056 & 312842 & 59968 & 312277 & 312277 & 312277 \\
\hline
\end{tabular}

Note: ${ }^{*} \mathrm{p}<0.1, * * \mathrm{p}<0.05,{ }^{* * *} \mathrm{p}<0.01$. Robust standard errors clustered at the county level in parentheses unless otherwise noted. Monitor-specific daily weather variables include air temperature, pressure, relative humidity, wind speed, and daily precipitable water. 
Figure A5 shows how the size of the estimates in column 7 of Table 1 vary with the chosen treatment distance cutoff. The thin black line corresponds to the cumulative density function of monitor readings. Estimated effects of leaded miles under 10 and 20 mile cutoffs are approximately zero which is consistent with the small number of monitors within 20 miles as shown in Figure A4 and Table A5. Table A5 showed that a substantial number of leaded miles occur in the 25-35 mile range. This is when we are sufficiently powered to estimate an effect and at the 30 mile cutoff we estimate an effect of 0.22 for leaded miles and an effect of approximately zero for unleaded miles. The leaded miles effect attenuates as the distance cutoff is expanded outward up to 100 miles.

Figure A5: Treatment effect by distance cutoff and the distribution of distance from monitor to nearest racetrack by leaded or unleaded race status.
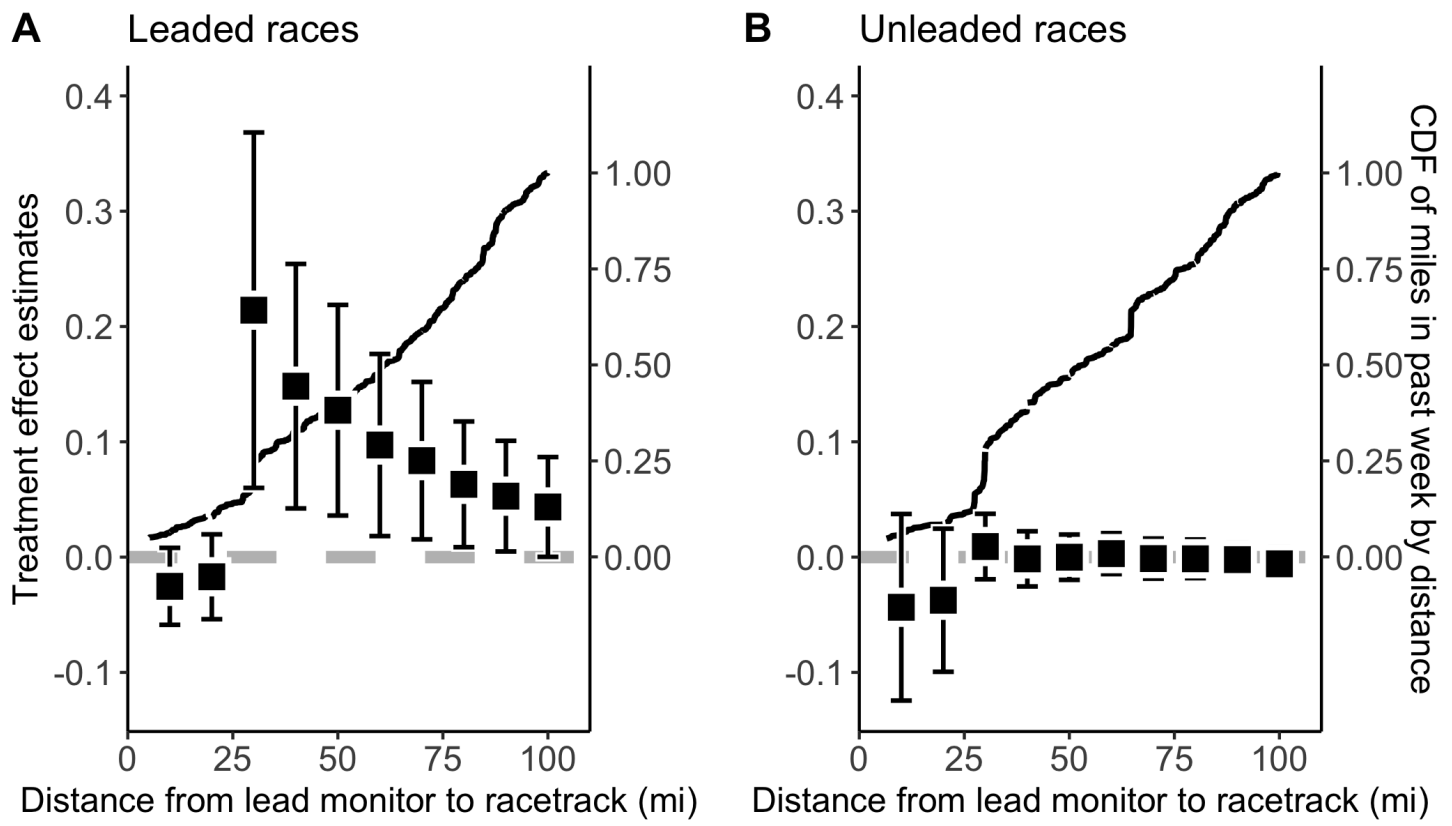

Note: This figure shows the effect of 100,000 leaded and unleaded race miles on ambient lead concentrations across increasing distances between the stadium and nearby racetrack. The left panel (A) plots the estimated effect of leaded race miles from a set of increasing distance cutoffs. The right panel (B) plots the estimated effect of unleaded race miles. Each regression is similar to Equation 1, but with a different distance bin. Each regression includes both leaded and unleaded miles in the past week within the given distance cutoff and controls for week-by-year fixed effects, monitor-by-year fixed effects, and daily monitor-specific weather controls. The dependent variable is asinh $(\mathrm{Pb})$. Brackets denote $95 \%$ confidence intervals, calculated from robust standard errors clustered at the county level. The estimates for 50 miles depicted in the figure correspond to the results shown in column 7 of Table 1 . The black line behind the coefficient estimates depicts the cumulative density function of all leaded race miles (A) and unleaded race miles (B) that occur within 100 miles of a stadium and occur in the week before a lead monitor reading. Over $50 \%$ of past week race miles between 0 and 50 miles of a race track occur between 25 and 35 miles. There are 261 unique monitor-racetrack pairs from 0 to 50 miles, 89 of these unique pairs occur between 25 and 35 miles. 


\section{A.6.2 Comparison tests and confounding pollutants}

Figures A6 and A7 display event study estimates when including treatment by a pair of placebo events and a set of potentially confounding pollutants using the same specification as the left panel of Figure 3. Figure A6 displays the results using the two placebo events: baseball games and IndyCar races. The estimates come specifications corresponding to the left panel Figure 3, but where we include identical treatment variables for IndyCar miles and baseball attendance in the regression. This tests whether similar large events are associated with changes in lead concentrations that may occur due to spurious lead trends, resuspension of soil lead, or increased leaded air travel. The top row shows the effect of NASCAR miles when now additionally controlling for IndyCar miles or baseball attendance. The event study estimates are nearly identical to Figure 3. The bottom row shows the effects of IndyCar race miles and baseball attendance on lead concentrations. Note that IndyCar did not use leaded fuel over our sample period. Both sets of estimates are centered around zero with no clear spike in lead concentrations following a race as was observed following leaded NASCAR and ARCA races.

Figure A7 displays results from the second set of placebo tests. These tests examine whether the switch to unleaded racing fuel affected concentrations of other automotive pollutants that could confound estimated effects on mortality (U.S. Environmental Protection Agency, 1994) ${ }^{32}$ For our estimates to be confounded, leaded and unleaded races would need to differentially affect levels of other pollutants. Similar to the left panel of Figure 3, we would need to find evidence that the levels of other pollutants increase following leaded or unleaded races, and that there is no change or a significantly smaller increase following the other type of race. Moreover, we would also need to demonstrate parallel pre-trends in the weeks preceding both leaded and unleaded races to provide the usual suggestive evidence that we are estimating a causal effect of races rather than background trends. We do not find convincing evidence that any of these pollutant levels were altered as a result of the deleading of NASCAR and ARCA races.

The first row of Figure A7 shows no effect of races on ambient CO or VOCs before or after deleading. CO levels at monitors within 4 weeks of a leaded or unleaded race tend to be the same as CO levels at control monitors. VOC concentrations tend to be higher at monitors nearby a race, but there is no clear effect of the race itself on VOC concentrations. The second row does not show strong evidence that either leaded or unleaded races affect ambient $\mathrm{PM}_{10}$ and $\mathrm{PM}_{2.5}$, although unleaded races tend to occur when $\mathrm{PM}_{2.5}$ concentrations are lower. There is an increase in $\mathrm{PM}_{2.5}$ two weeks after a leaded race, however this is likely

\footnotetext{
${ }^{32}$ If gasoline is not perfectly combusted inside the engine, a vehicle may emit hydrocarbons (a VOC), $\mathrm{NO}_{x}$, $\mathrm{PM}$, or CO. $\mathrm{NO}_{x}$ and VOCs can react in the air to form $\mathrm{O}_{3}$.
} 
Figure A6: The effect of other large events on ambient lead concentrations within 50 miles.

A.

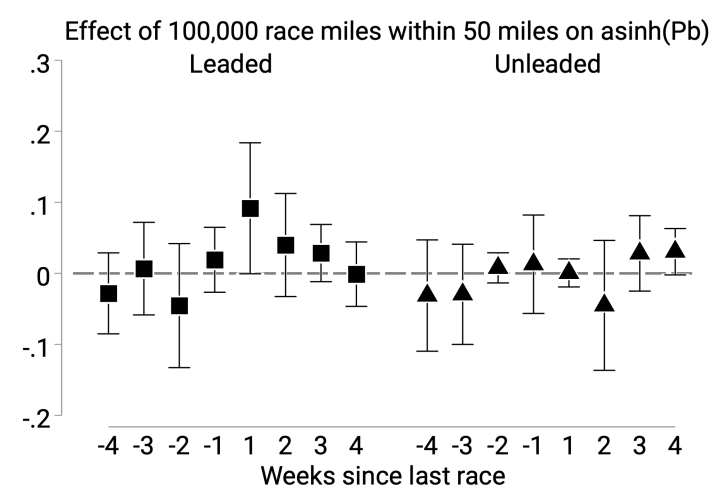

C.

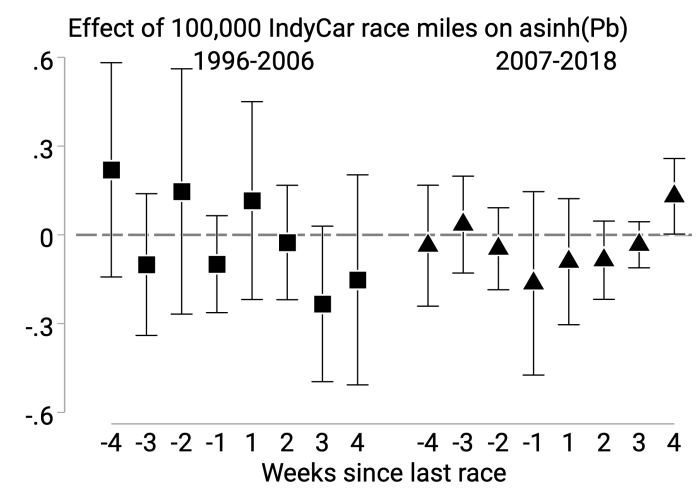

B.
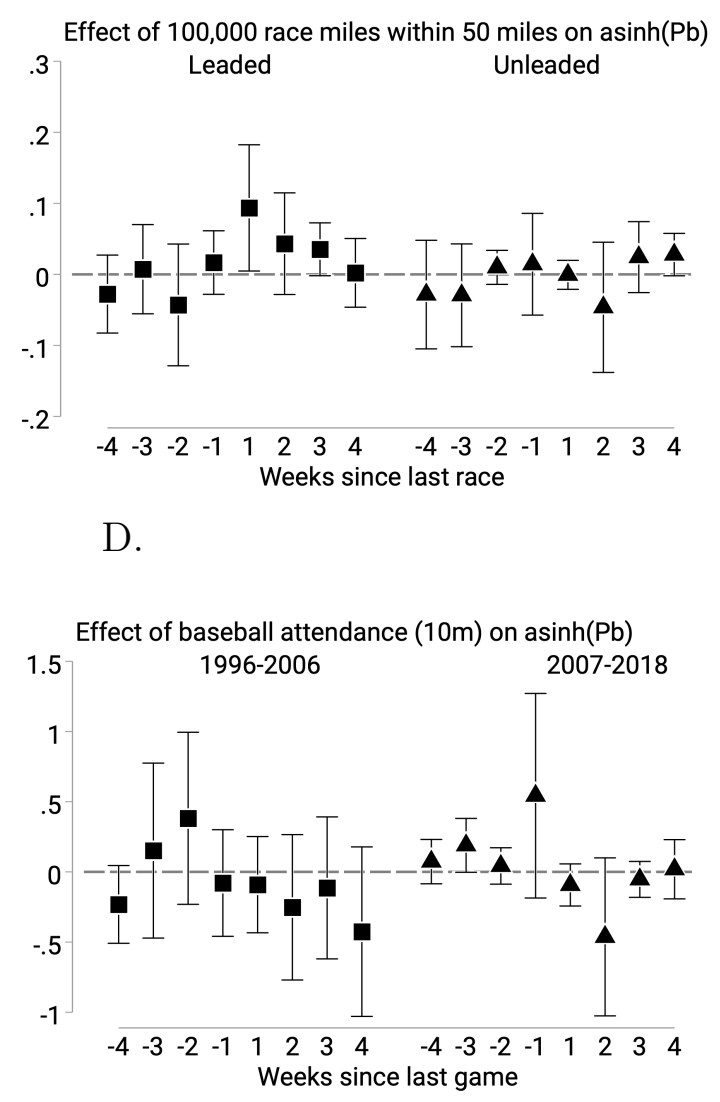

Note: The top left panel (A) shows the effect of 100,000 NASCAR/ARCA miles on ambient lead concentrations when controlling for IndyCar race miles. The top right panel (B) shows the effect of 100,000 NASCAR/ARCA miles on ambient lead concentrations when controlling for baseball attendance. The bottom left panel (C) shows the effect of 100,000 IndyCar race miles on ambient lead concentrations. The bottom right (D) panel shows the effect of 10,000,000 baseball attendees on ambient lead concentrations. For each panel, all coefficients come from the same regression. Each regression controls for week-by-year fixed effects, monitor-by-year fixed effects, and daily monitor-specific weather controls. The dependent variable is asinh $(\mathrm{Pb})$. We estimate effects separately before and after 2007 to approximately match the timing of deleading for NASCAR and ARCA. Brackets represent 95\% confidence intervals, calculated from robust standard errors clustered at the county level. Negative values on the $\mathrm{x}$-axis indicate monitor readings that occurred in the weeks prior to a race, and positive values on the $\mathrm{x}$-axis indicate monitor readings that occurred in the weeks after a race. For all outcomes only race miles (or attendance) within 50 miles are included. 
spurious. There is no increase in $\mathrm{PM}_{10}$ which contains $\mathrm{PM}_{2.5}$ as a subset, and the positive estimated effect is delayed until two weeks after a race and does not show the same decay pattern one would expect as in Figure 3.

The final row shows no effect of races on $\mathrm{NO}_{2}$ and $\mathrm{O}_{3}$ concentrations. $\mathrm{NO}_{2}$ concentrations tend to be lower in the weeks following both leaded and unleaded races, so although it tends to change after a race, there is no differential effect of leaded versus unleaded races that would confound identification of the effects of lead on mortality outcomes. For ozone, we cannot distinguish any of the leaded miles estimates from zero except for the estimates for a race four and two weeks in the future. Similar to the $\mathrm{PM}_{2.5}$ specification, $\mathrm{O}_{3}$ levels appear to be slightly lower in the weeks surrounding unleaded races, but there is no clear, unique effect immediately following a race. Finding no evidence of increases in concentrations in non-Pb pollutants is not entirely surprising. NASCAR and ARCA use high-quality fuel and have extremely efficient engines, making it more likely for gasoline to combust into $\mathrm{CO}_{2}$ and water rather than leaving uncombusted byproducts like CO. Unlike the hydrocarbons in gasoline, lead is not combusted into other compounds and thus either remains in a vehicle or is emitted from its tailpipe. 
Figure A7: The effect of race miles within 50 miles on other pollutant concentrations.

A.

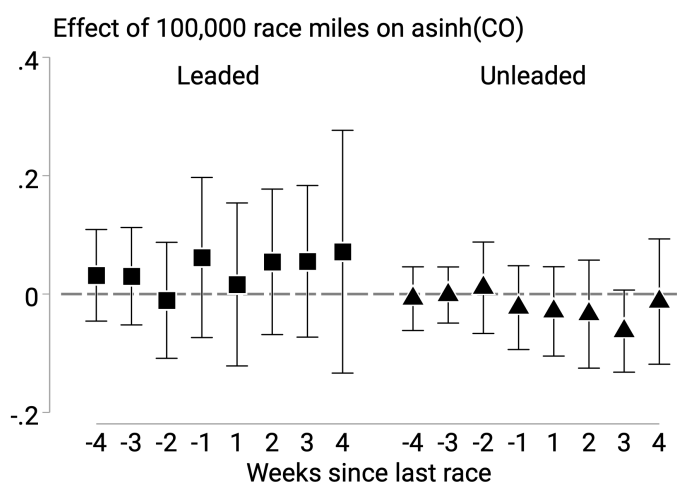

C.

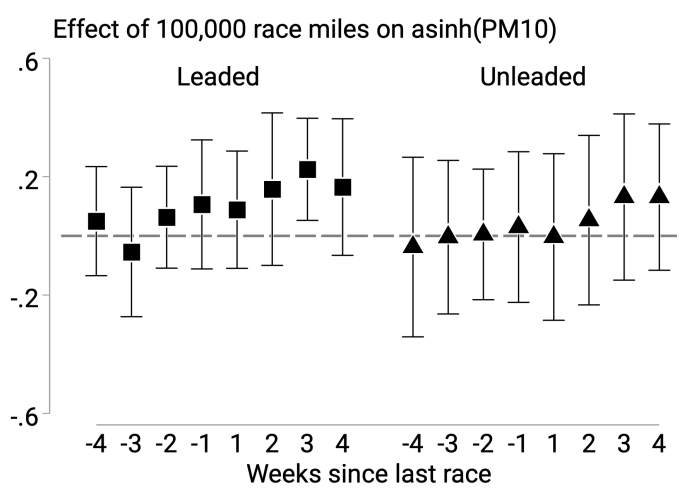

E.

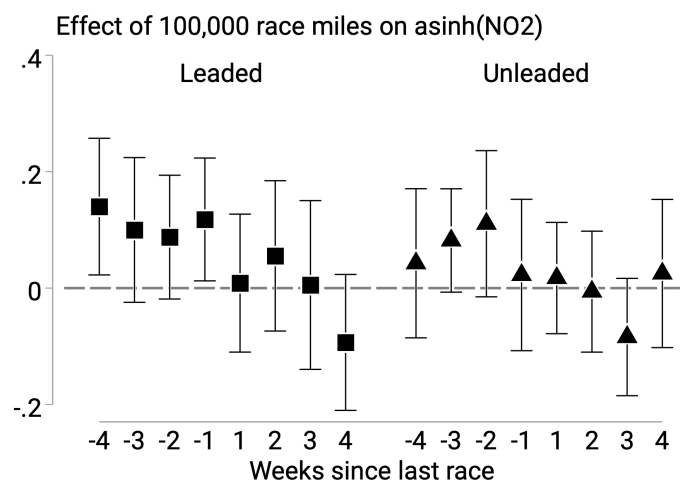

B.

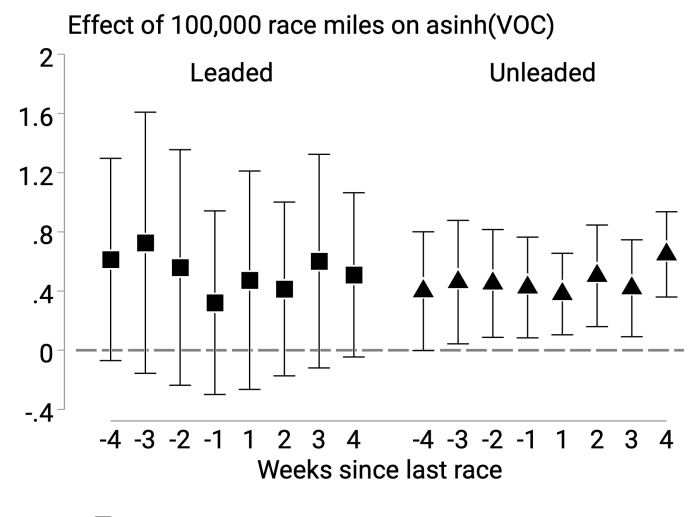

D.

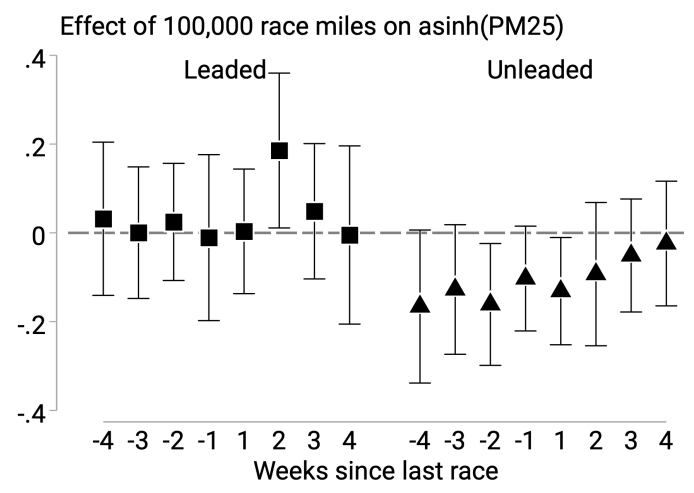

F.

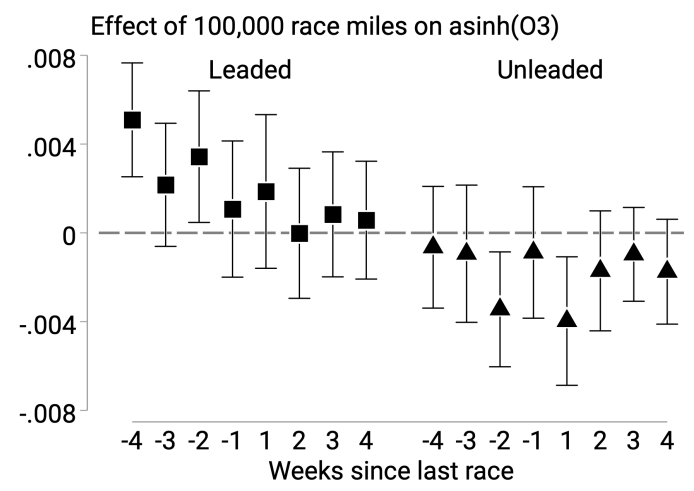

Note: Each panel shows the effect of 100,000 leaded and unleaded race miles on ambient concentrations of a non-lead pollutant (CO, VOCs, $\mathrm{PM}_{10}, \mathrm{PM}_{2.5}, \mathrm{NO}_{2}$, and $\mathrm{O}_{3}$ ). For each panel, all coefficients come from the same regression. Each regression controls for week-by-year fixed effects, monitor-by-year fixed effects, and daily monitor-specific weather controls. The dependent variable is $\operatorname{asinh}(\mathrm{Pb})$. We estimate effects separately before and after 2007 to approximately match the timing of deleading for NASCAR and ARCA. Brackets represent 95\% confidence intervals, calculated from robust standard errors clustered at the county level. Negative values on the $\mathrm{x}$-axis indicate monitor readings that occurred in the weeks prior to a race, and positive values on the $\mathrm{x}$-axis indicate monitor readings that occurred in the weeks after a race. For all outcomes only race miles (or attendance) within 50 miles are included. 
Estimated effects in terms of grams of lead Table A7 translates effects in miles into effects in grams of lead using the race mile fuel efficiency estimates from Section A.10. The estimates indicate that a metric ton of lead emitted from racing approximately doubles lead concentrations the following week.

\section{Distributions of wind direction and the initial bearing between the track and} monitor Figure A8 explores wind direction in the ambient lead dataset. The hexagonal heatmap shows the empirical joint distribution of the absolute value of the angle difference between the initial bearing (direction from track to monitor) and the prevailing wind direction at the monitor, and of the absolute value of the angle difference between the initial bearing (direction from track to monitor) and the prevailing wind direction at the track. The smoothed distributions are the marginal distributions. Observations to the left are those where the wind at the track is blowing toward the monitor, i.e. the monitor is downwind of the track, and observations to the bottom are those where the wind at the monitor is also blowing downwind. Wind at the monitor matters because the cells in the wind reanalysis dataset are relatively large. We define downwind to be if the prevailing wind direction is within $22.5^{\circ}$ of the initial bearing, a wedge of $45^{\circ}$ in total. Lighter colors indicate more observations in that hexagonal cell.

If the wind angle difference was uniformly distributed from 0 to $180^{\circ}$, we would expect $12.5 \%$ of observations to be downwind for each marginal distribution. This is not the case, only $9.7 \%$ percent of observations have the wind at the track blowing downwind, while $8.2 \%$ have wind at the monitor blowing downwind. In fact, most of our observations are upwind, and the mode of both marginal distributions is such that the prevailing direction blows in the opposite direction of the monitor. This is consistent with monitors tending to be located in populated areas, and large facilities like racetracks being located downwind of these areas to avoid noise and air pollution.

In total, our data contain fewer than 200 observations where the monitor is downwind of the track, significantly hampering our ability to estimate a model exploring the effect of wind direction.

\section{A.6.3 Excluding observations by monitor-racetrack distance deciles}

Figure A9 displays estimates using the same specification as column 7 of Table 1, but where each decile of monitor-racetrack is excluded, cutting our sample by $10 \%$. This test is to determine which distances are driving most of the effect while preserving statistical power. The estimates are insensitive to excluding deciles. 


\section{A.6.4 Alternative sample periods}

Figure A10 plots estimated effects of 100,000 leaded and unleaded miles on concentrations as a function of the years in our dataset using the same specification as column 7 of Table 1 . The top graph shows estimates as we expand the dataset year by year back to 1957. Expanding the panel back in time decreases the effect of leaded miles down to 0.1, however the effect is still statistically distinguishable from that of unleaded miles.

The bottom graph restricts the dataset to the two years around deleading for the leftmost pair of estimates, 2006-2007, and then expands in both directions year by year until we arrive at the 1996-2018 dataset used in the main ambient lead analysis in the right-most pair of estimates. With panel lengths under 4 years, the estimates are very noisy and in fact have the opposite of expected signs when there are only two years in the panel. As the panel length grows, the effects become more precise, particularly for unleaded miles, and the signs are correct.

\section{A.6.5 Raw data example of our fixed effects strategy}

Figure A11 plots an example of the raw data for the ambient lead concentrations. We selected Bristol Motor Speedway since it has three nearby lead monitors in operation in 1998 which facilitates a clear graph. The solid markers show the amount of leaded race miles in the past week, while the hollow markers show lead concentration readings at the nearby monitors. The vertical dashed lines denote the dates of the two races at Bristol in 1998. Prior to the races, lead concentrations fluctuate but are generally low. In the week after the races, concentrations spike at all three monitors to their highest or second-highest levels in the two-month window before falling back to normal levels.

Table A7: The effect of estimated grams of lead emitted from racing in the past week on ambient lead concentrations.

\begin{tabular}{lcc}
\hline & $\begin{array}{c}(1) \\
\operatorname{asinh}(\mathrm{Pb})\end{array}$ & $\begin{array}{c}(2) \\
\text { mean } \mathrm{Pb}\end{array}$ \\
\hline Lead emitted from racing in past week, metric tons & $\begin{array}{c}0.89^{* * *} \\
(0.31)\end{array}$ & $\begin{array}{c}1.69^{* *} \\
(0.83)\end{array}$ \\
\hline Daily weather controls & Yes & Yes \\
Monitor-by-year fixed-effects & Yes & Yes \\
Week-by-year fixed-effects & Yes & Yes \\
Standard errors clustered by & County & County \\
\hline Observations & 312277 & 312277 \\
\hline Note: $*$ p $<0.1, * * p<0.05, * * *$ \\
at the county level in parentheses. The procedure for estimating grams of \\
lead emitted can be found in Section A.10. Monitor-specific daily weather \\
variables include air temperature, pressure, relative humidity, wind speed, \\
and daily precipitable water.
\end{tabular}


Figure A8: Joint distribution of the difference between wind direction at the monitor and initial bearing from the racetrack to the monitor, and the difference between wind direction at the racetrack and initial bearing from the racetrack to the monitor.

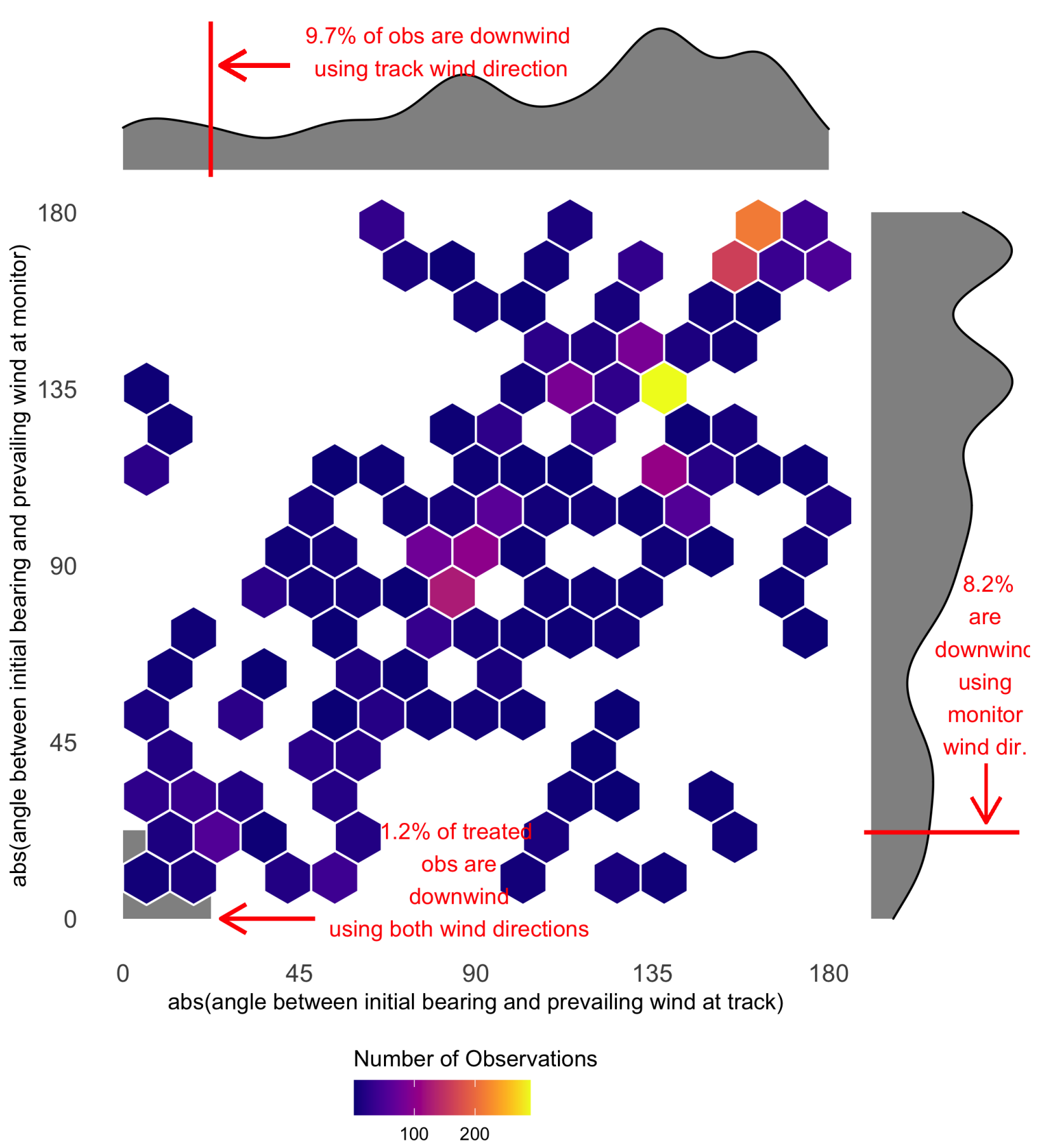

Note: Differences between initial bearing (direction from track to monitor) and wind direction at the monitor (y axis) and wind direction at the racetrack (x axis). Smoothed marginal distributions are shown in gray, and the joint distribution is plotted as a heatmap. Lighter colors indicate more observations. 
Figure A9: The effect of race miles within 50 miles on ambient lead excluding deciles of distance between monitor and racetrack.

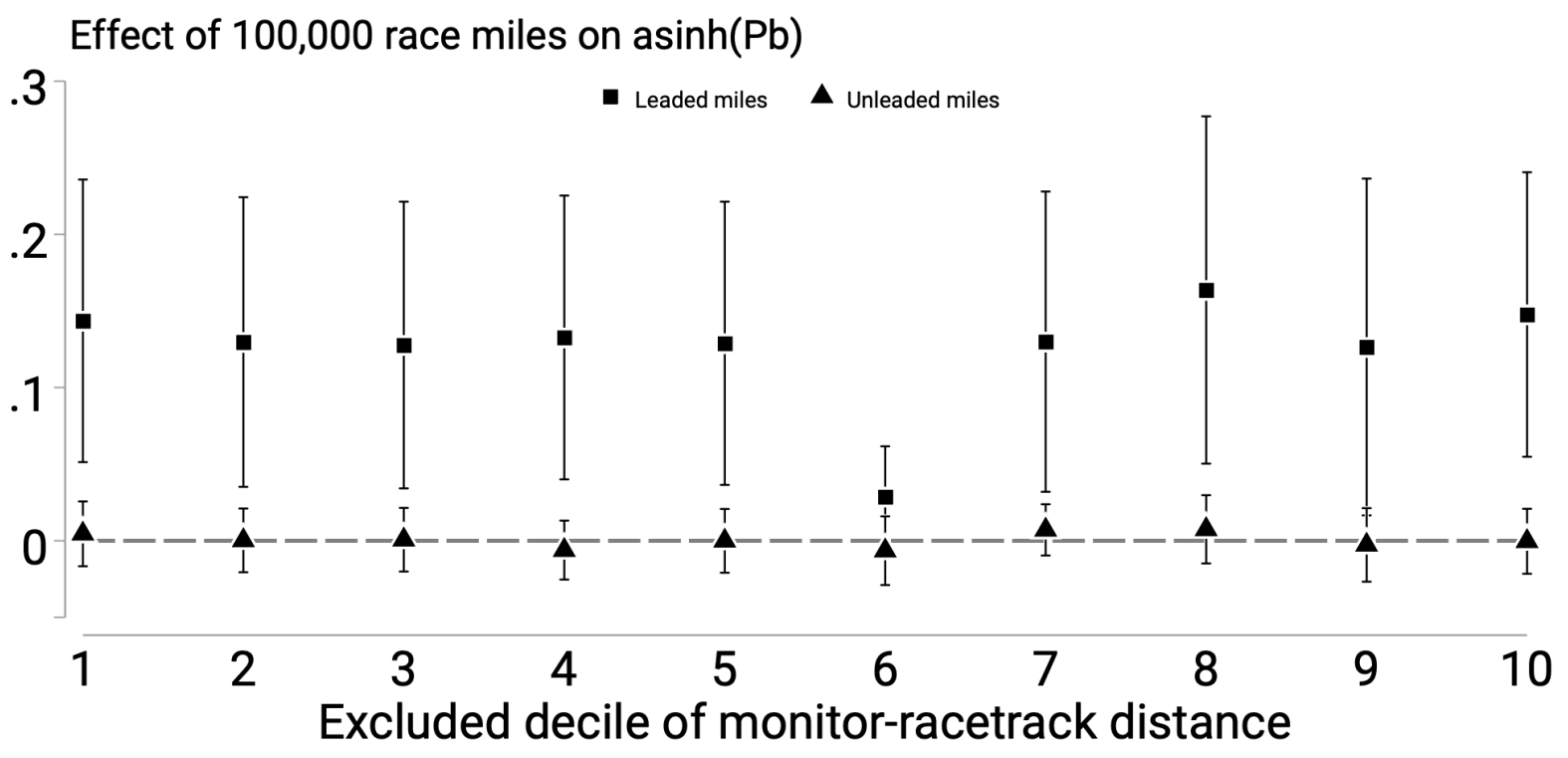

Note: This figure plots estimates corresponding to column 7 of Table 1 when excluding deciles of observations by monitor-racetrack distance within 50 miles. Each regression controls for week-by-year fixed effects, monitor-by-year fixed effects, and daily monitor-specific weather controls. The dependent variable is as$\operatorname{inh}(\mathrm{Pb})$. Only race miles within 50 miles in the past week are included. 
Figure A10: The effect of race miles within 50 miles on ambient lead by weeks since most recent race (left) and by distance from track (right).

A.

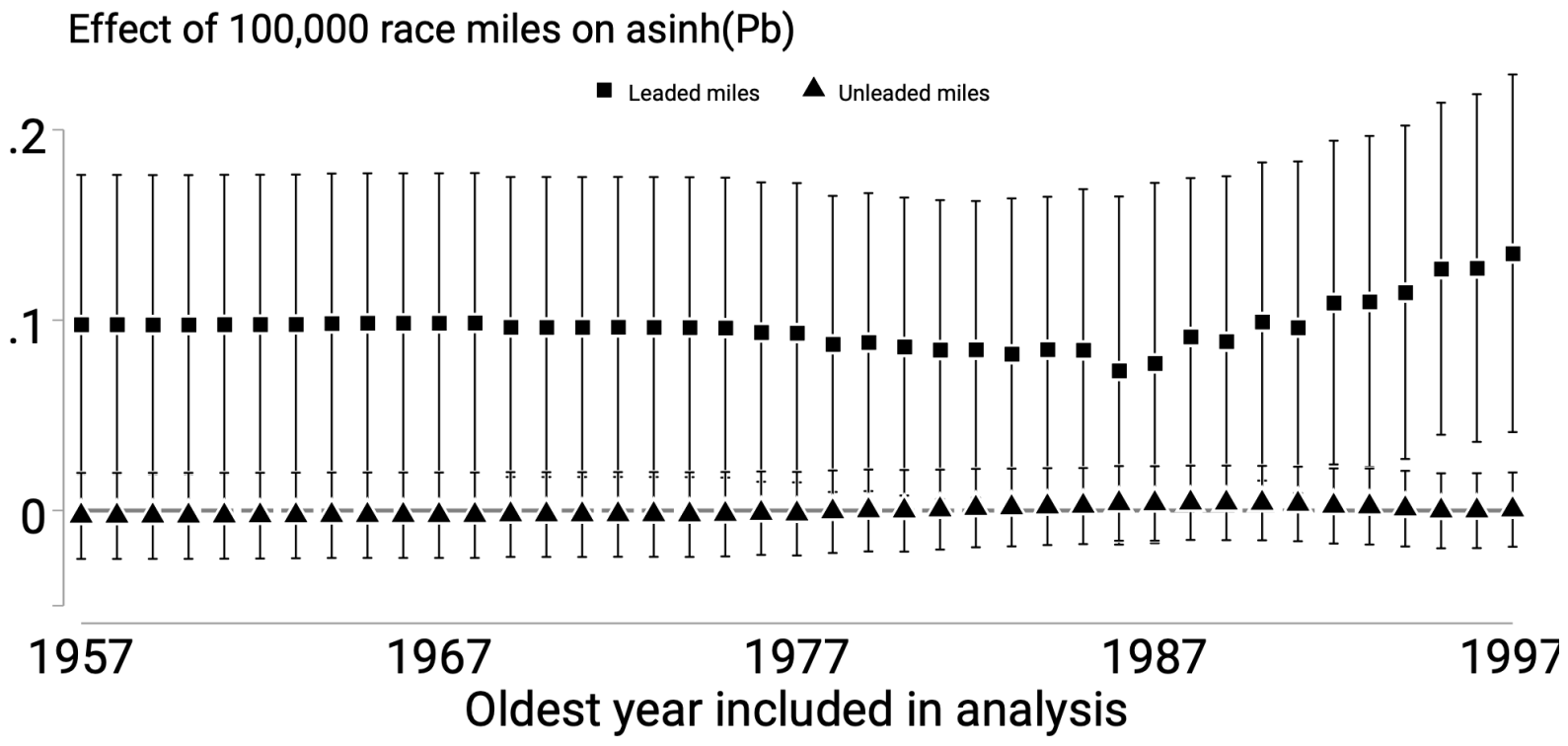

B.

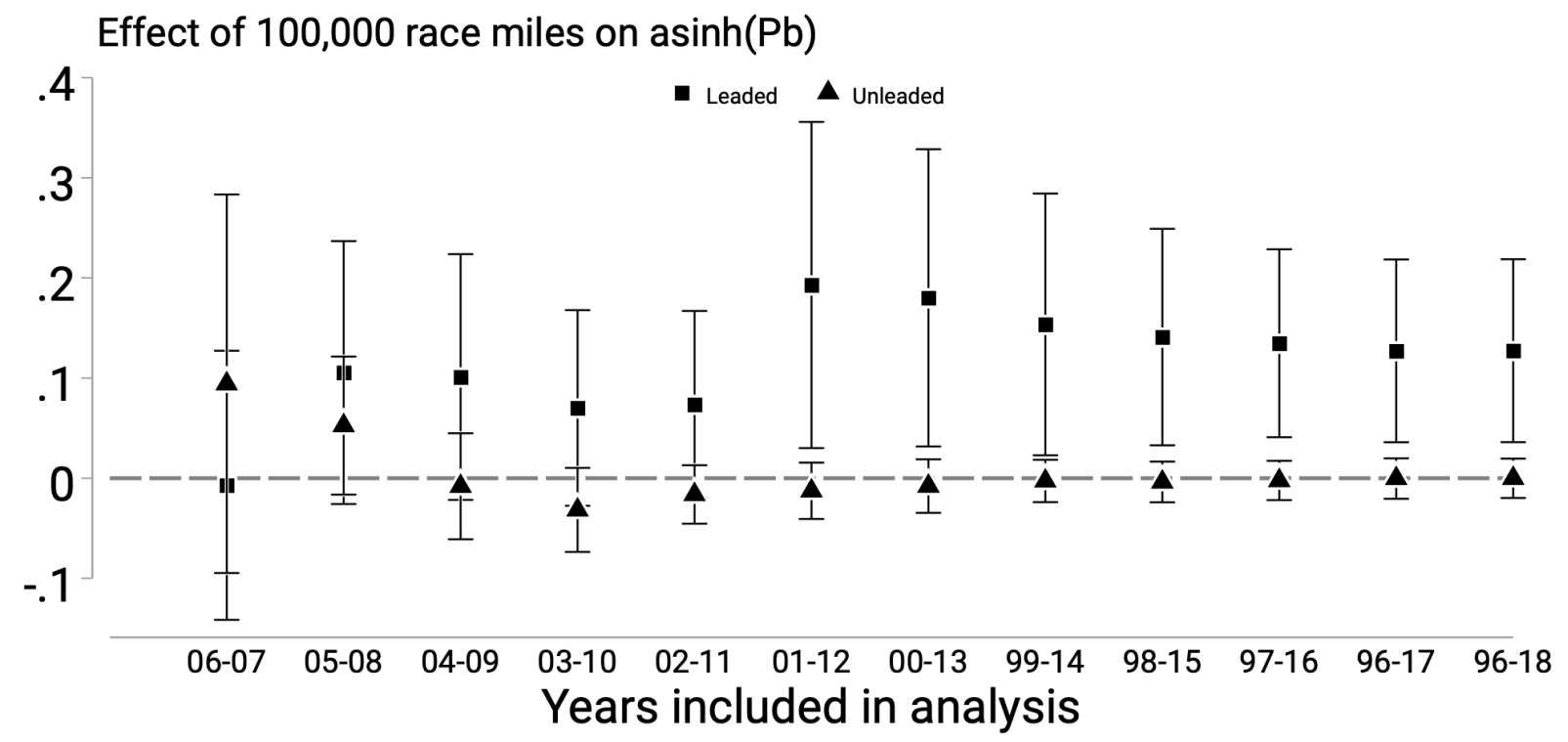

Note: This figure plots estimates corresponding to column 7 of Table 1 when varying the panel length. The top panel shows estimates when expanding the panel back to 1957, year by year. The bottom panel shows estimates when expanding the panel from just 2006-2007 to our full sample from 1996-2018. Each regression controls for week-by-year fixed effects, monitor-by-year fixed effects, and daily monitor-specific weather controls. The dependent variable is $\operatorname{asinh}(\mathrm{Pb})$. Only race miles within 50 miles in the past week are included. 
Figure A11: Raw data from three monitors around Bristol Motor Speedway for ambient lead concentration regressions.

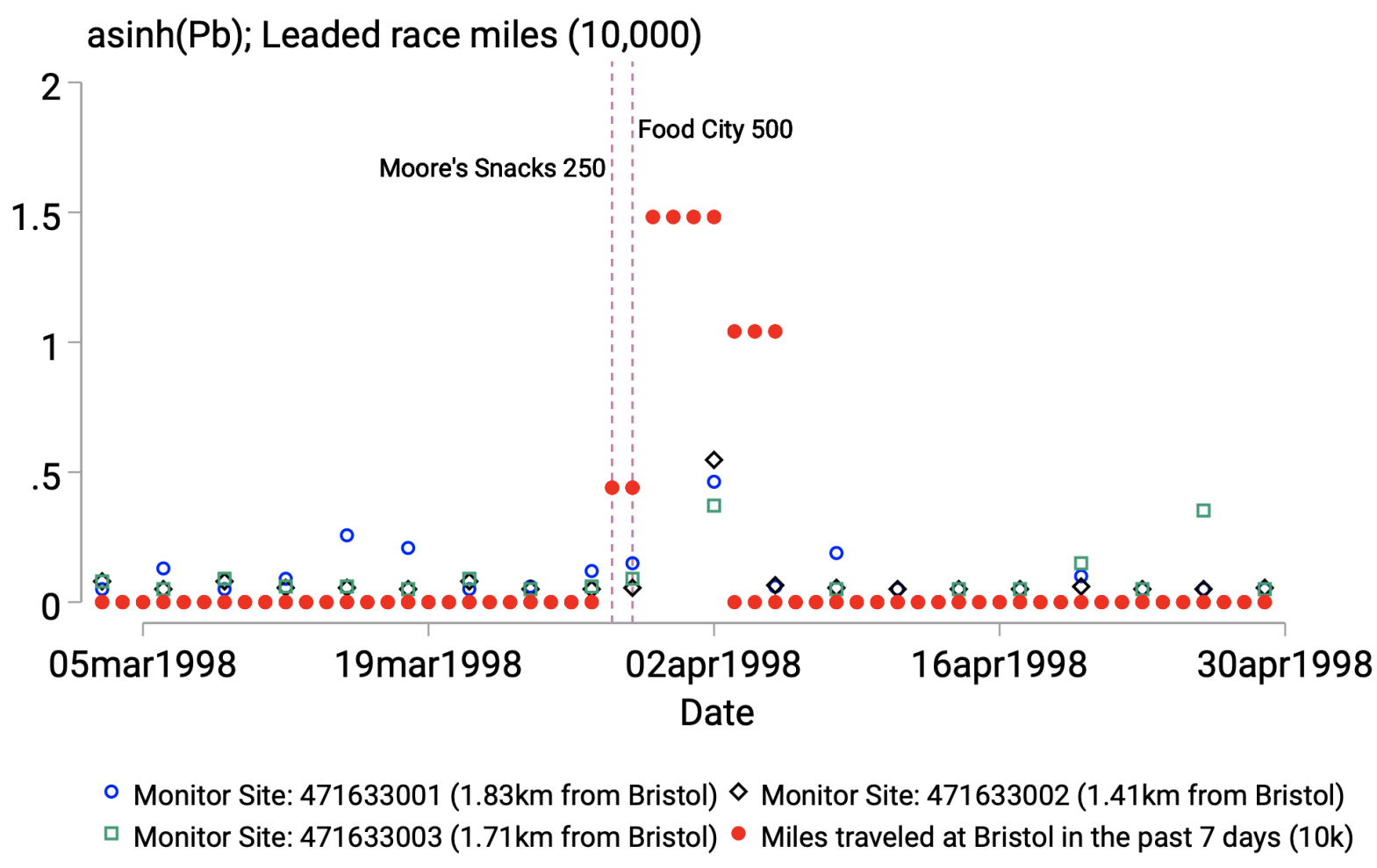

Note: The red markers are our variable of interest in equation (1), the number of leaded race miles in the past week within 50 miles. The hollow markers are the inverse hyperbolic sine lead readings at 3 nearby monitors. 


\section{A.7 Blood lead}

\section{A.7.1 Difference-in-differences}

Table A8 reports results from difference-in-differences regressions estimating the relative effect of having leaded races in a county or in a bordering county. Column 1 reports estimates only including county and year fixed effects, column 2 adds in the set of controls, column 3 adds in state-specific linear time trends, column 4 replaces the linear trends with stateby-year effects. The next four columns repeat the first four but use leaded miles instead of dummy variables. Column 9 is the same as column 4 but where the the indicator variable is now a continuous measure of the number of races. Columns 10 and 11 cluster standard errors at the state level and using the Conley approach with a 150 mile distance cutoff from the county centroid. The estimated effects are robust across all specifications, however estimates for the effect in per-mile terms are noisy.

\section{A.7.2 Untransformed outcome variable}

Figure A12 plots estimates corresponding to the same regression as the one used for Figure 5 but where the outcome variable is the untransformed percent of children tested with elevated blood lead. Estimates for race counties are similar to our main results with the inverse hyperbolic sine transformation.

\section{A.7.3 Targeted testing in high risk areas}

The data we use for the blood lead analysis comes from monitoring efforts that are targeted at high risk areas in ways we do not observe. This may confound our analysis in two ways. The first is if the the number of children tested in a county is changing differentially across county types. For example, if a county added more children to the testing pool, it may be because of a newly discovered lead hot spot, or additional funding which allows for testing in more marginal areas. Both of these effects would bias estimates but in opposite directions. The second way is if the targeting scheme within counties were changed differentially over time even though the number of children tested is constant. For example, if race counties spuriously changed their blood lead sampling population to even higher risk areas once NASCAR and ARCA deleaded, then our results would be biased toward zero.

To test whether these phenomena are occurring, we first estimate an unweighted version of equation (2) with the inverse hyperbolic sine of the number of children tested as the dependent variable. ${ }^{33}$ The estimates for the event study are shown in Figure A13. There is

\footnotetext{
${ }^{33}$ It is unweighted since the weights we previously used were the number of children tested.
} 
no clear differential trend across county types in the number of children tested except for a slightly increasing, but small, pre-trend in border counties. This suggests that differential changes in the number of children tested is not a concern for identification.

Differential trends in targeting schemes within counties is more difficult to directly test. Figure 5 provides supporting evidence in a similar way to pre-trends tests. Given that the number of children tested does not exhibit differential trends, if targeting is changing differentially in the post-period (which comprises most of our panel), we would expect EBLL rates to show differential trends across county types in the post-period. This is not the case. The trends are flat, providing supporting evidence that differential changes in targeting is not occurring.

Table A8: Effect of races and race miles on EBLL rates.

\begin{tabular}{|c|c|c|c|c|c|c|c|c|c|c|c|}
\hline & (1) & (2) & (3) & (4) & (5) & (6) & (7) & (8) & (9) & (10) & (11) \\
\hline 1(Leaded Race in County) & $\begin{array}{c}0.22^{* *} \\
(0.10)\end{array}$ & $\begin{array}{c}0.21^{* *} \\
(0.10)\end{array}$ & $\begin{array}{c}0.21^{* *} \\
(0.09)\end{array}$ & $\begin{array}{l}0.16^{* * *} \\
(0.06)\end{array}$ & & & & & & $\begin{array}{c}0.16^{* *} \\
(0.06)\end{array}$ & $\begin{array}{l}0.16^{* * *} \\
(0.05)\end{array}$ \\
\hline 1(Leaded Race in Border County) & $\begin{array}{c}0.09^{*} \\
(0.05)\end{array}$ & $\begin{array}{c}0.08^{*} \\
(0.05)\end{array}$ & $\begin{array}{c}0.07^{*} \\
(0.04)\end{array}$ & $\begin{array}{c}0.05 \\
(0.04)\end{array}$ & & & & & & $\begin{array}{c}0.05 \\
(0.05)\end{array}$ & $\begin{array}{c}0.05 \\
(0.04)\end{array}$ \\
\hline Leaded Miles in County (100k) & & & & & $\begin{array}{c}0.50 \\
(0.38)\end{array}$ & $\begin{array}{c}0.49 \\
(0.38)\end{array}$ & $\begin{array}{c}0.53^{*} \\
(0.32)\end{array}$ & $\begin{array}{c}0.23 \\
(0.16)\end{array}$ & & & \\
\hline Leaded Miles in Border County (100k) & & & & & $\begin{array}{c}0.15 \\
(0.13)\end{array}$ & $\begin{array}{c}0.12 \\
(0.12)\end{array}$ & $\begin{array}{c}0.14 \\
(0.10)\end{array}$ & $\begin{array}{c}0.04 \\
(0.07)\end{array}$ & & & \\
\hline Leaded Races in County & & & & & & & & & $\begin{array}{c}0.04^{*} \\
(0.02)\end{array}$ & & \\
\hline Leaded Races in Border County & & & & & & & & & $\begin{array}{c}0.01 * \\
(0.01)\end{array}$ & & \\
\hline County FE & Yes & Yes & Yes & Yes & Yes & Yes & Yes & Yes & Yes & Yes & Yes \\
\hline Year FE & Yes & Yes & Yes & No & Yes & Yes & Yes & No & No & No & No \\
\hline State-Specific Linear Time Trends & No & No & Yes & No & No & No & Yes & No & No & No & No \\
\hline State-by-Year FE & No & No & No & Yes & No & No & No & Yes & Yes & Yes & Yes \\
\hline Controls & No & Yes & Yes & Yes & No & Yes & Yes & Yes & Yes & Yes & Yes \\
\hline Clustered Standard Errors & County & County & County & County & County & County & County & County & County & State & Conley (150 miles) \\
\hline Observations & 22832 & 22832 & 22832 & 22831 & 22832 & 22832 & 22832 & 22831 & 22831 & 22831 & 22831 \\
\hline
\end{tabular}




\section{A.8 Mortality}

\section{A.8.1 Causes of death}

In our mortality analysis we aggregate causes of death into six categories: cardiovascular, ischemic heart disease, respiratory, diabetes, deaths of despair, and all-cause. We categorize each death using the primary cause of death reported on the death certificate and the CDC 113 cause of death recode. Each CDC 113 cause recode is an aggregate of ICD-10 causes of death. For each cause of death we use in the paper, we list below the category, the set of CDC 113 recodes composing the category, the associated ICD-10 codes for the category, and one example cause of death included in the category. For deaths of despair, we use a set of ICD-10 codes reported in Case and Deaton (2015) and thus do not report a 113 recode.

- Cardiovascular: CDC 113: 53-75; ICD-10: I00-I78; Hypertensive heart and renal disease

- Ischemic heart disease: CDC 113: 58-63; ICD-10: I20-I25; Acute myocardial infarction

- Respiratory: CDC 113: 76-89; ICD-10: J10-J18, J20-J22,J40-J47, J60-J66, J68, J69, J00-J06, J30-J39, J67, J70-J98; Acute bronchitis

- Diabetes: CDC 113: 46 ; ICD-10: E10-E14; Diabetes mellitus

- Deaths of despair (drugs, suicide, liver), as defined in Case and Deaton (2015):

- ICD-10 X40-X45; Accidental poisoning by and exposure to narcotics and psychodysleptics [hallucinogens], not elsewhere classified

- ICD10 Y10-Y15; Poisoning by and exposure to nonopioid analgesics, antipyretics and antirheumatics, undetermined intent

- ICD10 Y45, Y47, Y49; Adverse effects in therapeutic use: analgesics, antipyretics and anti-inflammatory drugs

- ICD10 X60-84, Y87.0; Intentional self-harm

- ICD10 K70, K73, K74; Alcoholic liver disease

- All-cause: All codes and causes.

\section{A.8.2 Raw data}

Figure A14 plots the data for cardiovascular, IHD, respiratory, and deaths of despair mortality. Cardiovascular mortality rates show a similar pattern to all-cause mortality rates. 
IHD and respiratory mortality rates were generally higher in race counties relative to control counties prior to deleading, but then were about the same or lower afterwards. Deaths of despair mortality rates are decreasing everywhere prior to about 2009 before starting to increase. Prior to 2007, deaths of despair mortality rates were higher in race counties than border counties, and higher in border counties than control counties. Beginning in 2007 mortality rates across the three types of counties are similar.

\section{A.8.3 Difference-in-differences}

Tables A10-A13 display estimates for our alternative specifications for the mortality results. The specifications for the mortality tables are the same as the blood lead specifications in Table A8. Results are consistent with estimates in the main text and robust to different choices of fixed effects, treatment variables, and clustering.

\section{A.8.4 Mortality analysis using publicly available data}

Figure A15 reports results from the same analysis as reported in Figure 7, but using publicly available data instead of restricted access data. The publicly available data are provided by CDC Wonder and report the all-cause age-standardized mortality rate for those age 65 and above in each county-year. These data differ from the restricted access data in that they suppress death rates from any county-year that contain fewer than ten deaths. Over $98 \%$ of all county-year observations are included in the public data, accounting for over $99.5 \%$ of all deaths. Results are similar when using this alternative dataset.

\section{A.8.5 Elderly mortality placebo}

Figure A16 displays event study estimates for our placebo cause of death: diabetes. We find little evidence of placebo effects. There is no trend over the full time-frame, nor any clear change in 2007.

\section{A.8.6 Split-sample instrumental variables}

Here we perform a split-sample IV similar to our mortality regressions to identify the effect of changes in ambient lead on mortality. Recognizing the fact that lead concentrations spike only temporarily after a race, we do the following for the first stage. At the county-year level, we estimate the effect of leaded races on ambient lead averaged across all weeks immediately following a race. Our first stage regression is

$\mathrm{Pb}$ in week after races $s c y=\beta_{l} 1$ (leaded race) $)_{s c y}+\gamma \mathbf{X}_{s c y}+\Theta_{c}+\Omega_{s y}+\varepsilon_{s c y}$. 
1 (leaded race) $)_{s c y}$ is an indicator variable equal to 1 if county $c$ in state $s$ had a leaded race in year $y$. The remaining variables are identical to the mortality regressions. For counties with lead monitors and racetracks, $\mathrm{Pb}$ in week after races $_{s c y}$ is the average across the lead concentrations in the 7 days immediately following races in county $c$ in year $y$. As stated above, we take this approach because Figure 3 indicates that lead concentrations spike in the first week after a race before declining back to baseline levels. Races also occur at the same time each year (e.g. the Daytona 500 is always in mid-February), so there are generally no changes in the season of when these lead readings occur. For counties with lead monitors but without racetracks (i.e. our control counties), $\mathrm{Pb}_{\text {scy }}$ is the average lead concentration in these counties in weeks of the year that immediately followed races other counties. In other words, we average across all lead readings in control county $c$ when 1 (leaded race in past week) sdy for any $d \neq c$. This lets us compare concentrations in race counties versus control counties on the same days of the year.

Our second stage regression is then

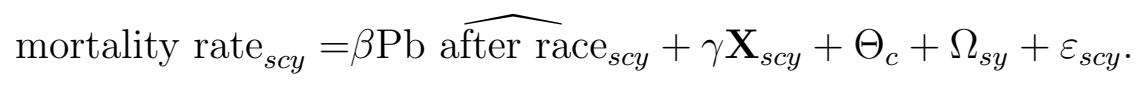

where $\mathrm{Pb}$ after race $_{\text {scy }}$ is the first stage prediction. We calculate non-parametric confidence intervals and p-values using a bootstrap procedure. We generate 500 randomly drawn bootstrap samples and estimate the model on each sample. The $95 \%$ confidence interval is the $2.5^{\text {th }}$ and $97.5^{\text {th }}$ percentiles from the distribution of bootstrap sample estimates. Because of this, the confidence interval may not be symmetric about the point estimate. The p-value is the percent of times a bootstrap sample estimate is larger in absolute value than the absolute value of our point estimate.

Results are reported in Panel A of Table A15. The instrument is well powered and operates in the expected direction with a Kleibergen-Paap F-stat of 14.76 and a first stage coefficient of .04 $(s e=.01, p<.01)$. After using the inverse hyperbolic sine elasticity formula, the estimates show a 1 percent increase in the ambient lead level increases elderly mortality by roughly $9 \%$, with about $50 \%$ of these deaths coming from Ischemic Heart Disease (IHD).

We obtain a nearly identical result when we use the untransformed lead level as our endogenous predictor instead of the $\operatorname{asinh}(\mathrm{Pb})$. This is displayed in column 7 of table A15. We find no statistically significant effect on deaths of despair or diabetes outcomes.

In addition to the split sample IV strategy, we also consider a more traditional instrumental variable strategy. Where we only use the subset of observations that have data on pollution, race miles, and mortality. This is the same subset of observations that is used to construct the first stage for results in panel A. Despite this analysis only having $3 \%$ of 
the observations as the split-sample analysis, we find consistent, albeit less precise, point estimates.

\section{A.8.7 Infant mortality event studies}

Figures A17 and A18 display event studies for infant mortality. We find no effect for our outcomes of interest or the placebos in either race counties or border counties. 
Figure A12: The effect of leaded races on the percent of children with elevated blood lead levels in race and border counties.

\section{Effect of a race on EBLL (\%)}
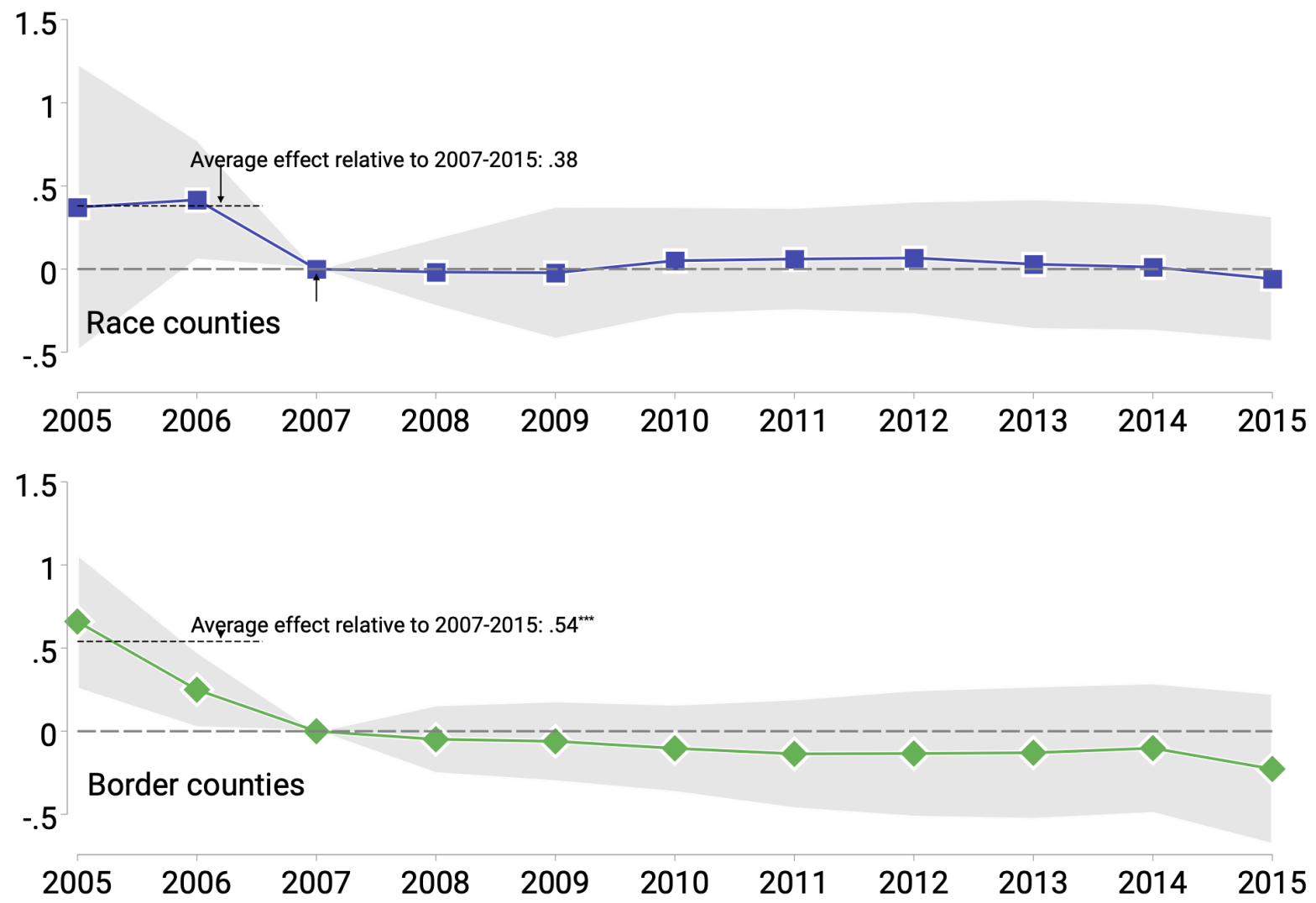

Note: The outcome variable is the untransformed percent of children tested with elevated blood lead. The top panel reports coefficients (blue squares) for children living in race counties. The bottom panel reports coefficients (green diamonds) for children living in border counties. Each coefficient represents the effect of being in a particular county type relative to 2007, which is omitted. The regression includes state-by-year fixed effects, county fixed effects, and controls for the unemployment rate, median income, $\%$ non-white, tons of lead emitted from TRI facilities, and total manufacturing payroll. All coefficients come from the same regression. The regression is weighted by the square root of the number of children tested. The shaded gray areas denote the $95 \%$ confidence interval calculated from robust standard errors clustered at the county level. The dashed line is the average effect from our preferred difference-in-differences regression, where the race county treated group consists of those counties that had at least one leaded race prior to 2007, and the border county treated group consists of those counties that did not have a leaded race but bordered a county with a leaded race prior to 2007. This regression defines the post-period as 2007 and after. 
Figure A13: The association between the inverse hyperbolic sine of the number of children tested for elevated blood lead and county type.

asinh(\# children tested) relative to control counties
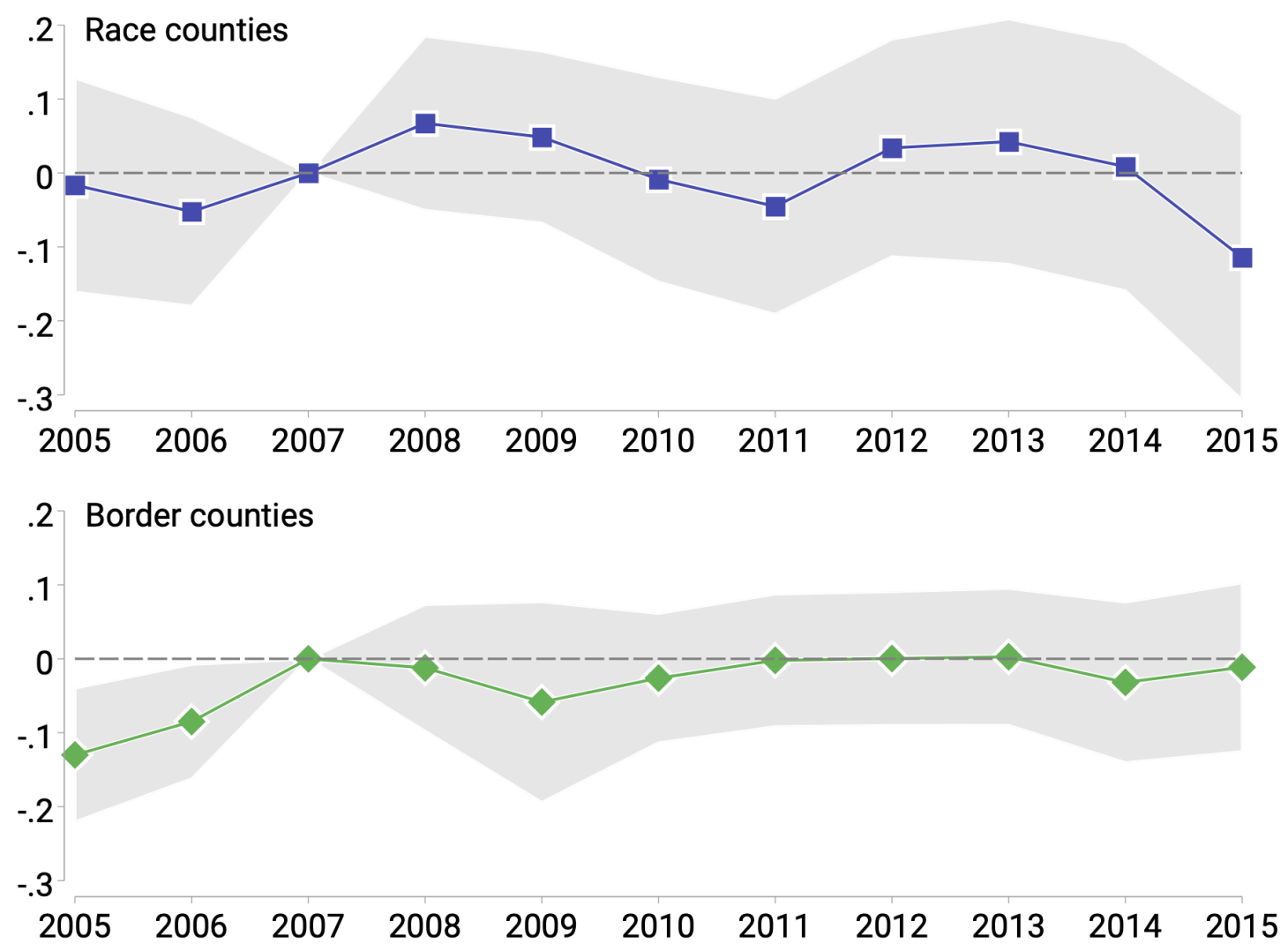

Note: The top panel reports coefficients (blue squares) for children living in race counties. The bottom panel reports coefficients (green diamonds) for children living in border counties. Each coefficient represents the effect of being in a particular county type relative to 2007, which is omitted. The regression includes state-by-year fixed effects, county fixed effects, and controls for the unemployment rate, median income, $\%$ non-white, tons of lead emitted from TRI facilities, and total manufacturing payroll. All coefficients come from the same regression. The shaded gray areas denote the $95 \%$ confidence interval calculated from robust standard errors clustered at the county level. 
Figure A14: Mean elderly mortality rates by cause of death, year, and county type.

A.

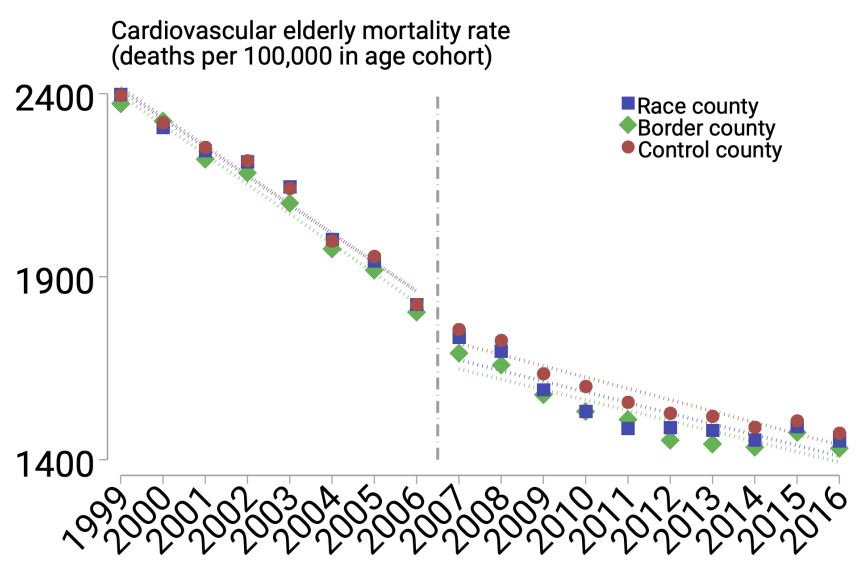

C.

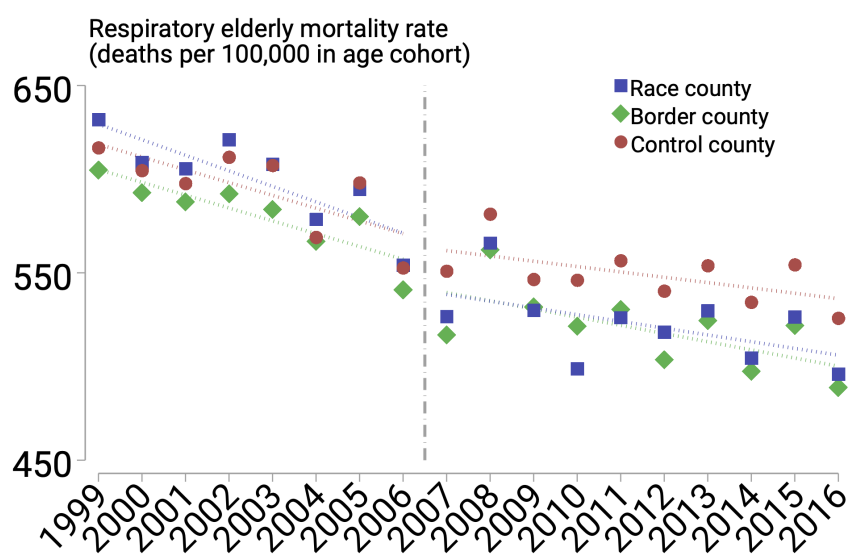

B.

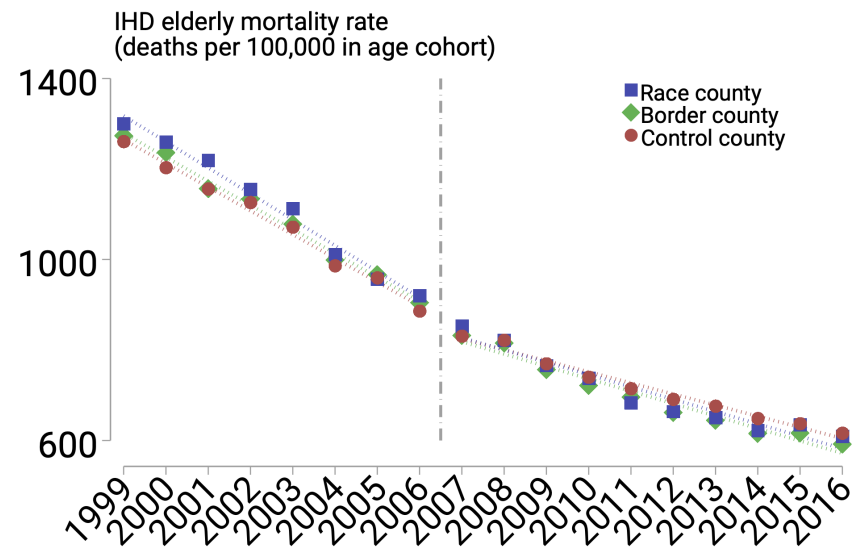

D.

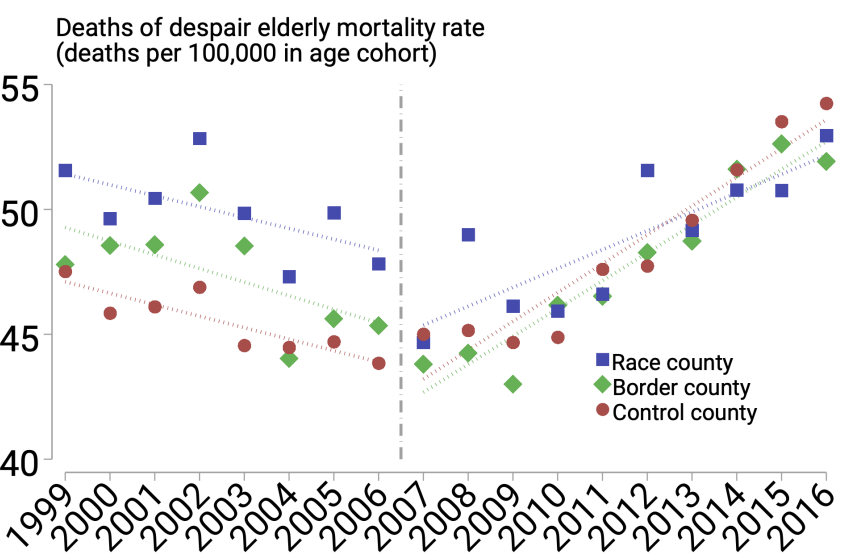

Note: Each panel presents the mean age-standardized elderly death rate by county type weighted by the square root of elderly population for each cause of death. The elderly population of the entire U.S. in the year 2000 was used as the reference population for standardization. Panel A shows cardiovascular death rate, panel B the death rate from ischemic heart disease (IHD), panel C shows the respiratory mortality death rate, and panel D shows the deaths of despair death rate. Exact ICD-10 codes for each of these causes of death are reported in Section A.8.1. County type refers to if there was a NASCAR or ARCA race in that county (blue squares) or in a border county (green diamond) in that year. All other counties are considered control counties (red circle). For this figure and in our regression estimates we use a balanced panel of counties. 
Table A9: Effect of races and race miles on all-cause elderly mortality rates.

\begin{tabular}{|c|c|c|c|c|c|c|c|c|c|c|c|}
\hline & (1) & $(2)$ & (3) & (4) & (5) & (6) & (7) & $(8)$ & $(9)$ & (10) & (11) \\
\hline 1(Leaded Race in County) & $\begin{array}{l}122.4^{* * *} \\
(30.5)\end{array}$ & $\begin{array}{l}103.8^{* * * *} \\
(27.6)\end{array}$ & $\begin{array}{l}98.8^{* * * *} \\
(28.1)\end{array}$ & $\begin{array}{l}91.2^{* * *} \\
(28.9)\end{array}$ & & & & & & $\begin{array}{l}91.2^{\text {**** }} \\
(27.3)\end{array}$ & $\begin{array}{l}91.2^{* * *} \\
(28.1)\end{array}$ \\
\hline 1(Leaded Race in Border County) & $\begin{array}{l}69.3^{* * *} \\
(17.1)\end{array}$ & $\begin{array}{l}56.4^{* * *} \\
(16.1)\end{array}$ & $\begin{array}{l}42.1^{* *} \\
(17.0)\end{array}$ & $\begin{array}{l}37.8^{* *} \\
(18.0)\end{array}$ & & & & & & $\begin{array}{c}37.8^{*} \\
(21.0)\end{array}$ & $\begin{array}{l}37.8^{* *} \\
(18.2)\end{array}$ \\
\hline Leaded Miles in County (100k) & & & & & $\begin{array}{l}279.9^{* * * *} \\
(100.5)\end{array}$ & $\begin{array}{l}224.4^{* *} \\
(96.7)\end{array}$ & $\begin{array}{c}184.7^{*} \\
(103.2)\end{array}$ & $\begin{array}{c}161.1 \\
(103.3)\end{array}$ & & & \\
\hline Leaded Miles in Border County (100k) & & & & & $\begin{array}{l}176.8^{* * *} \\
(42.4)\end{array}$ & $\begin{array}{l}137.9^{* * *} \\
(40.0)\end{array}$ & $\begin{array}{c}70.2 \\
(42.8)\end{array}$ & $\begin{array}{c}54.2 \\
(44.5)\end{array}$ & & & \\
\hline Leaded Races in County & & & & & & & & & $\begin{array}{l}21.4^{* *} \\
(9.1)\end{array}$ & & \\
\hline Leaded Races in Border County & & & & & & & & & $\begin{array}{c}6.5^{*} \\
(3.9)\end{array}$ & & \\
\hline County FE & Yes & Yes & Yes & Yes & Yes & Yes & Yes & Yes & Yes & Yes & Yes \\
\hline Year FE & Yes & Yes & Yes & No & Yes & Yes & Yes & No & No & No & No \\
\hline State-Specific Linear Time Trends & No & No & Yes & No & No & No & Yes & No & No & No & No \\
\hline State-by-Year FE & No & No & No & Yes & No & No & No & Yes & Yes & Yes & Yes \\
\hline Controls & No & Yes & Yes & Yes & No & Yes & Yes & Yes & Yes & Yes & Yes \\
\hline Clustered Standard Errors & County & County & County & County & County & County & County & County & County & State & Conley (150 miles) \\
\hline Observations & 58063 & 56202 & 56202 & 56184 & 58063 & 56202 & 56202 & 56184 & 56184 & 56184 & 56184 \\
\hline
\end{tabular}

Note: $* \mathrm{p}<0.1,{ }^{* *} \mathrm{p}<0.05, * * * \mathrm{p}<0.01$. Columns 1-4: Estimated effects of having a NASCAR or ARCA race in county, or in a bordering county, on the elderly all-cause mortality rate. Columns 5-8: Estimated effects of 100,000 leaded race miles in county, or in a bordering county, on the elderly all-cause mortality rate. Column 9: Same as column 4 but where the indicator for having a race is replaced with a continuous measure of the number of races. Columns 10-11: same as column 4 but with state clusters or Conley standard errors. Robust standard errors clustered at the county level in parentheses for columns 1-9. Weights are given by the square root of the elderly population.

Table A10: Effect of races and race miles on elderly cardiovascular mortality rates.

\begin{tabular}{|c|c|c|c|c|c|c|c|c|c|c|c|}
\hline & (1) & (2) & (3) & (4) & (5) & (6) & (7) & (8) & (9) & (10) & (11) \\
\hline 1(Leaded Race in County) & $\begin{array}{c}30.7^{* * *} \\
(14.8)\end{array}$ & $\begin{array}{c}25.6^{*} \\
(14.1)\end{array}$ & $\begin{array}{l}41.6^{\text {*** }} \\
(15.0)\end{array}$ & $\begin{array}{c}36.7^{* *} \\
(15.4)\end{array}$ & & & & & & $\begin{array}{c}36.7^{* *} \\
(14.5)\end{array}$ & $\begin{array}{c}36.7^{* *} \\
(15.1)\end{array}$ \\
\hline 1(Leaded Race in Border County) & $\begin{array}{l}22.3^{* *} \\
(10.5)\end{array}$ & $\begin{array}{c}18.2^{*} \\
(10.4)\end{array}$ & $\begin{array}{l}14.1 \\
(9.9)\end{array}$ & $\begin{array}{c}12.5 \\
(10.5)\end{array}$ & & & & & & $\begin{array}{c}12.5 \\
(11.0)\end{array}$ & $\begin{array}{c}12.5 \\
(10.4)\end{array}$ \\
\hline Leaded Miles in County (100k) & & & & & $\begin{array}{c}73.4 \\
(47.7)\end{array}$ & $\begin{array}{c}63.2 \\
(44.5)\end{array}$ & $\begin{array}{c}93.1^{* *} \\
(45.5)\end{array}$ & $\begin{array}{c}76.7^{*} \\
(46.1)\end{array}$ & & & \\
\hline Leaded Miles in Border County (100k) & & & & & $\begin{array}{l}62.1^{* *} \\
(24.2)\end{array}$ & $\begin{array}{l}48.4^{* *} \\
(24.2)\end{array}$ & $\begin{array}{c}38.4^{*} \\
(23.0)\end{array}$ & $\begin{array}{c}28.8 \\
(24.2)\end{array}$ & & & \\
\hline Leaded Races in County & & & & & & & & & $\begin{array}{l}10.3^{* *} \\
(4.3)\end{array}$ & & \\
\hline Leaded Races in Border County & & & & & & & & & $\begin{array}{c}2.5 \\
(2.2)\end{array}$ & & \\
\hline County FE & Yes & Yes & Yes & Yes & Yes & Yes & Yes & Yes & Yes & Yes & Yes \\
\hline Year FE & Yes & Yes & Yes & No & Yes & Yes & Yes & No & No & No & No \\
\hline State-Specific Linear Time Trends & No & No & Yes & No & No & No & Yes & No & No & No & No \\
\hline State-by-Year FE & No & No & No & Yes & No & No & No & Yes & Yes & Yes & Yes \\
\hline Controls & No & Yes & Yes & Yes & No & Yes & Yes & Yes & Yes & Yes & Yes \\
\hline Clustered Standard Errors & County & County & County & County & County & County & County & County & County & State & Conley (150 miles) \\
\hline Observations & 58063 & 56202 & 56202 & 56184 & 58063 & 56202 & 56202 & 56184 & 56184 & 56184 & 56184 \\
\hline
\end{tabular}

Note: $* \mathrm{p}<0.1,{ }^{* *} \mathrm{p}<0.05,{ }^{* * *} \mathrm{p}<0.01$. Columns 1-4: Estimated effects of having a NASCAR or ARCA race in county, or in a bordering county, on the elderly cardiovascular mortality rate. Columns 5-8: Estimated effects of 100,000 leaded race miles in county, or in a bordering county, on the elderly cardiovascular mortality rate. Column 9: Same as column 4 but where the indicator for having a race is replaced with a continuous measure of the number of races. Columns 10-11: same as column 4 but with state clusters or Conley standard errors. Robust standard errors clustered at the county level in parentheses for columns 1-9. Weights are given by the square root of the elderly population. 
Table A11: Effect of races and race miles on ischemic heart disease elderly mortality rates.

\begin{tabular}{|c|c|c|c|c|c|c|c|c|c|c|c|}
\hline & (1) & $(2)$ & (3) & (4) & (5) & (6) & (7) & $(8)$ & $(9)$ & (10) & (11) \\
\hline 1(Leaded Race in County) & $\begin{array}{l}48.5^{* *} \\
(23.3)\end{array}$ & $\begin{array}{c}41.9^{*} \\
(23.5)\end{array}$ & $\begin{array}{l}55.0^{* *} \\
(21.3)\end{array}$ & $\begin{array}{l}53.6^{* *} \\
(21.7)\end{array}$ & & & & & & $\begin{array}{l}53.6^{* * * *} \\
(18.9)\end{array}$ & $\begin{array}{l}53.6^{* *} \\
(20.8)\end{array}$ \\
\hline 1(Leaded Race in Border County) & $\begin{array}{l}33.5^{* * * *} \\
(10.6)\end{array}$ & $\begin{array}{l}28.7^{* * *} \\
(10.2)\end{array}$ & $\begin{array}{l}19.6^{* *} \\
(8.9)\end{array}$ & $\begin{array}{l}19.8^{* *} \\
(9.2)\end{array}$ & & & & & & $\begin{array}{c}19.8^{*} \\
(11.1)\end{array}$ & $\begin{array}{l}19.8^{* *} \\
(8.8)\end{array}$ \\
\hline Leaded Miles in County (100k) & & & & & $\begin{array}{l}114.1^{*} \\
(66.7)\end{array}$ & $\begin{array}{c}99.3 \\
(66.0)\end{array}$ & $\begin{array}{l}134.8^{* *} \\
(59.0)\end{array}$ & $\begin{array}{l}129.8^{* *} \\
(60.1)\end{array}$ & & & \\
\hline Leaded Miles in Border County (100k) & & & & & $\begin{array}{l}94.3^{* * *} \\
(25.1)\end{array}$ & $\begin{array}{l}82.2^{\text {*** }} \\
(24.0)\end{array}$ & $\begin{array}{l}70.0^{* * *} \\
(19.5)\end{array}$ & $\begin{array}{l}67.9^{* * *} \\
(20.5)\end{array}$ & & & \\
\hline Leaded Races in County & & & & & & & & & $\begin{array}{l}15.0^{* * *} \\
(5.8)\end{array}$ & & \\
\hline Leaded Races in Border County & & & & & & & & & $\begin{array}{l}6.5^{* * *} \\
(2.0)\end{array}$ & & \\
\hline County FE & Yes & Yes & Yes & Yes & Yes & Yes & Yes & Yes & Yes & Yes & Yes \\
\hline Year FE & Yes & Yes & Yes & No & Yes & Yes & Yes & No & No & No & No \\
\hline State-Specific Linear Time Trends & No & No & Yes & No & No & No & Yes & No & No & No & No \\
\hline State-by-Year FE & No & No & No & Yes & No & No & No & Yes & Yes & Yes & Yes \\
\hline Controls & No & Yes & Yes & Yes & No & Yes & Yes & Yes & Yes & Yes & Yes \\
\hline Clustered Standard Errors & County & County & County & County & County & County & County & County & County & State & Conley (150 miles) \\
\hline Observations & 58063 & 56202 & 56202 & 56184 & 58063 & 56202 & 56202 & 56184 & 56184 & 56184 & 56184 \\
\hline
\end{tabular}

Note: $\quad * \mathrm{p}<0.1,{ }^{* *} \mathrm{p}<0.05, * * * \mathrm{p}<0.01$. Columns 1-4: Estimated effects of having a NASCAR or ARCA race in county, or in a bordering county, on the elderly ischemic heart disease mortality rate. Columns 5-8: Estimated effects of 100,000 leaded race miles in county, or in a bordering county, on the elderly ischemic heart disease mortality rate. Column 9: Same as column 4 but where the indicator for having a race is replaced with a continuous measure of the number of races. Columns 10-11: same as column 4 but with state clusters or Conley standard errors. Robust standard errors clustered at the county level in parentheses for columns 1-9. Weights are given by the square root of the elderly population.

Table A12: Effect of races and race miles on respiratory elderly mortality rates.

\begin{tabular}{|c|c|c|c|c|c|c|c|c|c|c|c|}
\hline & (1) & $(2)$ & (3) & (4) & (5) & (6) & (7) & $(8)$ & $(9)$ & (10) & (11) \\
\hline 1(Leaded Race in County) & $\begin{array}{l}34.0^{* * * *} \\
(10.2)\end{array}$ & $\begin{array}{l}27.9^{* * *} \\
(9.2)\end{array}$ & $\begin{array}{l}22.3^{* * * *} \\
(6.9)\end{array}$ & $\begin{array}{l}20.3^{* * *} \\
(7.0)\end{array}$ & & & & & & $\begin{array}{l}20.3^{* * *} \\
(6.4)\end{array}$ & $\begin{array}{l}20.3^{* * *} \\
(6.9)\end{array}$ \\
\hline 1(Leaded Race in Border County) & $\begin{array}{l}13.1^{\text {*** }} \\
(4.9)\end{array}$ & $\begin{array}{l}9.1^{* *} \\
(4.6)\end{array}$ & $\begin{array}{c}6.1 \\
(4.6)\end{array}$ & $\begin{array}{c}4.7 \\
(4.9)\end{array}$ & & & & & & $\begin{array}{c}4.7 \\
(7.2)\end{array}$ & $\begin{array}{c}4.7 \\
(5.1)\end{array}$ \\
\hline Leaded Miles in County (100k) & & & & & $\begin{array}{l}90.0^{* * *} \\
(31.9)\end{array}$ & $\begin{array}{l}72.9^{* *} \\
(29.8)\end{array}$ & $\begin{array}{l}50.5^{* *} \\
(25.5)\end{array}$ & $\begin{array}{c}43.6^{*} \\
(24.2)\end{array}$ & & & \\
\hline Leaded Miles in Border County (100k) & & & & & $\begin{array}{l}27.4^{* *} \\
(12.2)\end{array}$ & $\begin{array}{c}18.0 \\
(11.4)\end{array}$ & $\begin{array}{c}1.4 \\
(11.2)\end{array}$ & $\begin{array}{c}-2.0 \\
(11.8)\end{array}$ & & & \\
\hline Leaded Races in County & & & & & & & & & $\begin{array}{l}5.7^{\text {*** }} \\
(2.1)\end{array}$ & & \\
\hline Leaded Races in Border County & & & & & & & & & $\begin{array}{c}0.5 \\
(1.1)\end{array}$ & & \\
\hline County FE & Yes & Yes & Yes & Yes & Yes & Yes & Yes & Yes & Yes & Yes & Yes \\
\hline Year FE & Yes & Yes & Yes & No & Yes & Yes & Yes & No & No & No & No \\
\hline State-Specific Linear Time Trends & No & No & Yes & No & No & No & Yes & No & No & No & No \\
\hline State-by-Year FE & No & No & No & Yes & No & No & No & Yes & Yes & Yes & Yes \\
\hline Controls & No & Yes & Yes & Yes & No & Yes & Yes & Yes & Yes & Yes & Yes \\
\hline Clustered Standard Errors & County & County & County & County & County & County & County & County & County & State & Conley (150 miles) \\
\hline Observations & 58063 & 56202 & 56202 & 56184 & 58063 & 56202 & 56202 & 56184 & 56184 & 56184 & 56184 \\
\hline
\end{tabular}

Note: $* \mathrm{p}<0.1, * * \mathrm{p}<0.05, * * * \mathrm{p}<0.01$. Columns 1-4: Estimated effects of having a NASCAR or ARCA race in county, or in a bordering county, on the elderly respiratory mortality rates. Columns 5-8: Estimated effects of 100,000 leaded race miles in county, or in a bordering county, on the elderly respiratory mortality rate. Column 9: Same as column 4 but where the indicator for having a race is replaced with a continuous measure of the number of races. Columns 10-11: same as column 4 but with state clusters or Conley standard errors. Robust standard errors clustered at the county level in parentheses for columns 1-9. Weights are given by the square root of the elderly population. 
Table A13: Effect of races and race miles on deaths of despair elderly mortality rates.

\begin{tabular}{|c|c|c|c|c|c|c|c|c|c|c|c|}
\hline & (1) & (2) & $(3)$ & (4) & (5) & (6) & (7) & $(8)$ & (9) & (10) & (11) \\
\hline 1(Leaded Race in County) & $\begin{array}{l}4.1^{* * *} \\
(1.2)\end{array}$ & $\begin{array}{l}4.1^{* * *} \\
(1.3)\end{array}$ & $\begin{array}{l}4.6^{* * *} \\
(1.2)\end{array}$ & $\begin{array}{l}4.4^{* * *} \\
(1.3)\end{array}$ & & & & & & $\begin{array}{l}4.4^{* * *} \\
(1.5)\end{array}$ & $\begin{array}{l}4.4^{\text {*** }} \\
(1.2)\end{array}$ \\
\hline 1(Leaded Race in Border County) & $\begin{array}{l}1.6^{* *} \\
(0.7)\end{array}$ & $\begin{array}{l}1.6^{* *} \\
(0.7)\end{array}$ & $\begin{array}{l}1.6^{* *} \\
(0.7)\end{array}$ & $\begin{array}{l}1.6^{* *} \\
(0.7)\end{array}$ & & & & & & $\begin{array}{l}1.6^{* *} \\
(0.7)\end{array}$ & $\begin{array}{l}1.6^{* *} \\
(0.7)\end{array}$ \\
\hline Leaded Miles in County (100k) & & & & & $\begin{array}{l}7.6^{* *} \\
(3.3)\end{array}$ & $\begin{array}{c}6.7^{*} \\
(3.5)\end{array}$ & $\begin{array}{l}7.7^{* *} \\
(3.5)\end{array}$ & $\begin{array}{c}6.8^{*} \\
(3.5)\end{array}$ & & & \\
\hline Leaded Miles in Border County (100k) & & & & & $\begin{array}{c}3.2^{*} \\
(1.7)\end{array}$ & $\begin{array}{c}3.4^{* *} \\
(1.6)\end{array}$ & $\begin{array}{l}3.3^{* *} \\
(1.6)\end{array}$ & $\begin{array}{c}2.9^{*} \\
(1.6)\end{array}$ & & & \\
\hline Leaded Races in County & & & & & & & & & $\begin{array}{l}0.9^{* *} \\
(0.4)\end{array}$ & & \\
\hline Leaded Races in Border County & & & & & & & & & $\begin{array}{l}0.4^{* *} \\
(0.2)\end{array}$ & & \\
\hline County FE & Yes & Yes & Yes & Yes & Yes & Yes & Yes & Yes & Yes & Yes & Yes \\
\hline Year FE & Yes & Yes & Yes & No & Yes & Yes & Yes & No & No & No & No \\
\hline State-Specific Linear Time Trends & No & No & Yes & No & No & No & Yes & No & No & No & No \\
\hline State-by-Year FE & No & No & No & Yes & No & No & No & Yes & Yes & Yes & Yes \\
\hline Controls & No & Yes & Yes & Yes & No & Yes & Yes & Yes & Yes & Yes & Yes \\
\hline Clustered Standard Errors & County & County & County & County & County & County & County & County & County & State & Conley (150 miles) \\
\hline Observations & 58063 & 56202 & 56202 & 56184 & 58063 & 56202 & 56202 & 56184 & 56184 & 56184 & 56184 \\
\hline
\end{tabular}

Note: $\quad * \mathrm{p}<0.1,{ }^{* *} \mathrm{p}<0.05,{ }^{* * *} \mathrm{p}<0.01$. Columns 1-4: Estimated effects of having a NASCAR or ARCA race in county, or in a bordering county, on the elderly deaths of despair mortality rates Case and Deaton (2015). Columns 5-8: Estimated effects of 100,000 leaded race miles in county, or in a bordering county, on the elderly deaths of despair mortality rate. Column 9: Same as column 4 but where the indicator for having a race is replaced with a continuous measure of the number of races. Columns 10-11: same as column 4 but with state clusters or Conley standard errors. Robust standard errors clustered at the county level in parentheses for columns 1-9. Weights are given by the square root of the elderly population.

Table A14: Effect of races and race miles on diabetes elderly mortality rates.

\begin{tabular}{|c|c|c|c|c|c|c|c|c|c|c|c|}
\hline & (1) & $(2)$ & (3) & (4) & (5) & $(6)$ & (7) & $(8)$ & $(9)$ & (10) & (11) \\
\hline 1(Leaded Race in County) & $\begin{array}{l}-6.7 \\
(4.1)\end{array}$ & $\begin{array}{l}-4.0 \\
(4.1)\end{array}$ & $\begin{array}{c}-3.2 \\
(3.2)\end{array}$ & $\begin{array}{c}-2.7 \\
(3.3)\end{array}$ & & & & & & $\begin{array}{l}-2.7 \\
(3.4)\end{array}$ & $\begin{array}{c}-2.7 \\
(3.2)\end{array}$ \\
\hline 1(Leaded Race in Border County) & $\begin{array}{c}-1.3 \\
(2.2)\end{array}$ & $\begin{array}{c}-0.3 \\
(2.2)\end{array}$ & $\begin{array}{c}-0.9 \\
(2.0)\end{array}$ & $\begin{array}{c}-0.9 \\
(2.1)\end{array}$ & & & & & & $\begin{array}{c}-0.9 \\
(2.2)\end{array}$ & $\begin{array}{c}-0.9 \\
(2.1)\end{array}$ \\
\hline Leaded Miles in County (100k) & & & & & $\begin{array}{l}-21.3^{* *} \\
(10.1)\end{array}$ & $\begin{array}{c}-14.7 \\
(10.4)\end{array}$ & $\begin{array}{r}-12.3^{*} \\
(7.4)\end{array}$ & $\begin{array}{r}-10.9 \\
(7.9)\end{array}$ & & & \\
\hline Leaded Miles in Border County (100k) & & & & & $\begin{array}{c}0.2 \\
(5.0)\end{array}$ & $\begin{array}{c}3.5 \\
(4.9)\end{array}$ & $\begin{array}{c}0.4 \\
(4.7)\end{array}$ & $\begin{array}{c}-0.1 \\
(4.9)\end{array}$ & & & \\
\hline Leaded Races in County & & & & & & & & & $\begin{array}{c}-0.9 \\
(0.9)\end{array}$ & & \\
\hline Leaded Races in Border County & & & & & & & & & $\begin{array}{c}0.0 \\
(0.5)\end{array}$ & & \\
\hline County FE & Yes & Yes & Yes & Yes & Yes & Yes & Yes & Yes & Yes & Yes & Yes \\
\hline Year FE & Yes & Yes & Yes & No & Yes & Yes & Yes & No & No & No & No \\
\hline State-Specific Linear Time Trends & No & No & Yes & No & No & No & Yes & No & No & No & No \\
\hline State-by-Year FE & No & No & No & Yes & No & No & No & Yes & Yes & Yes & Yes \\
\hline Controls & No & Yes & Yes & Yes & No & Yes & Yes & Yes & Yes & Yes & Yes \\
\hline Clustered Standard Errors & County & County & County & County & County & County & County & County & County & State & Conley (150 miles) \\
\hline Observations & 58063 & 56202 & 56202 & 56184 & 58063 & 56202 & 56202 & 56184 & 56184 & 56184 & 56184 \\
\hline
\end{tabular}

Note: $* \mathrm{p}<0.1, * * \mathrm{p}<0.05, * * * \mathrm{p}<0.01$. Columns 1-4: Estimated effects of having a NASCAR or ARCA race in county, or in a bordering county, on the elderly diabetes mortality rates. Columns 5-8: Estimated effects of 100,000 leaded race miles in county, or in a bordering county, on the elderly diabetes mortality rate. Column 9: Same as column 4 but where the indicator for having a race is replaced with a continuous measure of the number of races. Columns 10-11: same as column 4 but with state clusters or Conley standard errors. Robust standard errors clustered at the county level in parentheses for columns 1-9. Weights are given by the square root of the elderly population. 
Figure A15: The effect of leaded races on all-cause elderly mortality rates in race and border counties using publicly available mortality data.
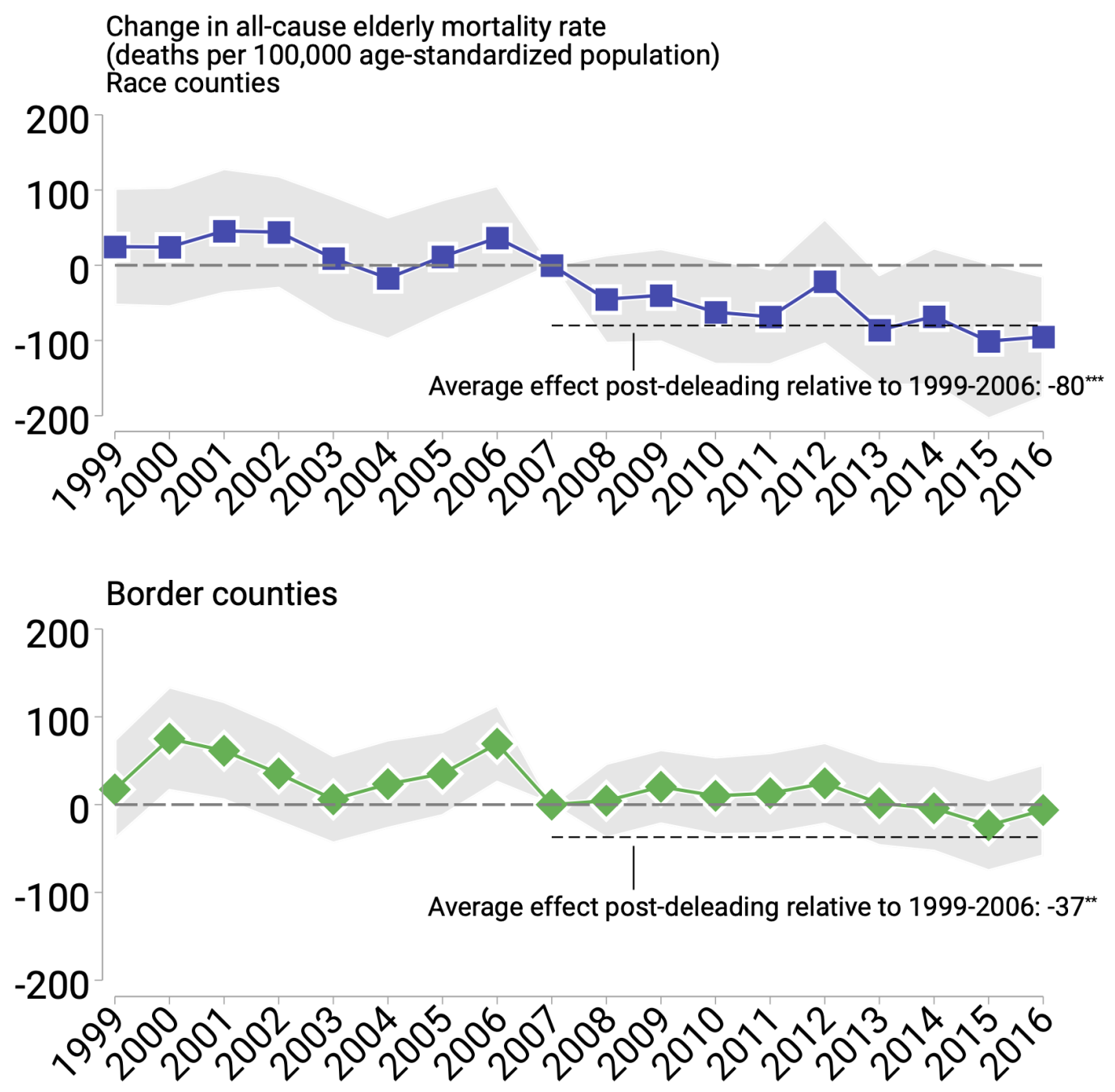

Note: These data use publicly available data obtained from CDC Wonder. These data differ from the restricted access data in that they suppress death rates from any county-year that contain fewer than ten deaths. The top panel reports coefficients (blue squares) for race counties, and the bottom panel reports coefficients (green diamonds) for border counties. Each coefficient represents the effect on the age-standardized, all-cause elderly morality rate from being in a particular county type relative to 2007, which is omitted. The regression includes state-by-year fixed effects, county fixed effects, and controls for the unemployment rate, median income, \% non-white, tons of lead emitted from TRI facilities, and total manufacturing payroll. All coefficients come from the same regression. The elderly population of the entire U.S. in the year 2000 was used as the reference population for age standardization. The regression is weighted by the square root of the elderly population. The shaded gray areas denote the $95 \%$ confidence interval calculated from robust standard errors clustered at the county level. The dashed line is the average effect of deleading from our preferred difference-in-differences regression, where the race county treated group consists of those counties that had at least one leaded race prior to 2007, and the border county treated group consists of those counties that did not have a leaded race but bordered a county with a leaded race prior to 2007. This regression defines the post-period as 2007 and after. 
Figure A16: The effect of leaded races on placebo elderly mortality rates in race and border counties.
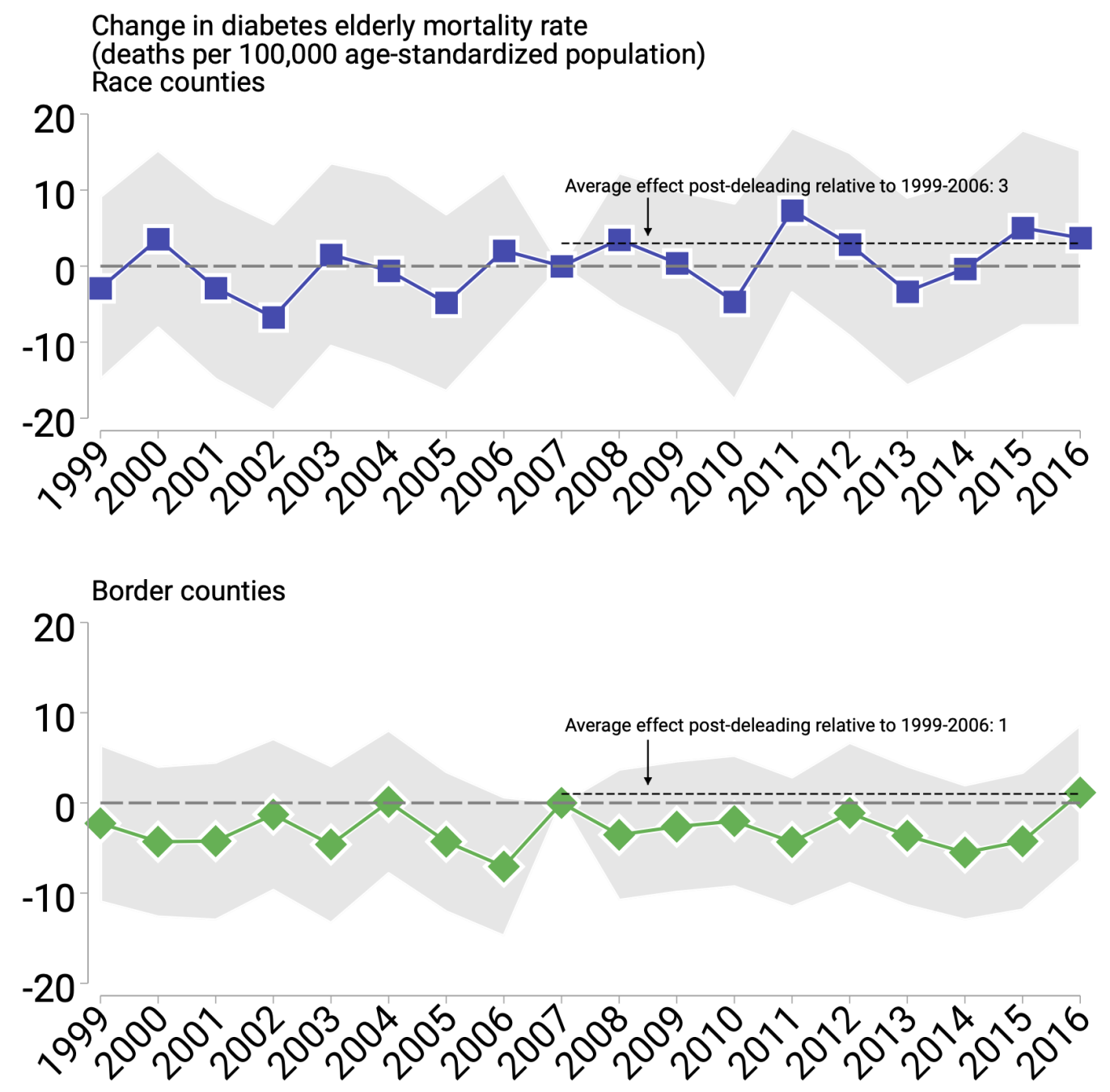

Note: The figure shows estimate for elderly diabetes mortality. The top panel reports coefficients (blue squares) for race counties, and the bottom panel reports coefficients (green diamonds) for border counties. Each coefficient represents the effect on the age-standardized, elderly morality rate for that cause of death from being in a particular county type relative to 2007, which is omitted. The regression includes state-byyear fixed effects, county fixed effects, and controls for the unemployment rate, median income, \% non-white, tons of lead emitted from TRI facilities, and total manufacturing payroll. All coefficients come from the same regression. The elderly population of the entire U.S. in the year 2000 was used as the reference population for age standardization. Each regression is weighted by the square root of the elderly population. The shaded gray areas denote the $95 \%$ confidence interval calculated from robust standard errors clustered at the county level. The dashed line is the average effect of deleading from our preferred difference-in-differences regression where, the race county treated group consists of those counties that had at least one leaded race prior to 2007, and the border county treated group consists of those counties that did not have a leaded race but bordered a county with a leaded race prior to 2007. This regression defines the post-period as 2007 and after. 
Figure A17: The effect of leaded races on infant mortality rates in race and border counties.

A. All-cause
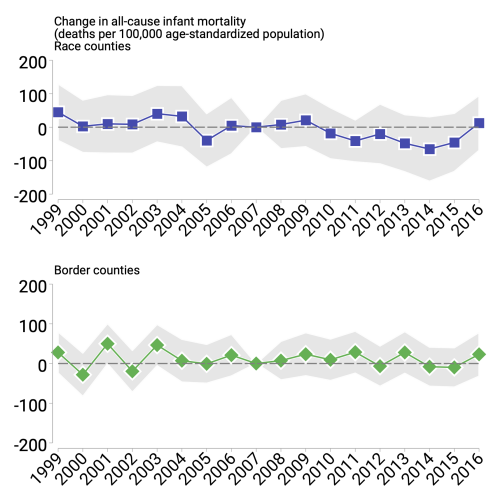

B. Cardiovascular
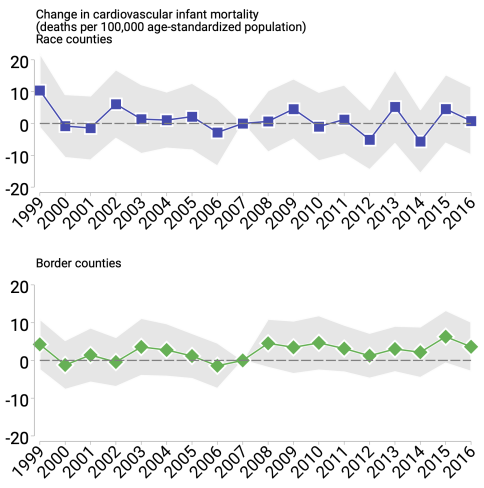

C. IHD
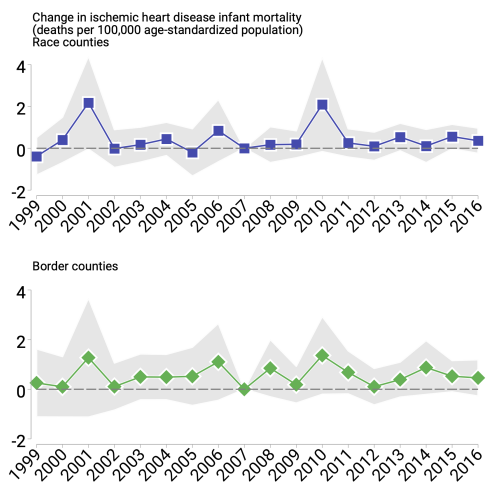

D. Respiratory
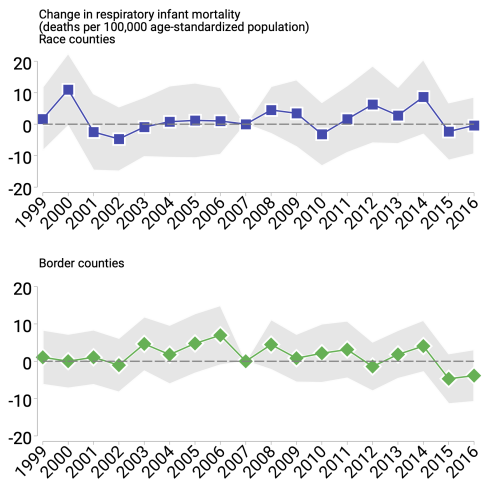

E. Deaths of despair

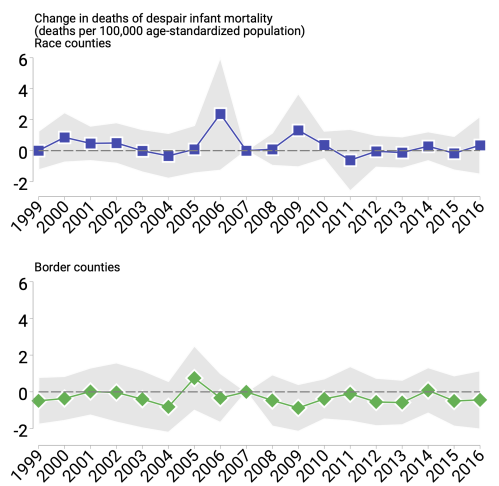

Note: Subfigure A shows estimate for infant all-cause mortality, Subfigure B shows estimates for infant cardiovascular mortality, Subfigure C shows estimates for infant ischemic heart disease (IHD) mortality, Subfigure D shows estimates for infant respiratory mortality, and Subfigure E shows estimates for infant deaths of despair mortality. The top panel of each subfigure reports coefficients (blue squares) for race counties, and the bottom panel reports coefficients (green diamonds) for border counties. Each coefficient represents the effect on the age-standardized, infant morality rate for that cause of death from being in a particular county type relative to 2007, which is omitted. The regression includes state-by-year fixed effects, county fixed effects, and controls for the unemployment rate, median income, $\%$ non-white, tons of lead emitted from TRI facilities, and total manufacturing payroll. All coefficients in each subfigure come from the same regression. The infant population of the entire U.S. in the year 2000 was used as the reference population for age standardization. Each regression is weighted by the square root of the infant population. The shaded gray areas denote the $95 \%$ confidence interval calculated from robust standard errors clustered at the county level. The dashed line is the average effect of deleading from our preferred difference-in-differences regression, where the race county treated group consists of those counties that had at least one leaded race prior to 2007, and the border county treated group consists of those counties that did not have a leaded race but bordered a county with a leaded race prior to 2007. This regression defines the post-period as 2007 and after. 
Figure A18: The effect of leaded races on placebo infant mortality rates in race and border counties.
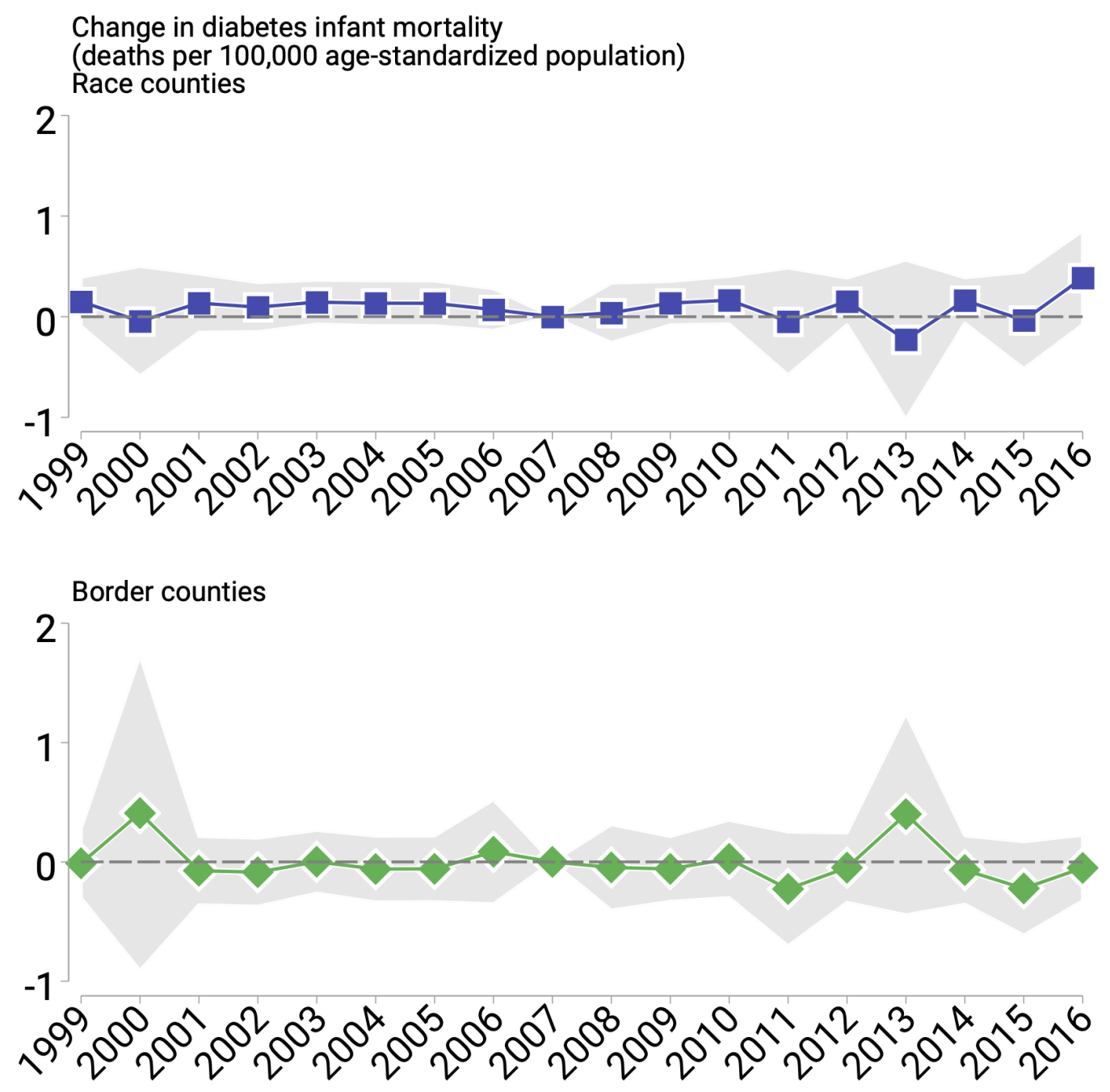

Note: The figure shows estimate for infant diabetes mortality. The top panel reports coefficients (blue squares) for race counties, and the bottom panel reports coefficients (green diamonds) for border counties. Each coefficient represents the effect on the age-standardized, infant morality rate for that cause of death from being in a particular county type relative to 2007, which is omitted. The regression includes state-byyear fixed effects, county fixed effects, and controls for the unemployment rate, median income, \% non-white, tons of lead emitted from TRI facilities, and total manufacturing payroll. All coefficients come from the same regression. The infant population of the entire U.S. in the year 2000 was used as the reference population for age standardization. Each regression is weighted by the square root of the infant population. The shaded gray areas denote the $95 \%$ confidence interval calculated from robust standard errors clustered at the county level. The dashed line is the average effect of deleading from our preferred difference-in-differences regression, where the race county treated group consists of those counties that had at least one leaded race prior to 2007 , and the border county treated group consists of those counties that did not have a leaded race but bordered a county with a leaded race prior to 2007. This regression defines the post-period as 2007 and after. 
Table A15: Split-sample instrumental variables estimates of the effect of ambient lead concentrations in the week after a race on mortality rates.

\begin{tabular}{|c|c|c|c|c|c|c|c|}
\hline & (1) & $(2)$ & $(3)$ & (4) & $(5)$ & (6) & (7) \\
\hline & All cause & Cardiovascular & Respiratory & IHD & $\begin{array}{c}\text { Deaths of } \\
\text { despair }\end{array}$ & Diabetes & All cause \\
\hline \multicolumn{8}{|l|}{ A. $2 S L S$ Split Sample } \\
\hline Lead level & $\begin{array}{c}3601^{*} \\
{[1886 \text { to } 10386]}\end{array}$ & $\begin{array}{c}1278^{*} \\
{[401 \text { to } 4063]}\end{array}$ & $\begin{array}{c}604^{*} \\
{[250 \text { to } 1839]}\end{array}$ & $\begin{array}{c}1736^{*} \\
{[753 \text { to } 5013]}\end{array}$ & $\begin{array}{c}69 \\
\text { [ } 16 \text { to 201] }\end{array}$ & $\begin{array}{c}7 \\
{[-222 \text { to } 226]}\end{array}$ & $\begin{array}{c}3402^{*} \\
{[1759 \text { to } 10334]}\end{array}$ \\
\hline Observations & 56183 & 56183 & 56183 & 56183 & 56183 & 56183 & 56183 \\
\hline \multicolumn{8}{|l|}{ B. $2 S L S$} \\
\hline Lead level & $\begin{array}{c}1246 \\
{[-778 \text { to } 3269]}\end{array}$ & $\begin{array}{c}629 \\
{[-495 \text { to } 1753]}\end{array}$ & $\begin{array}{c}100 \\
{[-402 \text { to } 601]}\end{array}$ & $\begin{array}{c}1554^{* *} \\
{[114 \text { to } 2994]}\end{array}$ & $\begin{array}{c}43 \\
{[-50 \text { to } 136]}\end{array}$ & $\begin{array}{c}-217 \\
{[-490 \text { to } 56]}\end{array}$ & $\begin{array}{c}1177 \\
{[-753 \text { to } 3107]}\end{array}$ \\
\hline Observations & 1731 & 1731 & 1731 & 1731 & 1731 & 1731 & 1731 \\
\hline County FE & Yes & Yes & Yes & Yes & Yes & Yes & Yes \\
\hline State-by-year FE & Yes & Yes & Yes & Yes & Yes & Yes & Yes \\
\hline Controls & Yes & Yes & Yes & Yes & Yes & Yes & Yes \\
\hline $\begin{array}{l}\text { Potentially } \\
\text { endogenous } \\
\text { measure of } \\
\text { lead level }\end{array}$ & $\operatorname{asinh}(\mathrm{Pb})$ & $\operatorname{asinh}(\mathrm{Pb})$ & $\operatorname{asinh}(\mathrm{Pb})$ & $\operatorname{asinh}(\mathrm{Pb})$ & $\operatorname{asinh}(\mathrm{Pb})$ & $\operatorname{asinh}(\mathrm{Pb})$ & mean $(\mathrm{Pb})$ \\
\hline F-Stat & 14.78 & 14.78 & 14.78 & 14.78 & 14.78 & 14.78 & 13.99 \\
\hline
\end{tabular}

Note: ${ }^{*} \mathrm{p}<0.1,{ }^{* *} \mathrm{p}<0.05,{ }^{* * *} \mathrm{p}<0.01 .95 \%$ confidence intervals reported in brackets. Both $\mathrm{p}$-values and $95 \%$ confidence intervals are bootstrapped and based upon a non-parametric randomization inference procedure. 95\% confidence intervals may not be symmetric. Panel A reports results from a split-sample strategy. The observations in first stage contain data on average race miles per race and average lead concentration in the week following a race. The observations in the second stage contain data on average race miles per race and mortality. We do this because there are not lead monitors in every county-year. Panel B shows results from a traditional IV strategy where we restrict our data to counties that have information on lead concentrations, race miles, and mortality. 


\section{A.9 Other robustness checks, sensitivity checks, and analyses}

\section{A.9.1 Soil lead cross-section robustness check}

To provide supporting evidence that leaded races emit substantial quantities of lead, we estimate the conditional correlation between soil lead concentrations and distance from a NASCAR/ARCA track. We obtain data on county urban-rural status from the USDA and data on soil lead from the U.S. Geological Survey (USGS). USGS sampled over 5,000 sites across the U.S. over 2007-2010. The samples were taken so that there was approximately one for every 1,600 square kilometers. We estimate a model of the following form:

$$
\operatorname{asinh}(\text { soil Pb })_{s y}=\beta \text { distance to } \operatorname{racetrack}_{s}+\gamma \mathbf{X}_{s y}+\Omega_{s y}+\varepsilon_{s y}
$$

$\operatorname{asinh}(\text { soil } \mathrm{Pb})_{s y}$ is the inverse hyperbolic sine of soil lead concentrations at site $s$, sampled

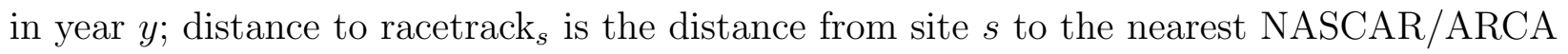
racetrack. $\mathbf{X}_{s y}$ is same set of controls in the EBLL results. $\Omega_{s y}$ is a state-by-year of sample

effect. $\varepsilon_{s y}$ is the error term which is robust to heteroskedasticity and clustered at the county level.

The left panel of Figure A19 plots the raw data. There is a strong negative correlation between soil lead concentrations and distance from a racetrack. The right panel of Figure A19 plots the residuals from estimating equation (5) without the distance to racetrack variable. After removing variation from potential confounders, we still find a negative relationship between soil lead concentrations and distance from a racetrack.

Table A16 shows the estimates from equation (5) as we add fixed effects and split the estimates into whether the samples were taken in urban or rural counties. We find a strong negative correlation between distance to the nearest racetrack and soil concentrations across all specifications. Inclusion of both state-by-year-of-sample fixed effects and controls attenuate the size of the negative correlation. We also find a slightly stronger negative correlation in urban areas. 
Figure A19: Inverse hyperbolic sine of soil lead concentrations as a function of distance to the nearest racetrack.
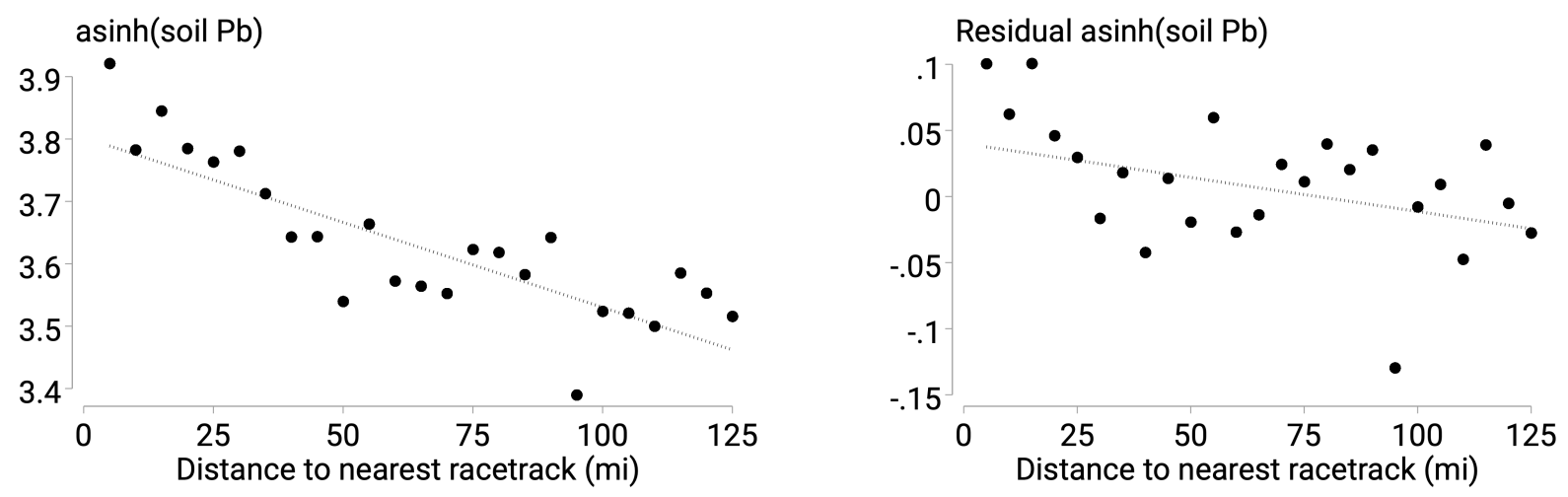

Note: The left panel shows the raw data correlation between the inverse hyperbolic sine of soil lead concentrations $(\mathrm{mg} / \mathrm{kg})$ and distance from the measurement site to the nearest NASCAR/ARCA track. The right panel is the same but uses residuals from a regression of asinh(soil $\mathrm{Pb}$ ) on the set of controls and fixed effects in equation (5). Data are averaged within 5 mile bins.

Table A16: Correlation between $\operatorname{asinh}($ soil $\mathrm{Pb}$ ) and distance to the nearest NASCAR/ARCA racetrack.

\begin{tabular}{lccccc}
\hline & $(1)$ & $(2)$ & $(3)$ & $(4)$ & $(5)$ \\
& & & & Urban & Rural \\
\hline Distance to Nearest Racetrack (1,000 miles) & $-1.26^{* *}$ & $-0.94^{* * *}$ & $-0.73^{* * *}$ & $-1.03^{* *}$ & $-0.51^{* *}$ \\
& $(0.48)$ & $(0.17)$ & $(0.17)$ & $(0.42)$ & $(0.21)$ \\
\hline State-by-Year of Sample FE & No & Yes & Yes & Yes & Yes \\
Controls & No & No & Yes & Yes & Yes \\
\hline Observations & 4839 & 4834 & 4682 & 1545 & 1751 \\
\hline
\end{tabular}

Note: $* \mathrm{p}<0.1,{ }^{* *} \mathrm{p}<0.05,{ }^{* * *} \mathrm{p}<0.01$. Robust standard errors clustered at the county level in parentheses. Control variables are unemployment rate, \% non-white, median income, lead emissions reported in Toxic Release Inventory, and total manufacturing payroll. Urban and rural indicates that the specifications are limited to urban or rural counties only. County urban or rural status is taken from the 2013 Rural-Urban Continuum Codes produced by the United States Department of Agriculture with a USDA continuum code of 1, 2, or 3, indicating an urban county and USDA continuum code of 7,8 , or 9 , indicating a rural county.

\section{A.9.2 Balance table}

Table A17 displays results from a series of regressions with different dependent variables, where each is a socio-economic measure that is not included as a control variable in our other analyses. Each column reports results from a separate regression. For each regression, 
the independent variables of interest are dummy variables that indicate whether or not there was a leaded race in a given county or border county in each year.

Each regression is analogous to our preferred difference-in-differences specifications for elevated blood lead levels and for elderly mortality; the results from these are reported in column 4 of Tables A9 to A13 (for mortality) and in column 4 of Table A8 (for blood lead). The key difference between our preferred specifications and results presented here is that in this robustness check we swap our dependent variable of interest for a socioeconomic variable. Each regression includes state-by-year fixed effects, county fixed effects, and controls for the unemployment rate, median income, \% non-white, tons of lead emitted from TRI facilities, and total manufacturing payroll. Standard errors are clustered at the county level.

This procedure follows Pei et al. (2019) and serves as a balance test. This balance test helps to verify the identification assumption that the variation in our independent variables of interest is unrelated to other omitted variables after conditioning our preferred set of controls and fixed effects. We find no clear, statistically significant or economically meaningful relationship between any of our independent variables of interest and these socio-economic variables. The null findings here mitigate concerns that the estimated relationships in our specifications of interest between exposure to leaded races and either blood lead levels or mortality are driven by omitted variables or differential trends that are not otherwise captured by our preferred covariates and fixed effects. 
Table A17: Balance table examining conditional relationship between county-race status and socioeconomic variables not included in regression of interest.

\begin{tabular}{lccccc}
\hline & $\begin{array}{c}(1) \\
\text { Adjusted } \\
\text { gross income } \\
\text { per return }\end{array}$ & $\begin{array}{c}(2) \\
\text { Manufacturing } \\
\text { employment } \\
\text { per } 1000\end{array}$ & \% in poverty & \% children & \% elderly \\
\hline 1(Leaded Race in County) & 505.055 & -0.630 & 0.000 & $0.002^{* * *}$ & $0.003^{*}$ \\
& $(410.941)$ & $(1.913)$ & $(0.002)$ & $(0.001)$ & $(0.002)$ \\
1 (Leaded Race in Border County) & 142.126 & 0.480 & 0.000 & $0.002^{* * *}$ & -0.001 \\
& $(290.145)$ & $(1.218)$ & $(0.001)$ & $(0.000)$ & $(0.001)$ \\
\hline Mean of dependent variable & 49761.29 & 45.07 & .14 & .06 & .14 \\
\hline County FE & Yes & Yes & Yes & Yes & Yes \\
Year FE & No & No & No & No & No \\
State-Specific Linear Time Trends & No & No & No & No & No \\
State-by-Year FE & Yes & Yes & Yes & Yes & Yes \\
Controls & Yes & Yes & Yes & Yes & Yes \\
\hline Observations & 56170 & 56173 & 56173 & 56149 & 56160 \\
\hline
\end{tabular}

Note: Regressions in this table correspond to specifications in column 4 of the mortality regressions in Tables A9 to A13 and to the specification column 4 of the blood lead level regressions in Table A8. However, here each dependent variable is a socio-economic variable that has not been included in other analyses. Each dependent variable is the at the county-year level. The independent variables of interest are whether or not there was a leaded race in a given county or border county in a given year. Each regression includes state-by-year fixed effects, county fixed effects, and controls for the unemployment rate, median income, \% non-white, tons of lead emitted from TRI facilities, and total manufacturing payroll. Robust standard errors clustered at the county level in parentheses and each regression is weighted by the square root of total population. ${ }^{*} \mathrm{p}<0.1,{ }^{* *} \mathrm{p}<0.05,{ }^{* * *} \mathrm{p}<0.01$.

\section{A.9.3 Collinearity of leaded and unleaded miles in annual regressions}

Here we show the high degree of collinearity between leaded and unleaded miles in our samples with annual variation. After conditioning on observational unit fixed effects, e.g. county fixed effects, there is effectively no variation in the sum of leaded and unleaded miles. Since their sum is approximately constant, it is difficult to separately identify them or identify the effect of race miles in an event study framework. We show this in Figure A20 by plotting the residualized unleaded miles against residualized leaded miles after taking out the observational unit fixed effects.

The left panel of Figure A20 shows the low degree of collinearity between the two types of miles in our ambient lead concentrations sample, which has daily variation. When regressing unleaded miles on leaded miles, we only obtain a correlation of -0.4. This allows us to 
separately identify the effect of leaded miles from unleaded miles. Collinearity is not an issue for the ambient lead setting because the data are in terms of days: the sum of the types of miles can take on the value of the actual miles driven over a racing weekend, a fraction of the actual miles driven, or zero if the monitor reading was taken more than a week after any race within the treatment radius.

The right panel of Figure A20 shows the near-perfect collinearity between the two types of miles in our county-year BLL and mortality samples. Regressing unleaded miles on leaded miles yields a correlation of -0.9. If there is an increase in unleaded miles in a given county by 1 , it is offset by a decrease in leaded miles by 0.9 . There is very little within-observational unit variation in the sum of leaded and unleaded miles. This hinders our ability to do event studies like Figure 5 for BLLs or mortality. Since there is not much inter-annual variation in total miles, it is effectively equivalent to a dummy variable. For the difference-in-differences specifications in Section A.7 we use leaded miles instead of indicator variables for leaded races and find similar results.

Figure A20: Collinearity between leaded and unleaded miles.

A.

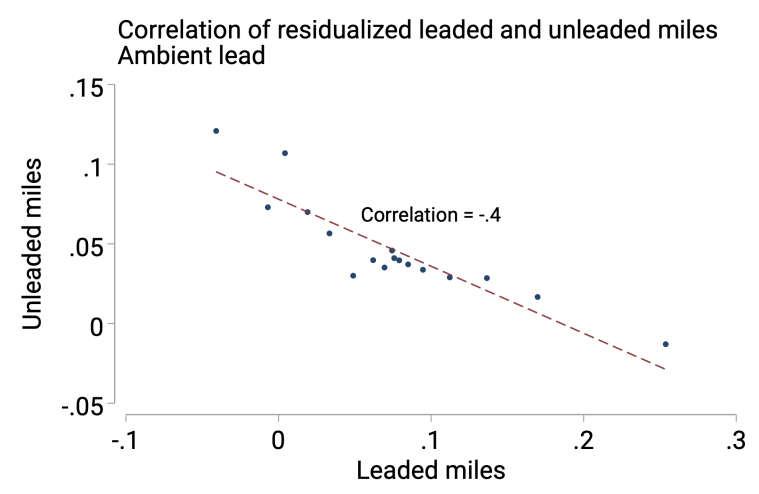

B.

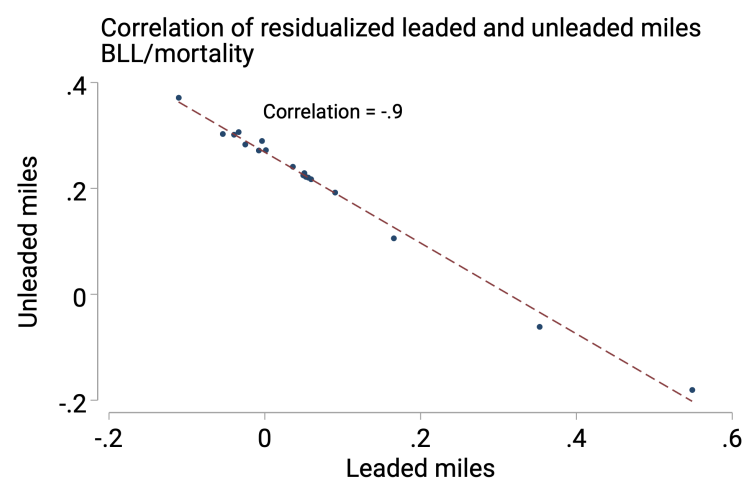

Note: Correlation between leaded and unleaded miles after conditioning on monitor effects in the ambient lead sample (left panel), or conditioning on county effects in the BLL and mortality samples (right panel).

\section{A.9.4 Environmental justice}

One concern about the effect of lead emissions from racing is that it may have negative environmental justice implications. Here we analyze associations between total county level exposure to leaded race miles and the average of five demographic variables over the last 5 years with leaded races. The five variables are the percent of the population that are children, non-white, male, or elderly, and the county's median income. To estimate the association, we run a cross-sectional county level regression with the the average of the variable on the 
left-hand side, and total leaded miles on the right-hand side. We estimate the associations separately for urban and non-urban counties, where urban counties have USDA continuum codes of 1,2 or 3 , while non-urban counties have continuum codes of 4, 5, or 6 . There are no leaded races in our sample with higher continuum codes.

Table A18 reports coefficient estimates on leaded miles. Here we find that in urban counties, areas with more leaded miles driven tend to have more children, more non-whites, more women, fewer elderly, and higher incomes. Non-urban areas generally show the same pattern except for children. Pooling the urban and non-urban samples together yields results almost identical to the urban sample. The associations suggest that races may be disproportionately harming certain subgroups of the overall population, based on demographic, but not necessarily socioeconomic variables.

Table A18: Associations between average county socioeconomic and demographic characteristics and total leaded race miles within county from 2002-2006.

\begin{tabular}{lccccccccccc}
\hline & & \multicolumn{3}{c}{ Urban } & \multicolumn{3}{c}{ Non-Urban } \\
& $(1)$ & $(2)$ & $(3)$ & $(4)$ & $(5)$ & $(6)$ & $(7)$ & $(8)$ & $(9)$ & $(10)$ \\
& \% Children & \% Non-White & \% Male & \% Elderly & Median Income & \% Children & \% Non-White & \% Male & \% Elderly & Median Income \\
\hline Total Leaded Miles 2002-2006 & $0.002^{* *}$ & $0.029^{*}$ & -0.002 & $-0.006^{*}$ & 1261.361 & -0.002 & 0.023 & -0.002 & -0.007 & 2145.133 \\
& $(0.001)$ & $(0.015)$ & $(0.002)$ & $(0.004)$ & $(1155.302)$ & $(0.002)$ & $(0.035)$ & $(0.004)$ & $(0.006)$ & $(1423.185)$ \\
\hline Observations & 1157 & 1228 & 1158 & 1158 & 1159 & 895 & 902 & 895 & 895 & 895 \\
\hline
\end{tabular}

Note: $* \mathrm{p}<0.1, * * \mathrm{p}<0.05, * * * \mathrm{p}<0.01$. Regressions have no controls or fixed effects. 


\section{A.9.5 Survey on beliefs about NASCAR fuel}

To determine whether the general public had knowledge about NASCAR fuels that may have caused behavior changes following the fuel switch, we conducted a survey on Amazon's Mechanical Turk. We surveyed 100 respondents and paid each $\$ 0.10$ for completing the survey. Respondents were restricted to those who live in the United States. We asked the respondents for their county of residence, state of residence, how far away they believe they live from the nearest NASCAR track, and two multiple choice questions:

1. What type of fuel did NASCAR use in 2002 ?
(a) Don't know
(b) $100 \%$ Ethanol
(c) Leaded gasoline
(d) Unleaded gasoline

2. What type of fuel did NASCAR use in 2010 ?
(a) Don't know
(b) $100 \%$ Ethanol
(c) Leaded gasoline
(d) Unleaded gasoline

Figure A21 shows results for the responses to the multiple choice questions. About half the respondents said they didn't know the fuel used either before or after the fuel switch. Conditional on answering with a specific fuel type, the 2002 responses are evenly spread across unleaded gasoline, leaded gasoline, and 100\% ethanol. Respondents tended to believe that NASCAR used pure ethanol in 2010 conditional on answering with a specific fuel type.

Regressing a binary variable for a correct fuel type response on believed distance from the track ${ }^{34}$ we do not find any correlation between distance to a track and knowing which fuel type NASCAR used in either year.

\footnotetext{
${ }^{34}$ We drop responses from the non-contiguous U.S. or where they believe they were more than 1000 miles from a NASCAR track, which is effectively impossible.
} 
Figure A21: Histograms of responses to our survey asking what respondents believed was the type of fuel used in NASCAR in 2002 (left) and 2010 (right).
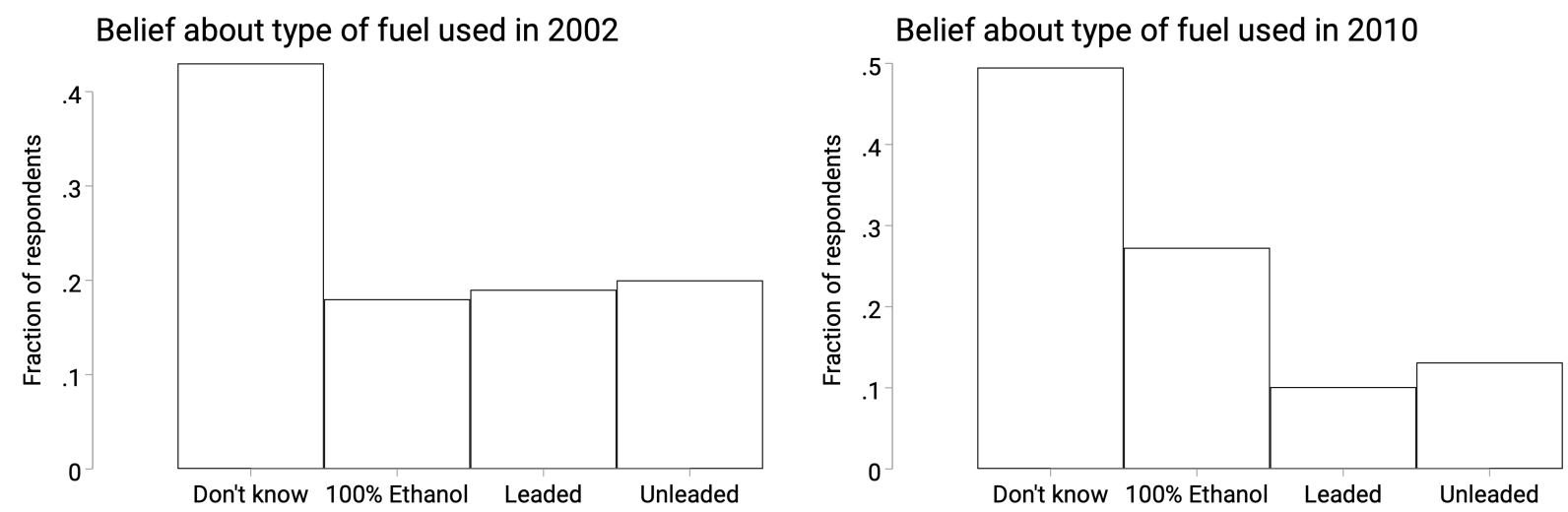

\section{A.10 City lead emissions counterfactuals}

In this section we use our quasi-experimental estimates to both predict out-of-sample historical lead concentrations and estimate the counterfactual ambient lead concentration if lead were still added to gasoline. Our estimates predict out-of-sample historical levels well, which provides credibility to our quasi-experimental estimates. Moreover, the counterfactual estimates give some insight into what ambient lead levels would have been in the absence of EPA abatement efforts and the Clean Air Act, which is an essential component for any attempt to value the benefits provided by these regulatory efforts.

Our out-of-sample historical prediction is performed in three steps. First we estimate the average grams of lead emitted from daily vehicle miles traveled (VMT) for U.S. cities from 1971 to 1995. Second, we convert our ambient lead estimates in Section 4.1 from changes in concentration per race mile to changes in concentration per gram of lead per gallon. This involves making assumptions about the fuel efficiency of the racing vehicles. Third, we combine these estimates to form our historical prediction. We perform our counterfactual prediction by a similar procedure, except where we assume that the lead content of gasoline remained at 1971 levels.

\section{A.10.1 Estimating historical lead emissions from daily VMT}

To estimate grams of lead emitted from daily VMT, we collect data from several sources that account for increases in VMT, changing fuel economy, and the decreasing use of lead additives across time. First, we obtain estimates of daily VMT for both highway and non-highway roads for 101 cities from 1982 to 2014 from the Texas A\&M Transportation Institute's Urban Mobility Scorecard. These estimates are based upon the Federal Highway Administration's 
Highway Performance Monitoring System Data. We estimate city VMT prior to 1982 by assuming each city's VMT growth followed the U.S. national trend, which is provided the U.S. Department of Energy's Alternative Fuels Data Center. National average annual fuel economy data are provided by the U.S. Energy Information Administration. Finally, the share of unleaded gasoline and the lead content in leaded gasoline by year come from Newell and Rogers (2003). We combine these measures as follows:

$$
\begin{aligned}
\text { Daily grams TEL from routine } \mathrm{VMT}_{c y}= & \text { (Daily VMT estimate }{ }_{c y} \times \\
& \text { Mean U.S. } \mathrm{MPG}_{y} \times \\
& \% \text { of all gasoline leaded }{ }_{y} \times \\
& \text { Mean grams TEL per leaded gallon } \left.{ }_{y}\right)
\end{aligned}
$$

\section{A.10.2 Converting race miles to grams of lead used per race}

Next we use our ambient lead estimates to translate grams of TEL emitted to changes in ambient lead concentrations. In Tables 1 and A6, we provide multiple estimates of the relationship between miles driven in a leaded race and the impact on ambient lead concentration in the following week. Our race data report the number of miles driven during each race, but do not report the number of gallons consumed at each race. One strategy to estimate fuel consumption would be to multiply the average fuel economy of a racecar by the total miles driven. In-race fuel economy has been cited to be between four and five miles per gallon (Belson, 2011). However, even if we knew the exact in-race fuel economy of each car in every race, using this measure exclusively would still cause us to under-count total fuel consumption because we would be neglecting additional fuel consumed during idling, practice, and qualifying sessions. The number of miles driven in addition to the in-race miles is unknown because practice and qualifying laps are not usually reported and will differ by race and series. We consider two estimates of the importance of these miles relative to in-race miles.

The first estimate uses data for a race that reported both in-race miles and practice miles, the 2019 Ticket Guardian 500. This race had 10,766 race miles and 3,053 practice miles. ${ }^{35}$ The total number of qualifying laps were not tracked since the qualifying procedure allows drivers to drive as many laps as they wish across a qualifying period that totals up to 25 minutes in length. ${ }^{36}$ Under the assumptions that the average driver travels 5 laps during a

\footnotetext{
${ }^{35}$ https://www.nascar.com/results/race_center/2019/monster-energy-nascar-cup-series/tic ketguardian-500/stn/practice1/

${ }^{36}$ Qualifying for the 2019 Ticket Guardian 500 occurred in three rounds. Drivers are ranked by their fastest single lap performed during each round. In the first round, 36 drivers drove for up to 10 minutes each. In the second round, 24 drivers drove for up to ten minutes each. In the third round, 12 drivers drove for up to five minutes each.
} 
ten-minute period, 330 miles were driven as a part of qualifying. Thus the 10,766 in-race miles represent only $76 \%$ of the total miles driven as a part of the entire event. Accounting for these additional non-race miles would mean adjusting in-race fuel economy to be between 3 and 3.8 .

This simple deflator does not account for gasoline combustion due to idling or testing that may also occur as a part of the race. To address this last issue, we provide another fuel economy estimate that comes from reports that the top series in NASCAR used 175,000 gallons of fuel in 2008 (Fryer, 2008). In the previous season, the top series ran 566,130 in-race miles; combining these two estimates suggests that there are 3.24 in-race miles traveled per gallon used for all race activities. This estimate is within the bounds of the first one, so we will use 3.24 as our measure of total gallons used per race mile.

To obtain the total grams of lead emitted per race, we first multiply the number of inrace miles traveled by 3.24 to calculate the number of gallons of fuel used for all race-related activities. ${ }^{37}$ We then multiply by our year-specific estimate of the grams of TEL added to each each gallon to get the grams of lead emitted per race. Next., we estimate the same specifications displayed in Tables 1 and A6, but with the estimated metric tons of lead emitted during each race as our treatment variable rather than the number of race miles traveled. This gives us the relationship between an additional metric ton of lead emitted at a race and ambient lead concentrations. The resulting coefficients are displayed in Table A7.

\section{A.10.3 Comparison of historic lead emitted from daily VMT to automotive racing sample}

Figure A22 compares how both historical ambient airborne lead concentrations and historical lead emissions from daily motor vehicle traffic compare to the analogous measures used in our automotive racing analysis. Panels A and B compare the distributions of estimated quantities of lead emissions caused by NASCAR and ARCA races to average daily traffic in 101 major U.S. cities across different decades. Below the densities, the blue bar shows the range of emissions that share common support with our automotive racing analysis. Panel A shows the density of average lead emissions from a day's worth of traffic in the 1970s and 1980s, while panel B shows the distribution of estimated lead emissions from daily traffic from 1990 to 1995 and from NASCAR/ARCA races from 1996 to 2018. A single race generally emits more lead than all daily traffic in a major city in the 1990s and is on the lower end of daily emissions from major cities in the 1970s and 1980s. Panels C and

\footnotetext{
${ }^{37}$ We have data on the grams of TEL added to each gallon of fuel used in NASCAR from 1951 to 2006 (Wusz, 1994). From 2003 to 2006, NASCAR used Sunoco Supreme fuel, which contains 5.2 grams of TEL per gallon. This was confirmed by e-mail with Sunoco Race Fuels.
} 
D present the distribution of mean ambient lead concentrations for these same 101 cities across time. Mean daily lead pollution levels for each city and year are calculated using EPA lead monitoring data; see Section 3. Panel C shows that lead concentrations in the 1970s were generally higher than in the 1980s, reflecting the effect of the EPA's policies. Panel $\mathrm{D}$ zooms in on the support of the distribution of lead concentrations during the period of our automotive racing analysis (1996-2018) and shows again that lead concentrations have continued to decrease relative to ambient concentrations from the early 1990s.

\section{A.10.4 Out-of-sample historical prediction}

Figure A23 presents results that directly compare a non-parametric estimate of the historic relationship between lead emitted from daily VMT and mean ambient lead levels to an estimate of the relationship that is based upon our quasi-experimental automotive racing analysis. Panel A presents a binscatter showing the non-parametric relationship between estimated lead emitted from daily vehicle traffic and average daily ambient lead concentrations in 101 U.S. cities. The binscatter is created by dividing the x-axis into ten equally sized bins, computing the mean of the $\mathrm{x}$ and $\mathrm{y}$ variable for each bin, and then showing a scatterplot of the mean pairs for each bin. Our x-axis is the average daily metric tons of lead emitted due to vehicle travel in 101 U.S. cities from 1971 to 1995 . The y-axis is the mean average daily ambient lead concentration for 101 U.S. cities in each year from 1971 to 1995. The blue and red bars at the bottom of the panel denote the range of both lead emissions and mean ambient lead that overlap with the data we use in our automotive racing analysis. Panel B zooms in on the support of Panel A that overlaps with the range of each axis used in our automotive racing analysis. Thus only the first four deciles of the binscatter are shown. Panel B also shows predicted ambient lead concentrations using our estimates from Table A7. The prediction based on $\operatorname{asinh}(\mathrm{Pb})$ and its associated $95 \%$ confidence interval are displayed in red (on the right), and the prediction using unadjusted (i.e., linear) $\mathrm{Pb}$ as the dependent variable is reported in blue (on the left). We form the prediction by multiplying each coefficient by an amount of lead released across an evenly spaced grid from 0 to .11 metric tons. For the $\operatorname{asinh}(\mathrm{Pb})$, we perform the correct transformation of the estimate and calculate the standard errors and resulting 95\% confidence interval using the delta method.

Both our estimates do an excellent job of predicting the out-of-sample historic mean lead concentrations. However these predictions are so far limited to be within the support of our automotive racing analysis. In Figure A24 we extend this comparison back to 1971, which is far off of the support of both our dependent and independent variables from our preferred analysis. We report the mean of the prediction for the 101 cities in each year. The prediction based on the asinh regression is depicted with the solid orange line, while predictions using 
the linear regression are depicted with the dashed orange line. The actual average historical ambient lead concentration for these 101 U.S. cities is depicted by the solid black line. Our quasi-experimental estimates predict historical ambient lead levels quite well, suggesting that our estimates are capable of predicting out-of-sample ambient lead levels with a good degree of accuracy.

\section{A.10.5 Counterfactual ambient lead levels}

We next estimate counterfactuals that attempt to predict ambient lead concentrations if leaded gasoline use was still widespread. The counterfactuals assume that TEL additives remained constant at the 1970 level of $2.1 \mathrm{~g} /$ gallon, that all cars used leaded gasoline, and that there were no counterfactual changes in VMT or fuel economy. Figure A24 reports the results from two counterfactuals. The solid gray line represents the counterfactual estimate using our asinh regression, and the dashed gray line is the counterfactual from our linear specification. Our most conservative counterfactual estimates suggest that if tetraethyl lead was still added to gasoline, ambient lead levels would be $6.34 \mu \mathrm{g} / \mathrm{m}^{3}-4$ times larger than the 1971 mean lead concentration of $1.45 \mu \mathrm{g} / \mathrm{m}^{3}$ and 500 times higher than the actual 2014 concentration. 
Figure A22: Comparison of lead emissions and lead pollution for data used in our quasiexperimental specification with estimates for 101 U.S. cities by decade.

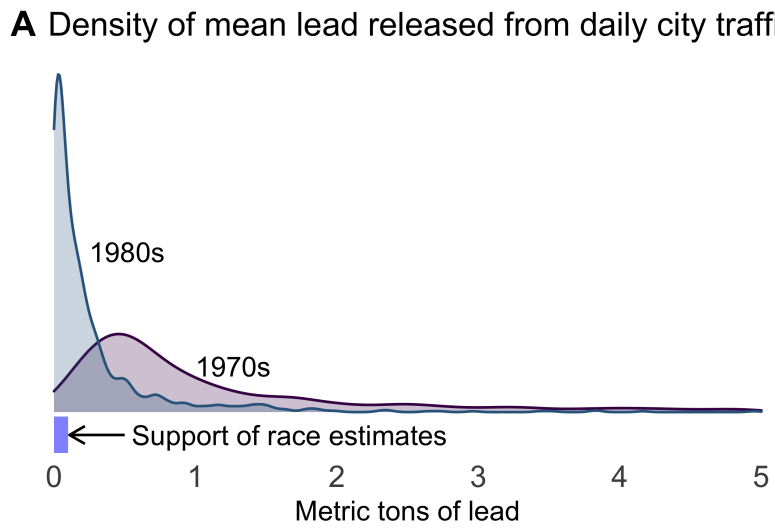

B Density of mean lead released from each race and from daily city traffic

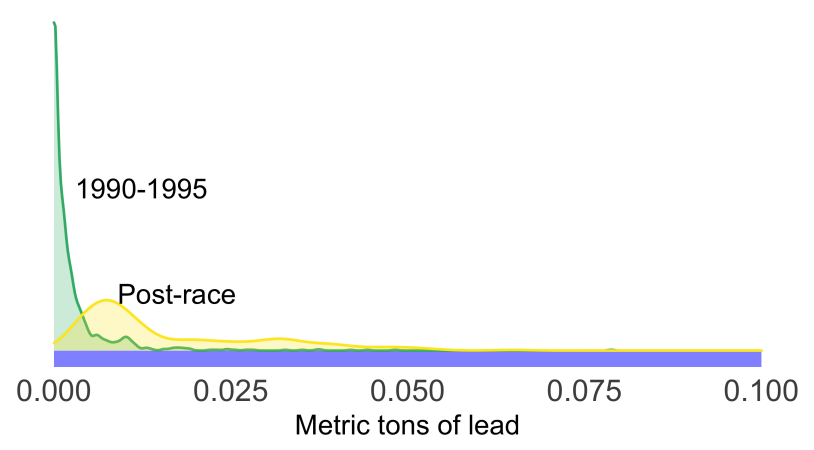

C Density of mean ambient lead pollution

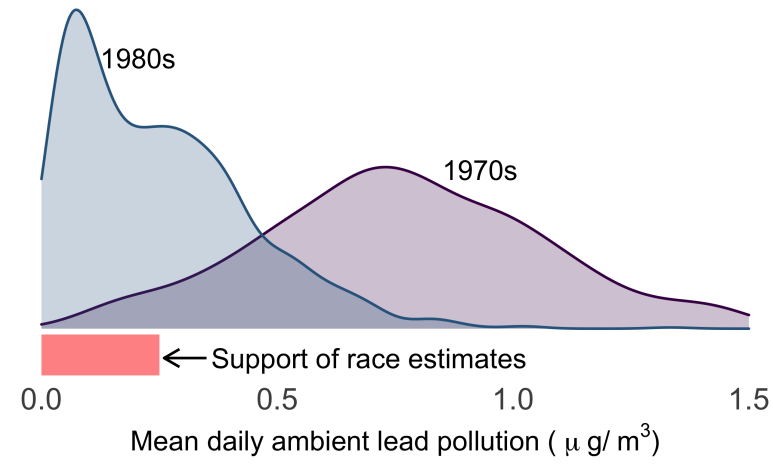

D Density of mean ambient lead pollution

Data used in race analysis (1996 to 2018)

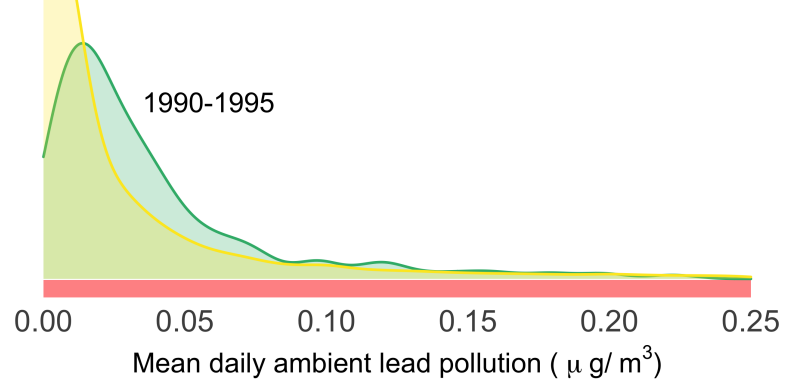

Note: Data plotted in yellow represent the data used in our main analysis outlined in Section 4.1. The post-race density in panel $\mathrm{B}$ only displays the subset of data in the week following a race. The analogous density in panel D includes all observations, both before and after a race. The range of support for these data are indicated by the blue and red bars at the bottom of each panel. The data sources and procedure used to estimate city VMT across time are outlined in Section A.10. Mean daily lead pollution levels for each city and year are calculated using EPA lead monitoring data; see Section 3. Overall this panel shows that the amount of lead released after a typical race is greater than the average amount of lead released from all of a city's daily VMT in the early 1990s. A large NASCAR race (about 3 hours long) emits about as much lead as was emitted from all vehicle miles traveled on an average day in Buffalo, NY in 1987. 
Figure A23: Predicted out-of-sample lead levels using our ambient lead estimates.

A Unconditional binscatter of city-level daily vehicle lead emissions and mean ambient lead

Mean ambient lead level $\left(\mu \mathrm{g} / \mathrm{m}^{3}\right)$

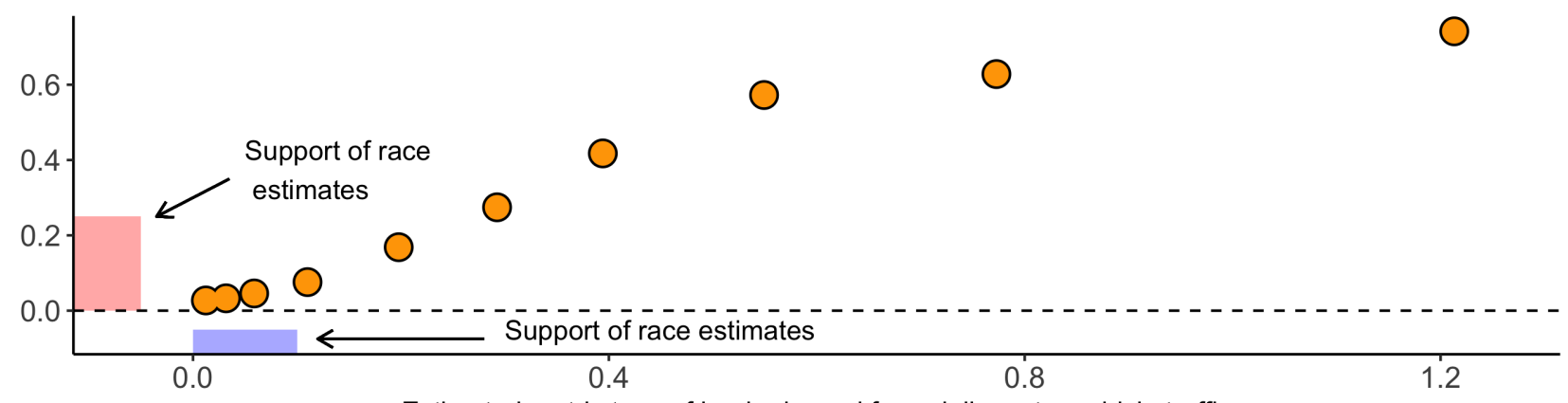

Estimated metric tons of lead released from daily motor vehicle traffic

B Zoomed in binscatter plus estimated lead level using coefficients from automotive racing analysis Mean ambient lead level $\left(\mu \mathrm{g} / \mathrm{m}^{3}\right)$

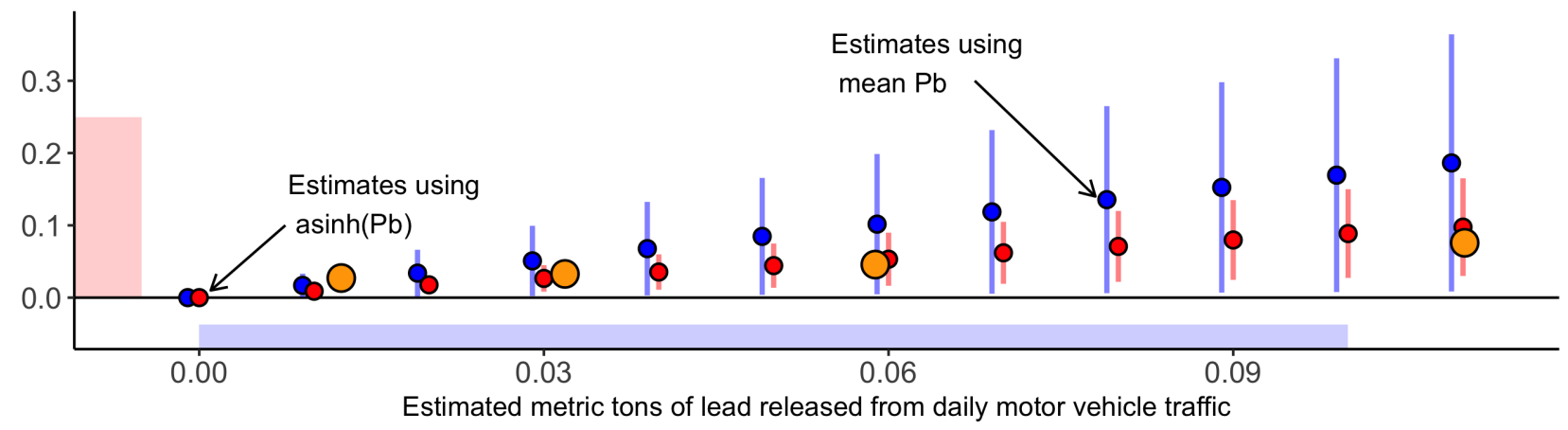

Note: Panel A presents a binscatter showing the non-parametric relationship between estimated lead emitted from daily vehicle traffic and average daily ambient lead concentrations in 101 U.S. cities. The binscatter is created by dividing the x-axis into ten equally sized bins, computing the mean of the $\mathrm{x}$ and $\mathrm{y}$ variable for each bin, and then showing a scatterplot of the mean pairs for each bin. Our x-axis is the average daily metric tons of lead emitted due to vehicle travel in 101 U.S. cities from 1971 to 1995 . The $\mathrm{y}$-axis is the mean average daily ambient lead concentration for 101 U.S. cities in each year from 1971 to 1995 . The data sources and procedure used to estimate daily city lead emissions from VMT across time are outlined in Section A.10. Mean daily lead pollution levels for each city and year are calculated using EPA lead monitoring data; see Section 3. The blue and red bars at the bottom of the panel denote the range of both lead emissions and mean ambient lead that overlap with the data we use in our automotive racing analysis. Panel B zooms in on the support of Panel A that overlaps with the range of each axis used in our automotive racing analysis. Thus only the first four deciles of the binscatter are shown. Panel B also shows predicted ambient lead concentrations using our estimates from Table A7. The prediction based on $\operatorname{asinh}(\mathrm{Pb})$ and associated $95 \%$ confidence interval are displayed in red (on the right), and the prediction using unadjusted (i.e., linear) $\mathrm{Pb}$ as the dependent variable is reported in blue (on the left). We form the prediction by multiplying each coefficient by an amount of lead released across an evenly spaced grid from 0 to .11 metric tons. For the $\operatorname{asinh}(\mathrm{Pb})$, we perform the correct transformation of the estimate and calculate the standard errors and resulting $95 \%$ confidence interval using the delta method. 
Figure A24: Predicted counterfactual lead levels using our ambient lead estimates.

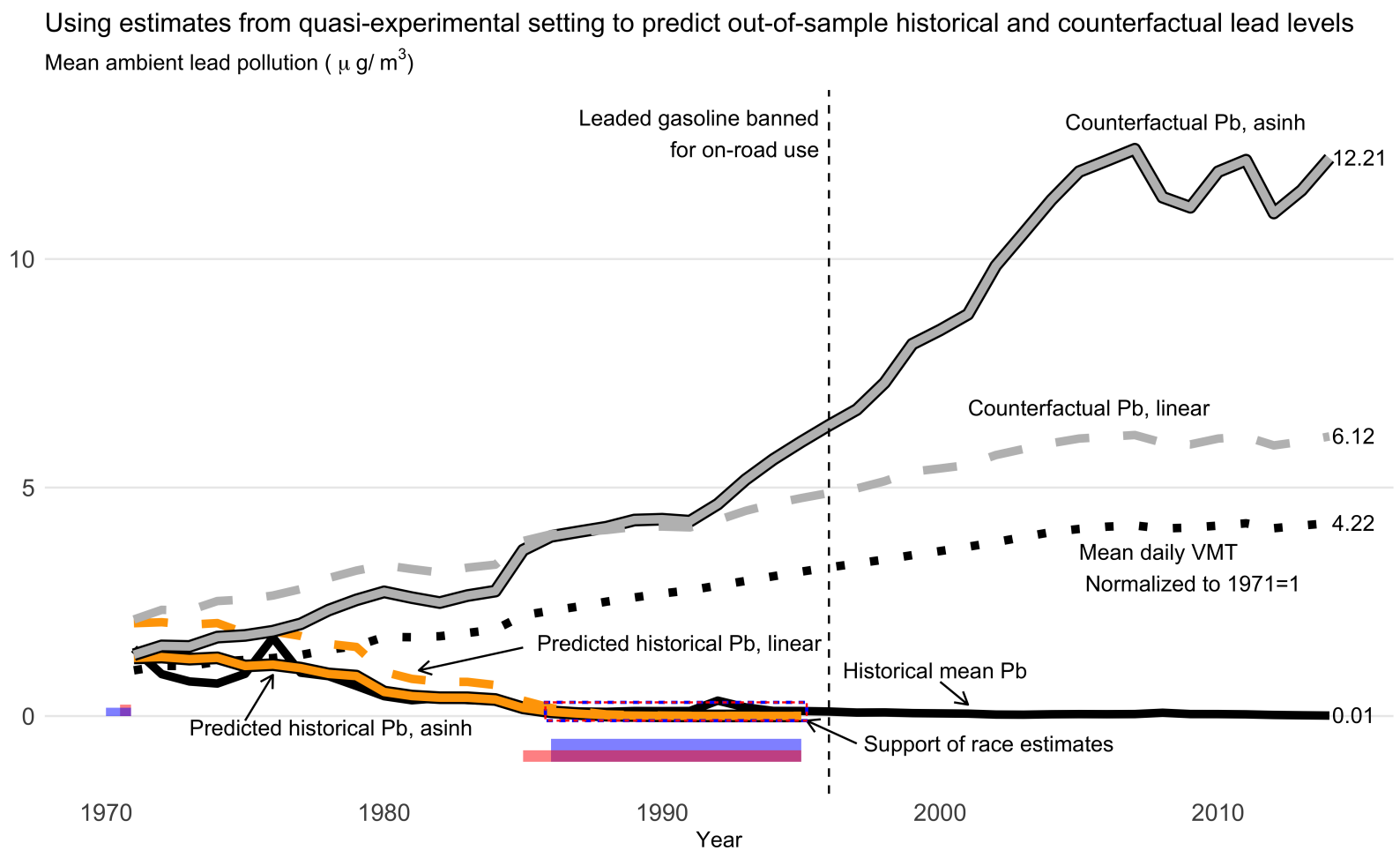

Note: The average historical ambient lead concentration in U.S. cities is depicted by the solid black line. We construct a city-year estimates of daily grams of lead emitted due to VMT from 1971 to 1995 . We multiply this estimate by the coefficient estimate of our ambient lead regression in Table A7, which assumes automotive racing uses 3.24 gallons of fuel per mile raced. This provides us with predictions of historical ambient lead concentrations due to daily leaded traffic in each city and year. Prediction based upon the asinh regression are depicted with the solid orange line, while predictions using the linear regression are depicted with the dashed orange line. Counterfactuals assume that TEL additives in gasoline remained constant at the 1970 level of $2.1 \mathrm{~g} /$ gallon and that there were no changes in VMT or fuel economy. The solid gray line represents the counterfactual estimate using our asinh regression, and the dashed gray line is the counterfactual from our linear specification. Average daily VMT relative to 1970 is plotted by the dashed black line. 


\section{A.11 Calculations used in the main text}

\section{A.11.1 Deleading is equivalent to a $10 \mu \mathrm{g} / \mathrm{m}^{3}$ reduction in $\mathrm{PM}_{2.5}$ concentrations}

We compare our finding to a result from Deryugina et al. (2019) that reports that a $1 \mu \mathrm{g} / \mathrm{m}^{3}$ increase in daily $\mathrm{PM}_{2.5}$ exposure results in an additional 0.69 deaths per million elderly in the subsequent 3 days.

We first use our difference-in-differences estimate that living in a race county results in a $1.7 \%$ increase in the all-cause mortality rate. We use this to compute the number of additional deaths per million elderly in each county-year caused by in-county races. We compute this by multiplying the change in the mortality rate by the county-year elderly mortality rate and elderly population per 100,000 for each county-year

$$
\begin{aligned}
\text { county-year } \widehat{\text { death}} \text { s per million }= & \% \text { change } \widehat{\text { in mortality rate }} \\
& \times \text { deaths per } 100,000 \text { elderly } \\
& \times \frac{10 \times 100,000}{1 \text { million }}
\end{aligned}
$$

where hats indicate estimated values and the other terms are data or scalars. To put this in $\mathrm{PM}_{2.5}$ terms, we first translate our annual estimate into a 3-day number of deaths, and use the Deryugina et al. (2019) estimate of the mortality effect of $\mathrm{PM}_{2.5}$ to get an estimated equivalent effect of $\mathrm{PM}_{2.5}$

$$
\begin{aligned}
\text { equivalent county } \mathrm{PM}_{2.5} \text { change }= & \text { county-year } \widehat{\text { deaths }} \text { per million } \\
& \times \frac{1 \text { year }}{365 \text { days }} \\
& \times 3 \text { days } \\
& \times \frac{1 \widehat{\mu \mathrm{g} / \mathrm{m}^{3}}}{0.69 \text { deaths per million elderly over } 3 \text { days }} .
\end{aligned}
$$

We then take the average of this value over race counties in 2006 resulting in an average of an 8.7 $\mu \mathrm{g} / \mathrm{m}^{3}$ reduction in $\mathrm{PM}_{2.5}$ concentrations.

\section{A.11.2 NASCAR and ARCA used an estimated 2 million grams of TEL}

In 2005, our data give us that NASCAR and ARCA drove approximately 1.2 million race miles. Using our estimate of 3.2 race miles per gallon from Section A.10, this gives us that there were 370 thousand gallons used during that season. Lead content of the fuel prior to deleading was 5.2 grams of TEL per gallon, yielding approximately 2 million grams.

$$
1,146,547 \text { miles } \times \frac{1 \text { gallon }}{3.2 \text { miles }} \times \frac{5.2 \text { grams }}{1 \text { gallon }}=1.9 \text { million grams }
$$

